Florida International University FIU Digital Commons

$11-7-2017$

\title{
Development of System-Based Methodology to Support Ramp Metering Deployment Decisions
}

Homa Fartash

Florida International University, hfart001@fiu.edu

DOI: $10.25148 /$ etd.FIDC006590

Follow this and additional works at: https://digitalcommons.fiu.edu/etd

Part of the Civil Engineering Commons, and the Transportation Engineering Commons

\section{Recommended Citation}

Fartash, Homa, "Development of System-Based Methodology to Support Ramp Metering Deployment Decisions" (2017). FIU Electronic Theses and Dissertations. 3648.

https://digitalcommons.fiu.edu/etd/3648 


\section{FLORIDA INTERNATIONAL UNIVERSITY}

Miami, Florida

\section{DEVELOPMENT OF SYSTEM-BASED METHODOLOGY TO SUPPORT RAMP METERING DEPLOYMENT DECISIONS}

A dissertation submitted in partial fulfillment of the

requirements for the degree of

DOCTOR OF PHILOSOPHY

in

CIVIL ENGINEERING

by

Homa Fartash 
To: $\quad$ Dean John L. Volakis

College of Engineering and Computing

This dissertation, written by Homa Fartash, and entitled Development of System-Based Methodology to Support Ramp Metering Deployment Decisions, having been approved in respect to style and intellectual content, is referred to you for judgment.

We have read this dissertation and recommend that it be approved.

Albert Gan

$\begin{array}{r}\hline \text { Xia Jin } \\ \hline \text { Wensong Wu } \\ \hline \text { L. David Shen }\end{array}$

Yan Xiao

Priyanka Alluri

Mohammed Hadi, Major Professor

Date of Defense: November 07, 2017

The dissertation of Homa Fartash is approved.

Dean John L. Volakis College of Engineering and Computing

Andrés G. Gil Vice President for Research and Economic Development and Dean of the University Graduate School

Florida International University, 2018 
(C) Copyright 2018 by Homa Fartash All rights reserved. 


\section{DEDICATION}

This dissertation is dedicated to my beloved husband, Mohammad Lavasani, for his unbounded support, and to my parents, Shokat and Mohammadreza, for their unconditional love and sacrifices. 


\section{ACKNOWLEDGMENTS}

I would like to take this opportunity to acknowledge everyone who supported me during my Ph.D. study. First and foremost, I would like to express my sincere gratitude to my advisor Dr. Mohammed Hadi for his kindness, motivation, immense knowledge and most importantly, his trust in my work. He believed in me more than I believed in myself.

I am grateful to my committee members, Dr. Albert Gan, Dr. L. David Shen, Dr. Xia Jin, Dr. Wensong Wu, Dr. Yan Xiao and Dr. Priyanka Alluri for serving on my dissertation committee and for their insightful comments and encouragement.

I would like to express my deepest gratitude to my classmate, colleague, mentor, best friend and soulmate, my beloved husband, Dr. Mohammad Lavasani. He provided the greatest support one could ask for in all aspects of my life. His love and support made every hardship disappear. Words cannot express how grateful I am to my family, my parents and lovely brother, Hamidreza who dreamed for this day since I was a little girl. Thank you for all the love and sacrifices you have made for me to follow my dreams.

I am also grateful to my friends and colleagues Dr. Eazaz Sadeghvaziri, Mr. Seyedmirsajad Mokhtarimousavi and Mr. Md Asif Raihan for their support and encouragement.

I will forever be thankful to the entire FIU family for providing the opportunity for me to pursue my Ph.D. degree and making this challenging journey an enjoyable adventure. 


\title{
ABSTRACT OF THE DISSERTATION \\ DEVELOPMENT OF SYSTEM-BASED METHODOLOGY TO SUPPORT RAMP METERING DEPLOYMENT DECISIONS
}

\author{
by \\ Homa Fartash \\ Florida International University, 2018 \\ Miami, Florida \\ Professor Mohammed Hadi, Major Professor
}

Ramp metering is an effective management strategy, which helps to keep traffic density below the critical value, preventing breakdowns and thus maintaining the full capacity of the freeway. Warrants for ramp metering installation have been developed by a number of states around the nation. These warrants are generally simple and are based on the traffic, geometry, and safety conditions in the immediate vicinity of each ramp (local conditions). However, advanced applications of ramp metering utilize system-based metering algorithms that involve metering a number of on-ramps to address system bottleneck locations. These algorithms have been proven to perform better compared to local ramp metering algorithms. This has created a disconnection between existing agency metering warrants to install the meters and the subsequent management and operations of the ramp metering. Moreover, the existing local warrants only consider recurrent conditions to justify ramp metering installation with no consideration of the benefits of metering during non-recurrent events such as incidents and adverse weather. 
This dissertation proposed a methodology to identify the ramps to meter based on system-wide recurrent and non-recurrent traffic conditions. The methodology incorporates the stochastic nature of the demand and capacity and the impacts of incidents and weather using Monte Carlo simulation and a ramp selection procedure based on a linear programming formulation. The results of the Monte Carlo simulation are demand and capacity values that are used as inputs to the linear programming formulation to identify the ramps to be metered for each of the Monte Carlo experiments. This method allows the identification of the minimum number of ramps that need to be metered to keep the flows below capacities on the freeway mainline segment, while keeping the on-ramp queues from spilling back to the upstream arterial street segments. The methodology can be used in conjunction with the existing local warrants to identify the ramps that need to be metered. In addition, it can be used in benefit-cost analyses of ramp metering deployments and associated decisions, such as which ramps to meter and when to activate in real-time. The methodology is extended to address incidents and rainfall events, which result in nonrecurrent congestion. For this purpose, the impacts of non-recurrent events on capacity and demand distributions are incorporated in the methodology. 


\section{TABLE OF CONTENTS}

CHAPTER

PAGE

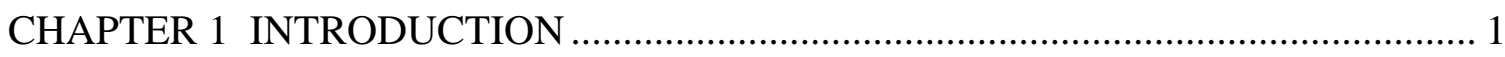

1.1 Problem Statement .............................................................................. 4

1.2 Research Objectives and Scope ................................................................. 6

1.3 Dissertation Organization ..................................................................... 7

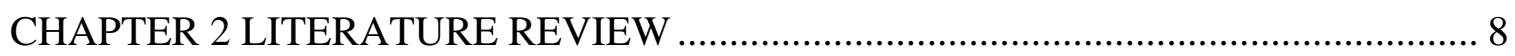

2.1 Ramp Metering Warrants.......................................................................... 8

2.1.1 Manual on Uniform Traffic Control Devices (MUTCD) ....................... 8

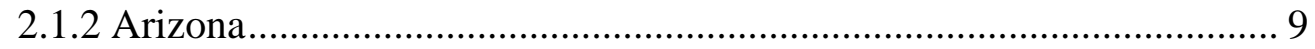

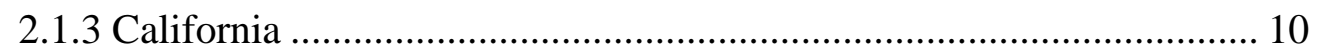

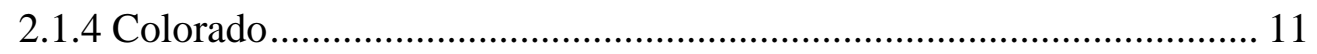

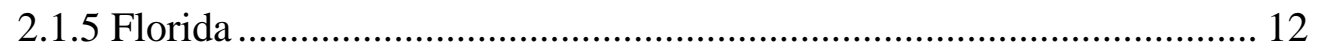

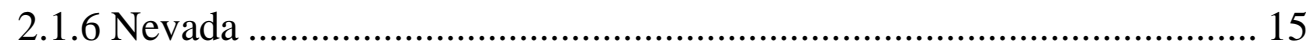

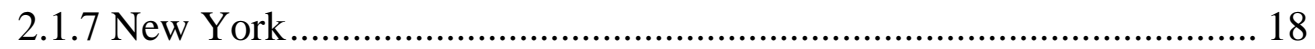

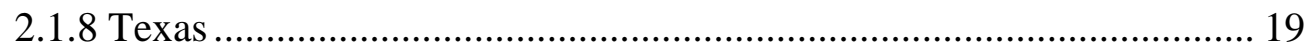

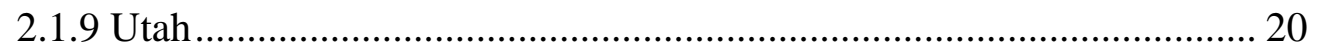

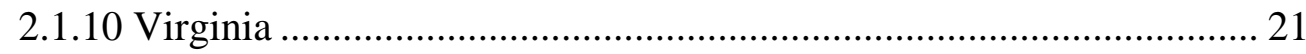

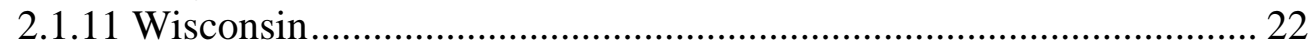

2.1.12 Summary of Existing Warrants.......................................................... 23

2.2 Ramp Metering Strategies ..................................................................... 25

2.2.1 Metering Rate Selection Mode …………………............................ 25

2.2.2 Metering Activation Strategies .......................................................... 26

2.2.3 Ramp Metering Extent and Associated Algorithms ............................ 26

2.2.3.1 Local Ramp Metering Algorithms ................................................... 30

2.2.3.2 System-Wide Ramp Metering Algorithms ……………………....... 34

2.2.4 Useful Concepts from Metering Algorithms ……………………......... 47

2.3 Additional Considerations for Ramp Metering ............................................ 48

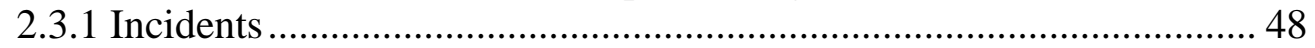

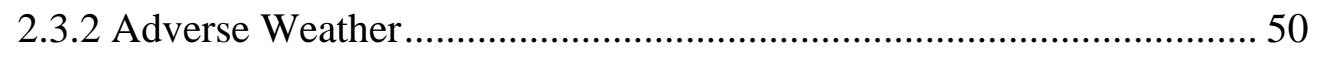

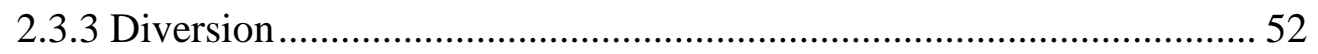

2.3.4 Vehicle Class .................................................................................. 54

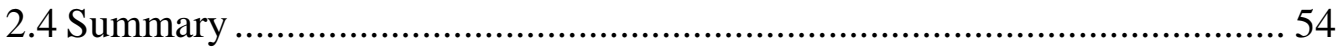

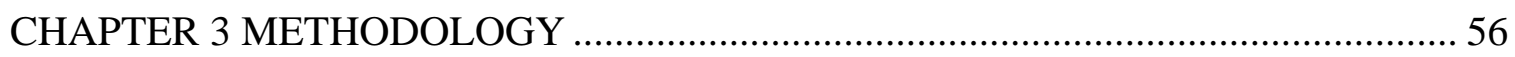

3.1 Methodology Outline ................................................................................ 56

3.2 Introduction of the Study Area and Required Data ..................................... 57

3.2.1 Case Study …………………….................................................... 57

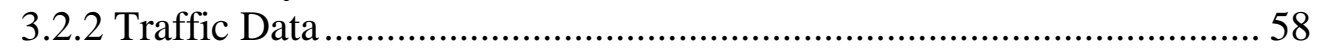

3.2.3 Incident and Adverse Weather Data ................................................. 59

3.3 Assessment of the Need for Developing System-Based Methodology ...... 59

3.3.1 Applying Existing Ramp Metering Warrants ......................................... 60 
3.3.2 Selecting Ramps Based on System Bottlenecks .................................. 60

3.3.2.1 Stochastic Capacity Analysis ......................................................... 60

3.3.2.2 Selecting Ramps for Metering based on System Bottlenecks........ 63

3.3.3 Comparison Based on Simulation........................................................ 65

3.4 Developed Methodology for Identification of Ramps for Metering............ 66

3.4.1 Off-Line Ramp Selection for Recurrent Conditions .............................. 70

3.4.1.1 Stochastic Demand Analysis......................................................... 71

3.4.1.2 Generating Analysis Scenarios Using Monte Carlo Simulation.... 73

3.4.2 Off-Line Ramp Selection for Non-Recurrent Conditions..................... 74

3.4.2.1 Incident Impact on Capacity ......................................................... 74

3.4.2.2 Incident Impact on Demands ..................................................... 75

3.4.2.3 Rainfall Impact on Capacity ........................................................ 76

3.4.3 Benefit-Cost Analysis for Ramp Metering Deployment ……….......... 78

3.4.4 Real-Time Ramp Selection for Activation ........................................... 79

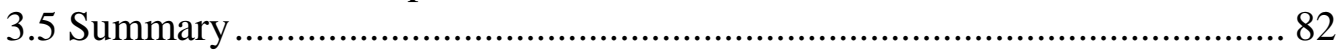

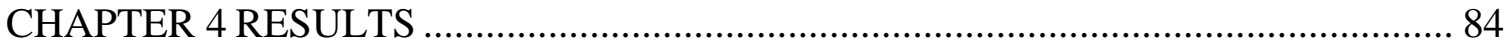

4.1 Assessment of the Need to Develop System-Based Warrants..................... 84

4.2 Off-Line Ramp Selection for Recurrent and Non-Recurrent Conditions ... 92

4.2.1 Application of Monte Carlo Simulation............................................... 93

4.2.2 Demand to Capacity Ratio Distributions Derived Based on Monte

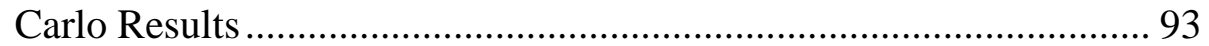

4.2.3 Determining the Number of Ramps to Meter ....................................... 96

4.2.4 Estimation of Ramp Queue Lengths ..................................................... 97

4.2.5 Benefit-Cost Analysis of Ramp Metering Deployment ........................ 98

4.3 Real-Time Ramp Selection for Application ............................................. 100

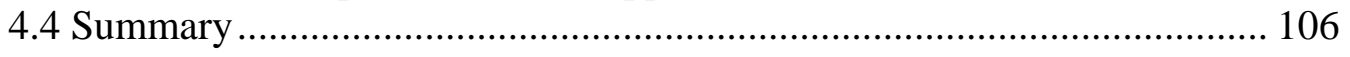

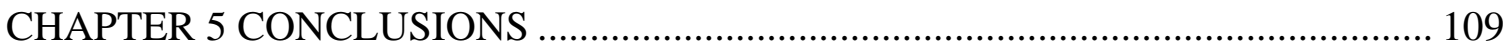

5.1 Summary and Conclusions ..................................................................... 109

5.2 Research Contributions .......................................................................... 113

5.3 Study Limitations and Recommendations for Future Research ............... 113

REFERENCES

VITA 


\section{LIST OF TABLES}

TABLE

PAGE

Table 2-1: UDOT Total Mainline and Ramp Volume Thresholds (TransCore, 2001) .... 20

Table 2-2: UDOT Ramp Volume Thresholds (TransCore, 2001) .................................. 21

Table 2-3: Summary of Ramp Metering Warrants for Traffic Criteria .......................... 24

Table 2-4: Comparison of Pre-Timed and Traffic Responsive Ramp Metering Algorithms (Cambridge Systematics, 2001)............................................... 28

Table 2-5: Summary of Ramp Metering Algorithms (Atkins, 2013) ............................ 29

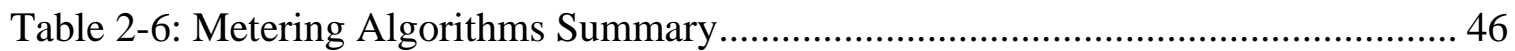

Table 3-1: Remaining Capacity Ratio for Open Lanes after Closure due to Incident Occurrence (HCM, 2016) .................................................................... 75

Table 3-2: Estimated Diversion Rates due to Incident Occurrence (Hadi et al., 2013).... 76

Table 3-3: Remaining Capacity Ratio for Rainfall (HCM, 2016) ................................. 77

Table 3-4: Diversion and Capacity Adjustment Coefficients for Non-Recurrent Senarios on a 4-Lane Freeway Segment ................................................... 77

Table 4-1: List of Warranted Ramp Metering Based on Existing Florida Warrants and System-Wide Consideration ............................................................ 86

Table 4-2: Delay Savings due to System Justified vs. Locally Justified Ramp Metering and the Associated Benefit-Cost Analysis....

Table 4-3: Total Number of Ramps to Meter for Recurrent and Non-Recurrent Conditions 96

Table 4-4: Cumulative Probability of Average Queue Length (Feet) for Recurrent and Non-Recurrent Conditions

Table 4-5: Delay Savings due to Ramp Metering with Recurrent and Non-Recurrent Conditions and the Associated Benefit-Cost Analysis 100

Table 4-6: Look-Up Table for Real-Time Activation of the Ramps ............................ 103

Table 4-7: Real-Time Activation Results for the Morning. 104 
Table 4-8: Real-Time Activation Results for the Afternoon 


\section{LIST OF FIGURES}

FIGURE

PAGE

Figure 1-1: Schematic Illustration of Ramp Metering ............................................. 1

Figure 1-2: Fundamental Flow-Density Diagram ................................................. 2

Figure 2-1: FDOT Ramp Metering Warrants Flowchart (Gan et al., 2011) .................... 14

Figure 2-2: NDOT Ramp Metering Warrants Analysis (Jacobs, 2013) ........................ 15

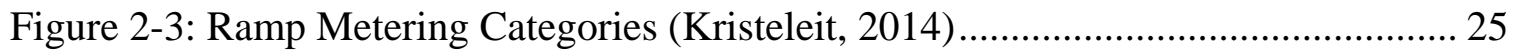

Figure 2-4: Zone and Layer Structure in SZM (Elefteriadou et al., 2009) ..................... 38

Figure 2-5: Fuzzy Logic Ramp Metering Structure (Bogenberger et al., 2001).............. 44

Figure 3-1: Study Area, I-95 Northbound in Broward County, Florida .......................... 58

Figure 3-2: Schematic Demonstration for the Variables of Linear Programming

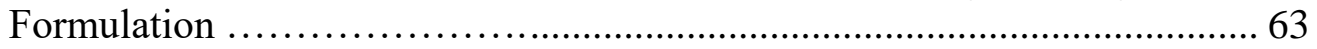

Figure 3-3: Main Steps of the Developed Methodology ......................................... 70

Figure 3-4: Breakdown Probability Model for I-95 NB ramp from 103rd St.

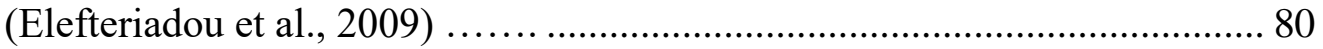

Figure4-1: Stochastic Capacity Distribution for Bottleneck Location and VISSIM

Calibration Results.................................................................... 85

Figure 4-2: Speed Contours for Freeway Mainline $\left(95^{\text {th }}\right.$ and $80^{\text {th }}$ Percentile Capacity

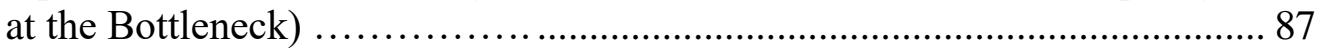

Figure 4-3: Speed Contours for Freeway Mainline $\left(50^{\text {th }}\right.$ and $30^{\text {th }}$ Percentile Capacity

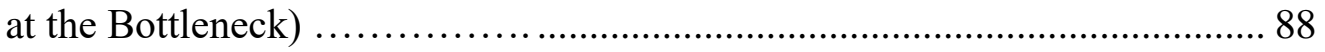

Figure 4-4: Travel Time on the Freeway Mainline with Different Percentiles of Bottleneck Capacity and Metering Scenarios ........................................... 89

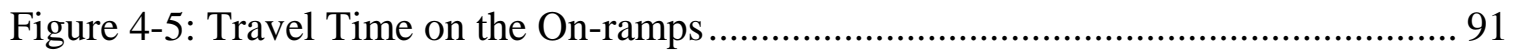

Figure 4-6: Demand Distribution for the Morning and Afternoon Peaks....................... 93

Figure 4-7: Cumulative Probability of the D/C Ratios for the Morning and Afternoon 
Peaks during Recurrent Conditions

Figure 4-8: Simulated D/C Histogram for the Morning Peak during Recurrent

Conditions .....

Figure 4-9: Simulated D/C Histogram for the Afternoon Peak during Recurrent Conditions 95

Figure 4-10: Historical Demand Distribution for the Morning Peak Period .................. 101

Figure 4-11: Historical Demand Distribution for the Afternoon Peak Period.. 101 


\section{LIST OF ACRONYMS}

\begin{tabular}{|c|c|}
\hline AASHTO & American Association of State Highway and Transportation Officials \\
\hline ACCEZZ & Adaptive and Coordinated Control of Entrance Ramps with Fuzzy Logic \\
\hline ADOT & Arizona Department of Transportation \\
\hline ALINEA & Asservissement Linéaire d'Entrée Autoroutière \\
\hline ARM & Annual Reliability Matrix \\
\hline BII & Bottleneck Intensity Index \\
\hline CBI & Congestion and Bottleneck Identification \\
\hline CCTV & Closed-Circuit Television \\
\hline CDOT & Colorado Department of Transportation \\
\hline DIVE & Duration, Intensity, Variability, Extent \\
\hline FDOT & Florida Department of Transportation \\
\hline FHWA & Federal Highway Administration \\
\hline FTI & Florida Transportation Information \\
\hline $\mathrm{HCM}$ & Highway Capacity Manual \\
\hline $\mathrm{HOV}$ & High Occupancy Vehicle \\
\hline ITE & Institute of Transportation Engineers \\
\hline ITS & Intelligent Transportation Systems \\
\hline LOS & Level of Service \\
\hline MnDOT & Minnesota Department of Transportation \\
\hline MPC & Model Predictive Control \\
\hline mph & Miles per Hour \\
\hline MUTCD & Manual on Uniform Traffic Control Devices \\
\hline NCHRP & National Cooperative Highway Research Program \\
\hline
\end{tabular}




$\begin{array}{ll}\text { NDOT } & \text { Nevada Department of Transportation } \\ \text { NYSDOT } & \text { New York State Department of Transportation } \\ \text { pcphpl } & \text { Passenger Cars per Hour per Lane } \\ \text { PLM } & \text { Product Limit Method } \\ \text { RHMVM } & \text { Rate per Hundred Million Vehicle-Miles } \\ \text { RITIS } & \text { Regional Integrated Transportation Information System } \\ \text { SDRMS } & \text { San Diego Ramp Metering System } \\ \text { SWARM } & \text { System-Wide Area Ramp Metering } \\ \text { SZM } & \text { Stratified Zone Metering } \\ \text { TMC } & \text { Traffic Management Centers } \\ \text { TMUTCD } & \text { Texas Manual on Uniform Traffic Control Devices } \\ \text { TTC } & \text { Time to Collision } \\ \text { vTI } & \text { Texas Transportation Institute } \\ \text { TxDOT } & \text { Texas Department of Transportation } \\ \text { UDOT } & \text { Utah Department of Transportation } \\ \text { USA } & \text { United States of America } \\ \text { Vehicles per Hour } \\ \text { Vehicles per Hour per Lane }\end{array}$




\section{CHAPTER 1 INTRODUCTION}

Recurrent congestion during the peak hours and non-recurrent congestion due to incidents, work zones, weather and special events significantly reduce the throughput and operating speed of freeways. Ramp metering is a ramp management strategy, which helps to keep the density below the critical value, preventing breakdown, and thus maintaining the full capacity of the freeway. Ramp metering regulates entering flow to freeway facilities by using traffic signals installed at on-ramps. As illustrated in Figure 1-1, once the ramp metering is activated, a ramp signal alternates between green and red to allow one or two entering vehicles (depending on the metering strategy) to merge into the freeway mainline traffic smoothly and safely (Balke et al., 2009). Basically, ramp meters aim to control the entering flow to the freeway, reduce freeway demand, and break up the entering platoons (Balke et al., 2009).

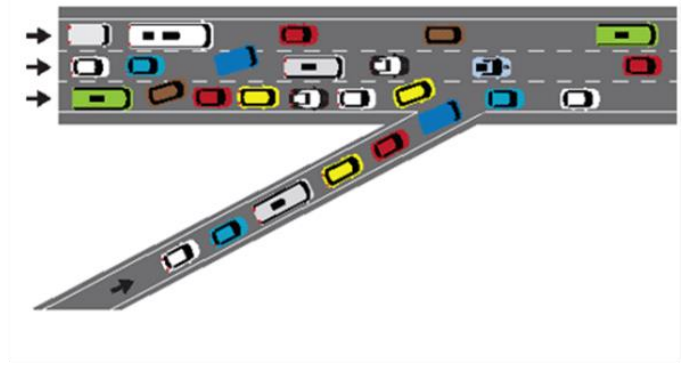

Freeway without Ramp Metering

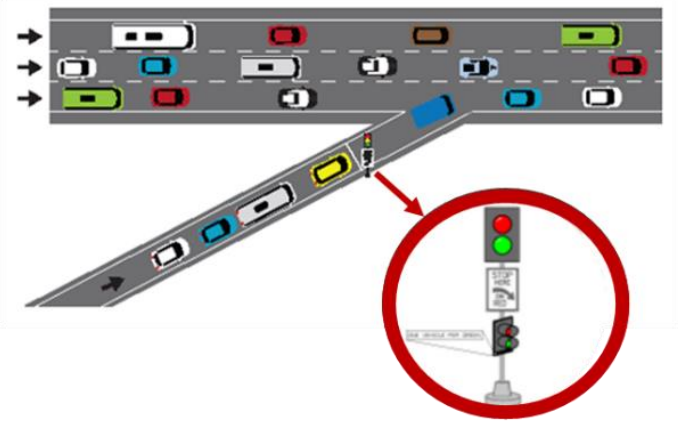

Freeway with Ramp Metering

\section{Figure 1-1: Schematic Illustration of Ramp Metering}

In order to better understand the impacts of congestion on traffic operations and how ramp metering can reduce these impacts, it is necessary to reference the macroscopic traffic flow fundamental theory that relates the flow, density, and speed of the uninterrupted 
flow on freeway facilities. Figure 1-2 illustrates a fundamental Flow-Density Diagram. As shown in this figure, when the traffic density $(\mathrm{k})$, defined as the number of vehicles occupying a certain space (vehicle/mile/lane), reaches a critical value $\mathrm{k}_{c}$, the freeway flow reaches its maximum value of $\mathrm{q}_{\max }$; which is the segment capacity, as defined in the Highway Capacity Manual (HCM). Beyond this point, increasing freeway density due to increased demands leads to a reduction in traffic flow (throughput). When the density reaches its maximum possible value, referred to as jam density $\left(\mathrm{k}_{\mathrm{j}}\right)$, the traffic flow becomes zero and the traffic stops. If the density is lower than the critical value $\left(\mathrm{k}_{\mathrm{k}}<\mathrm{k}_{\mathrm{c}}\right)$, the flow is considered stable (uncongested). When the density exceeds the critical value $\left(\mathrm{k}>\mathrm{k}_{\mathrm{c}}\right)$, the flow is considered unstable (congested) and the maximum possible throughput drops.

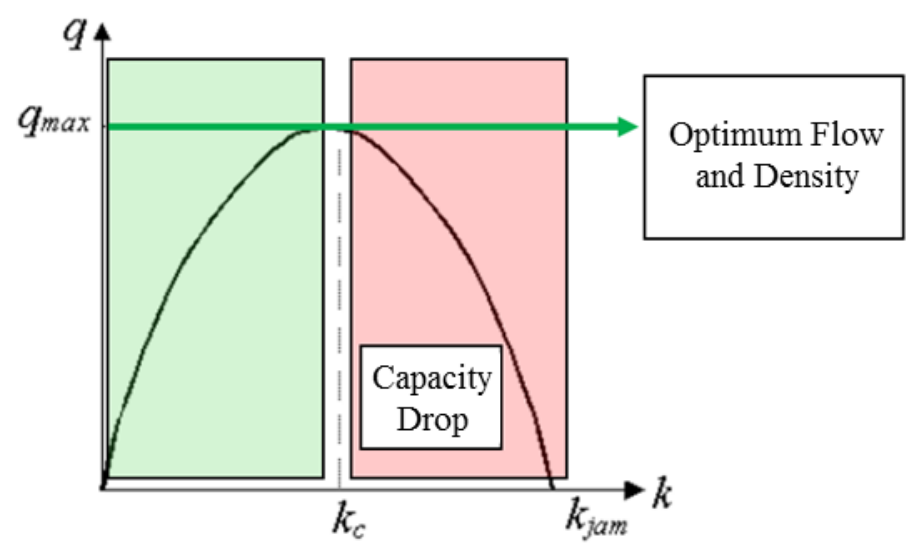

\section{Figure 1-2: Fundamental Flow-Density Diagram}

Ramp metering can help to keep the density as close as possible but below the critical density value to prevent the reduction in flow (throughput), and thus maintain the full capacity of the freeway. It is very important to select a proper metering rate. If the metering rate is too restrictive, the ramp queue spills back to the surface street while part of the freeway capacity may still be unused and indeed wasted. On the other hand, if the 
metering rate is too permissive, the freeway congestion increases and the capacity drops as the traffic operates in the "unstable region" (Hasan, 1999).

Proper ramp metering can increase freeway throughput and travel speed, which leads to reductions in fuel consumption and emissions. Freeway safety can also be improved with the implementation of ramp metering by smoothing the merging traffic and reducing the stop-and-go patterns. The first ramp metering in the United States was implemented on the Eisenhower Expressway in Chicago in 1963. In Florida, the first ramp signal was installed on an I-95 section in Miami-Dade County in 2009 by the Florida Department of Transportation (FDOT), District Six (Gan et al., 2011).

The performance of ramp metering is highly affected by selecting the geographic extent and specific ramps to meter, ramp metering activation/deactivation, operation strategies, metering strategy and algorithm, metering parameters, queue management and signing (FHWA, 2006). These parameters have to be considered in the decision-making process of ramp metering planning, implementation, operations, and management.

Proper ramp metering can improve safety and mobility, in addition to improving the environmental conditions. A 5\% to $37 \%$ reduction in crash potential was reported as a result of ramp metering (Gan et al., 2011). Ramp metering can also improve travel speed and throughput by decreasing the probability of traffic breakdown, improving travel time reliability, and diverting local traffic to the arterials for short trips (Shea et al., 2015). Reducing congestion also leads to reductions in fuel consumption and vehicle emissions. Overall, the benefits of ramp metering can be summarized as traffic throughput improvement, travel time and travel time reliability improvements, safety benefits, environmental benefits, and reduction in fuel consumption (Gan et al., 2011). 
Despite all of the advantages of ramp metering, it may cause long queues on the ramps and spillbacks to upstream intersections. This needs to be addressed by metering rate adjustments. Moreover, the ramp metering may cause traffic diversion to parallel routes, which can result in congestion in the network. However, a successful metering approach can overcome these disadvantages by better selection of implementation parameters (Jacobs, 2013).

\subsection{Problem Statement}

Although the potential benefits of ramp metering are well recognized, it is crucial to select metering locations, the associated metering rates, and other metering parameters to realize and maximize these benefits (Hasan, 1999). Not all freeway sections can benefit from ramp metering, and the specific ramps to be metered will have to be selected carefully, both off-line and in real-time operations.

Ramp metering can cause long queues on the ramps, which may spill back to upstream intersections. Moreover, ramp metering causes diversion to parallel streets and alternative routes, which can create congestion problems if these routes do not have enough capacity to accommodate the diverted flow. Therefore, there is a need to determine the conditions under which ramp metering is justified to be implemented for improving traffic conditions. To accomplish this, transportation agencies have developed guidelines and warrants to support the decisions to implement ramp metering during the planning stage and procedures to activate/deactivate the meters in real-time operations. The real-time activation decisions have generally been made based on time of day combined with 
decisions made by operators at traffic management centers based on their observations of the traffic conditions.

A summary of ramp metering installation warrants is presented in the review of the literature section. These existing warrants consider local conditions of the subject ramp and freeway mainline in the vicinity of the on-ramp merge area. However, the most advanced applications of ramp metering utilize system-based metering algorithms that involve metering a set of on-ramps to address a single system bottleneck location. These algorithms have been proven to perform better compared to the local ramp metering algorithm. This has created a disconnection between existing agency metering warrants based on local conditions and the subsequent operations of the ramp meters based on system bottleneck consideration.

Moreover, transportation system management and operation agencies have realized the need to activate metering during non-recurrent events like incidents and adverse weather conditions. Some of these agencies have assigned operators to activate ramp metering during non-recurrent conditions based on their observations of traffic conditions using closed circuit television (CCTV) cameras. Previous studies showed that nonrecurrent conditions contribute significantly to the congestion and unreliability of the transportation system. However, the existing ramp metering warrants do not consider nonrecurrent events as a contributing factor.

\subsection{Research Objectives and Scope}

As aforementioned, all of the existing metering warrants are based on local traffic conditions in the vicinity of the on-ramps. On the other hand, system-wide ramp metering 
algorithms also consider traffic conditions in a broader area around the subject ramp that include downstream bottlenecks, as well as upstream and downstream ramps. This points to the need for developing additional methodology that considers system conditions to bridge the gap between the installation warrants at the planning stage and the actual operations of the meters. In addition, there is a need to provide methodologies to support real-time decisions to activate ramp metering.

This dissertation research focuses on developing methods that can be used in addition to local warrants for ramp metering installation in the planning stage and activation of real-time operations under recurrent and non-recurrent conditions. Such methods will need to be developed to prevent breakdowns at bottleneck locations and improve the performance measures of freeway segments beyond the local ramp locations. The objectives of this dissertation research are as follows:

1. To develop system-based methods under recurrent conditions for ramp metering installation in the planning stage.

2. To extend the system-based methods to address non-recurrent conditions for ramp metering installation in the planning stage.

3. To extend the off-line system-based method for real-time selection of the ramps for activation.

A system is defined as a freeway section with multiple on-ramps and off-ramps.

\subsection{Dissertation Organization}

This document consists of four chapters. Chapter 2 summarizes the review of the existing literature for ramp metering warrants, as well as ramp metering strategies and 
algorithms. Chapter 3 describes the proposed methodology for the objectives of the research. Chapter 4 presents the results for the implementation of the proposed methodology. Finally, Chapter 5 presents the summary and conclusions of this dissertation research. 


\section{CHAPTER 2}

\section{LITERATURE REVIEW}

This chapter will first review the existing ramp metering warrants that have been used by agencies around the United States. It will then present a review of ramp metering strategies and the associated algorithms to allow better understanding of how the systems actually operate after the warrants have been implemented.

\subsection{Ramp Metering Warrants}

As previously mentioned, not all freeway sections can benefit from ramp metering despite its advantages as a traffic management strategy. Thus, there is a need to determine the conditions under which ramp metering may be suitable for improving traffic conditions. As a result, agencies have produced guidelines for the implementation of ramp metering. In the remainder of this section, warrants developed by different jurisdictions in the United States of America will be introduced.

\subsubsection{Manual on Uniform Traffic Control Devices (MUTCD)}

The 2003 version of the Manual on Uniform Traffic Control Devices (MUTCD, 2003) recommended the consideration of ramp metering implementation, if at least one of the following criteria is met:

1. "Congestion recurs on the freeway because traffic demand is in excess of the capacity, or a high frequency of crashes exists at the freeway entrance because of an inadequate ramp merging area." According to the MUTCD, a good indicator of recurring freeway congestion is a freeway operating speed less than $50 \mathrm{mph}$ 
occurring regularly for at least a half-hour period. Freeway operating speeds less than $30 \mathrm{mph}$ for a half-hour period or more indicates severe congestion.

2. "Controlling traffic entering a freeway assists in meeting local transportation system management objectives identified for freeway traffic flow, such as:

- Maintenance of a specific freeway level of service.

- Priority treatments with higher levels of service for mass transit and carpools.

- Redistribution of freeway access demand to other on-ramps."

3. "Predictable, sporadic congestion occurs on isolated sections of freeway because of short period peak traffic loads from special events or from severe peak loads of recreational traffic.”

The latest edition of the MUTCD (2009) refers to the Federal Highway Administration's (FHWA) Ramp Management and Control Handbook as the guideline for ramp metering warrants and eliminates the abovementioned warrants (MUTCD, 2009). However, the FHWA's handbook does not specify any quantitative criteria for considering ramp metering and generally mentions safety, congestion, convenience, ramp capacity, ramp queues, access, and adjacent facility operations as the justifications to consider ramp management strategies (FHWA, 2006).

\subsubsection{Arizona}

The Arizona Department of Transportation (ADOT) identified two ramp metering warrants that should be satisfied simultaneously to warrant the installation of ramp metering. In addition, the acceleration and ramp queue storage distance must be acceptable to recommend a ramp meter. The two warrants are (Simpson and Yasmin, 2013): 
1. Freeway right lane and entrance ramp flow rate: During a typical 15-minute period, the combined flow rate of the entrance ramp and the rightmost freeway lane is greater than 2,050 vehicles per hour (vph) and during the same period, the entrance ramp flow rate is greater than $400 \mathrm{vph}$.

2. During a typical 15 -minute period, the speed of the freeway general purpose lanes (not including HOV, auxiliary, and entrance ramp lanes) is less than 50 miles per hour (mph) due to recurring congestion adjacent to or within two miles downstream of the entrance ramp.

\subsubsection{California}

The California Ramp Meter Design Manual suggests considering "customization" for each specific case when using any design advices or guidelines. Given this suggestion, the following warrants are recommended by this manual (Caltrans, 2000):

1. A single-lane ramp meter should be geometrically designed for volumes up to 900 vph. Where truck volumes (three axles or more) are 5\% or greater on ascending entrance ramps to freeways with sustained upgrades exceeding 3\% (at least throughout the merge area), a minimum 500 feet in length of the auxiliary lane should be provided beyond the ramp merge area. If the volume exceeds $900 \mathrm{vph}$ and/or when a High Occupancy Vehicle (HOV) lane is determined to be necessary, a two- or three-lane ramp meter should be provided.

2. Freeway-to-freeway connectors may also be metered when warranted. The need to meter a freeway-to-freeway connector should be determined on an individual basis. 
3. The storage length for ramp meters have practical lower and upper output limits of 240 and 900 vph per lane, respectively. Ramp meter signals set for flow rates outside of this range tend to have high violation rates and cannot effectively control traffic. Therefore, on a ramp with peak-hour volume between 500 and $900 \mathrm{vph}$ per lane, a two-lane ramp meter may be provided to double the available queue storage area on the ramp. A single-lane ramp meter should be used when the rate is below $500 \mathrm{vph}$ and no HOV preferential lane is provided.

4. Ramp meter installations should operate in conjunction with and complement other transportation management system elements and transportation modes. As such, ramp meter installations should include preferential treatment of carpools and transit riders. Specific treatment(s) must be tailored to the unique conditions at each ramp location; however, the standard or base treatment upon which other strategies are designed is the $\mathrm{HOV}$ preferential lane. An $\mathrm{HOV}$ preferential lane shall be provided at all ramp meter locations.

\subsubsection{Colorado}

The Colorado Department of Transportation (CDOT) considers three conditions for ramp metering to be warranted (Gaisser and DePinto, 2015):

1. The first condition is that the total of the upstream mainline volume and ramp volume exceeding defined thresholds is as follows:

- 2,650 vph for two mainline lanes

- $\quad 4,250 \mathrm{vph}$ for three mainline lanes

- $\quad 5,850 \mathrm{vph}$ for four mainline lanes 
2. The second condition considers ramp volumes of up to $900 \mathrm{vph}$ for single-lane ramps and above $900 \mathrm{vph}$ for two-lane ramps.

3. The third condition is descriptive and recommends field observation and experience to justify ramp metering for the considered locations.

\subsubsection{Florida}

Seven warrants were developed in Florida that consider traffic operation, geometric and safety criteria. According to these warrants, ramp metering is warranted if the following conditions are met (Gan et al., 2011):

1. Mainline Volume: The average mainline volume during the peak hour is higher than 1,200 vphpl.

2. Mainline Speed: The average mainline speed during the peak hour is below $50 \mathrm{mph}$.

3. Ramp Volume: Ramp metering is warranted when:

- The peak hour on-ramp volume is between $240 \mathrm{vph}$ and 1,200 vph for singlelane ramps.

- The peak hour on-ramp volume is between $400 \mathrm{vph}$ and 1,700 vph for ramps with multiple lanes.

4. Total Mainline and Ramp Volumes: Ramp metering is warranted when the total mainline and ramp volume during the peak hour exceeds the following thresholds:

- For two mainline lanes, the total volume is greater than 2,650 vph.

- For three mainline lanes, the total volume is greater than 4,250 vph.

- For four mainline lanes, the total volume is greater than 5,850 vph.

- For five mainline lanes, the total volume is greater than 7,450 vph. 
- For six mainline lanes, the total volume is greater than 9,050 vph.

- For more than six mainline lanes, the total volume is greater than $10,650 \mathrm{vph}$.

The number of lanes in the list above is for one direction, including auxiliary lane(s) that continue for at least $1 / 3$ of a mile downstream from the ramp gore.

5. Peak Hour Volume for the Rightmost Lane: Ramp metering is also warranted when the peak hour volume of the rightmost lane exceeds 2,050 vph.

6. Acceleration Distance: Ramp metering may be warranted where the acceleration distance after the stop bar is greater than the required safe merging distance, as estimated by Equation 2-1:

$$
L=0.14 V^{2}+3 V+9.21
$$

where,

$L=$ required minimum acceleration distance $(\mathrm{ft})$, and

$V=$ freeway mainline prevailing speed ( $\mathrm{mph})$.

7. Crash Rate: Ramp metering is warranted at a location where the facility or roadway segment has a crash rate of over 80 crashes per hundred million vehicle miles (HMVM). The rate is calculated using Equation 2-2:

$$
R H M V M=\frac{\text { Number } \text { of } \text { crashes per year } \times 100,000,000}{A A D T \times 365 \times \text { Distance }}
$$

where,

$$
\begin{aligned}
& \text { RHMVM }=\text { crash rate per hundred million vehicle-miles, } \\
& \text { AADT = Average Annual Daily Traffic on the facility (vpd), and } \\
& \text { Distance = length of roadway segment (mile). }
\end{aligned}
$$


The flowchart illustrated in Figure 2-1 presents the steps for applying the Florida warrants.

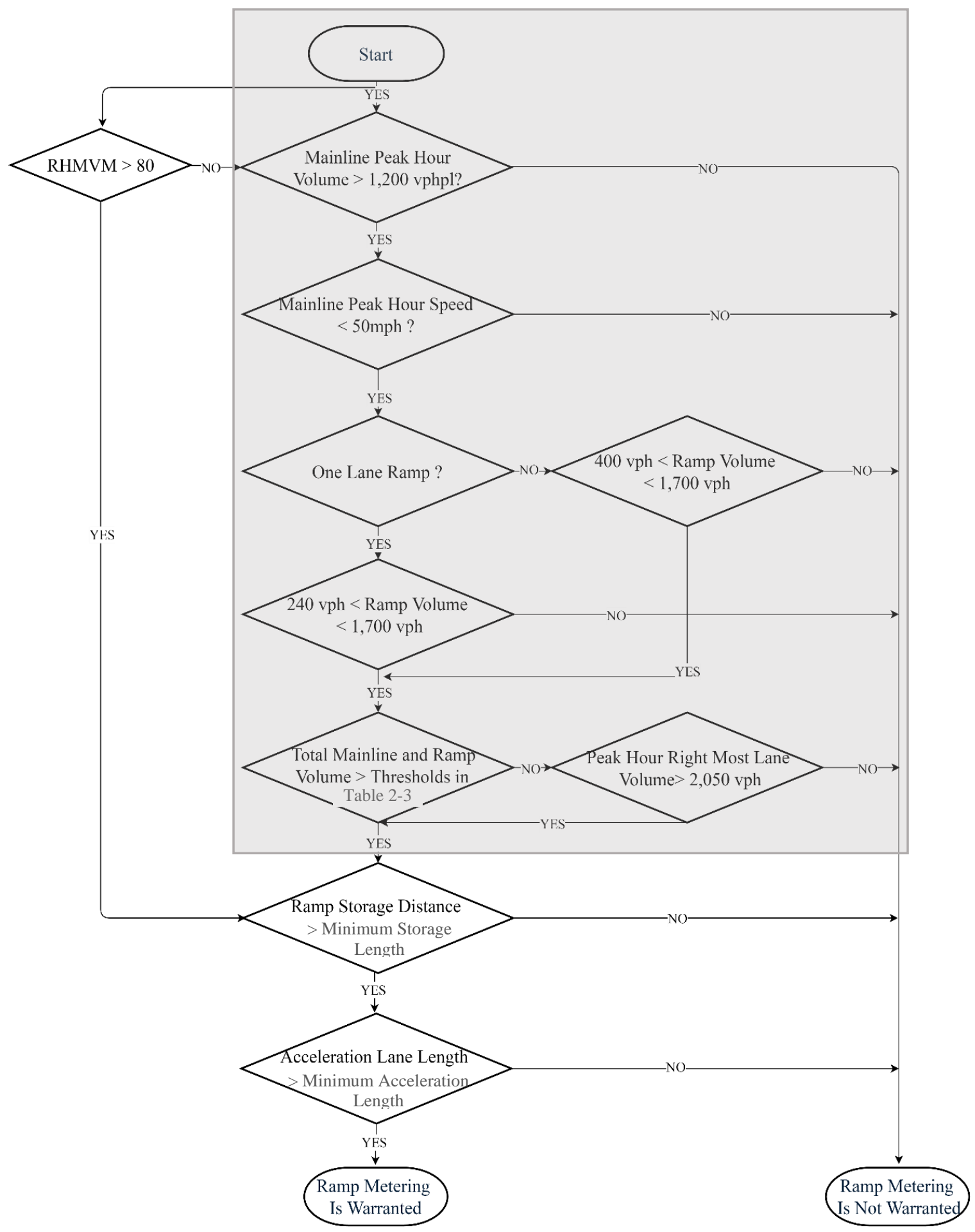

Figure 2-1: FDOT Ramp Metering Warrants Flowchart (Gan et al., 2011) 
The warrants shaded in gray are mobility-related warrants. Mobility is the main consideration in this dissertation research.

\subsubsection{Nevada}

The Nevada Department of Transportation (NDOT) introduced nine warrants for ramp metering installation (Jacobs, 2013). Figure 2-2 illustrates NDOT's application of these warrants.

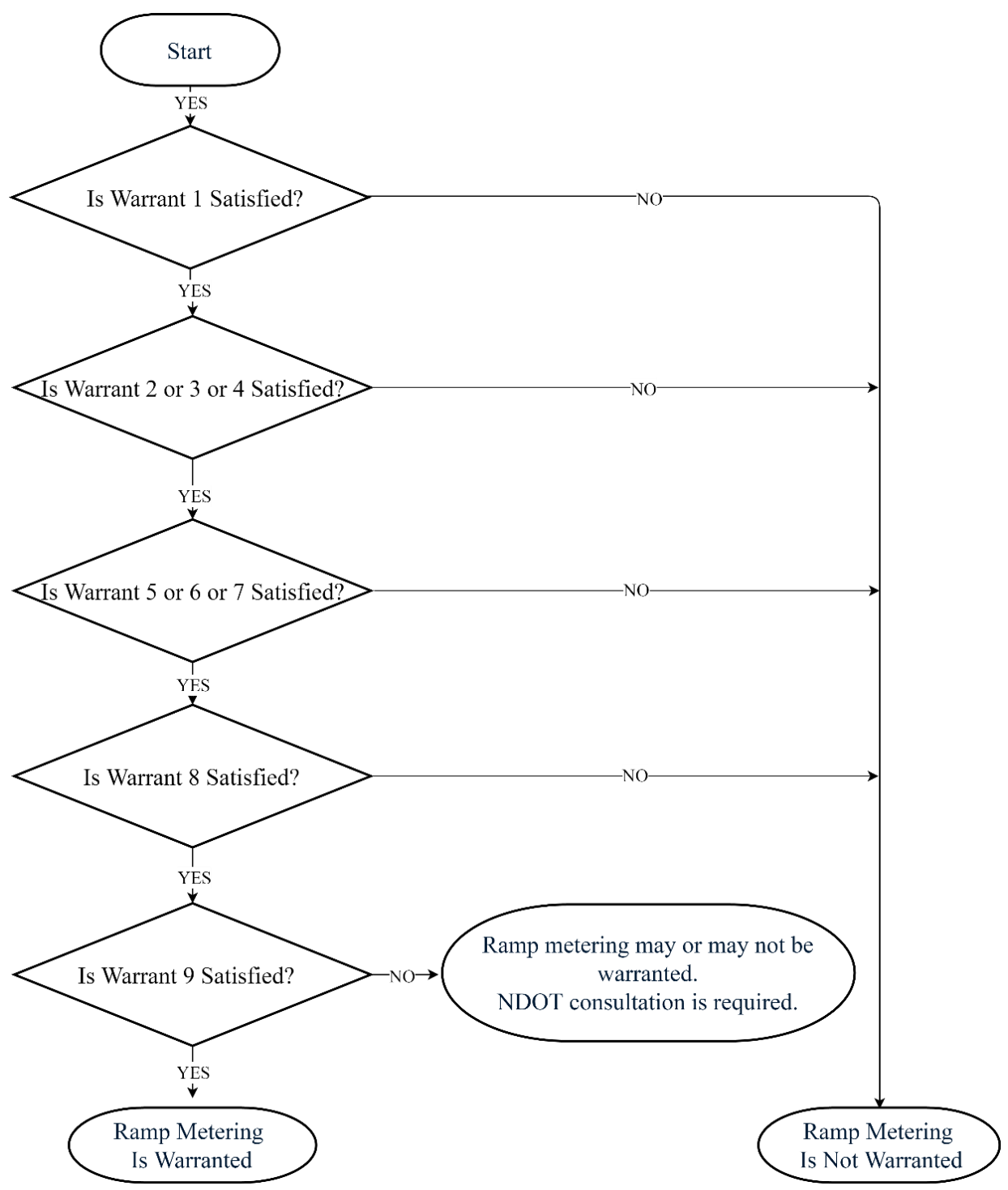

Figure 2-2: NDOT Ramp Metering Warrants Analysis (Jacobs, 2013) 
These nine warrants are as follows:

1. Ramp Volume: The minimum ramp volume during the critical peak hour is higher than 240 vphpl.

2. Crash Rate: The crash rate within 500 feet of the ramp gore point is higher than the mean crash rate for similar sections on freeways in the metropolitan area.

3. Speed: For 200 or more days per year, the freeway operates at speeds lower than $50 \mathrm{mph}$ for at least 30 minutes.

4. Level of Service: The peak period level of service (LOS) for the freeway is worse than LOS D.

5. Mainline Volume and Ramp volume: The total peak period mainline volume in one direction (excluding the managed lanes volume) and downstream of the gore exceeds:

- 2,650 vph for two mainline lanes,

- 4,250 vph for three mainline lanes,

- $\quad 5,850 \mathrm{vph}$ for four mainline lanes,

- $\quad 7,450 \mathrm{vph}$ for five mainline lanes,

- 9,050 vph for six mainline lanes, and

- $\quad 10,650 \mathrm{vph}$ for more than six mainline lanes.

6. Mainline Right Lane Volume and Ramp Volume: The ramp volume plus mainline right lane volume downstream of the gore is more than 2,100 vph during the peak hour. 
7. Platoons from Signalized Intersections: The hourly volume entering from arterials, based on the highest 30 -second volume readings (during the critical peak period) projected to hourly values, is greater than $1,100 \mathrm{vph}$.

8. Acceleration Length: The available acceleration length after the stop bar is greater than the required acceleration length. The acceleration length must accommodate enough distance between the stop bar and the convergence point of the ramp and freeway mainline to allow vehicles on the ramp to accelerate within $5 \mathrm{mph}$ of the freeway's operating speed. Providing inadequate acceleration length is not allowed under any circumstance.

9. Ramp Storage Length: The available ramp storage length is greater than the estimated queuing length on the ramp. The queueing length is calculated using the following steps.

- Step 1: Obtain a 20-year projected peak hour ramp demand volume.

- $\quad$ Step 2: Assume a peak hour factor of 0.8 and calculate the 140-second arrival rate.

- Step 3: If the ramp peak hour volume is between 240-800 vph, consider a singlelane ramp; if the volume is higher than $800 \mathrm{vph}$, consider a two-lane ramp.

- Step 4: Assume a discharge rate of 31 vehicles per 140 seconds for single-lane ramps, and 62 vehicles per 140 seconds for two-lane ramps. Subtract the discharge rate from the arrival rate calculated in Step 2 to determine the excess number of vehicles per 140 seconds.

- Step 5: Calculate the total queue length by multiplying the excess vehicles by a vehicle spacing of 30 feet. 
- Step 6: Calculate the queue length per lane by dividing the calculated total queue length by the number of lanes.

- Step 7: The required storage lane length is the calculated queue length per lane plus the minimum storage length. This minimum storage length accounts for platoons of vehicles arriving at the ramp meter. The required minimum storage lengths are 480 feet per lane for a one or two-lane ramp, and 510 feet for a threelane ramp.

The calculated storage length is to be rounded up to a multiple of 30 . Additional storage must be provided if there is a significant number of trucks, buses, or RVs using the ramp.

\subsubsection{New York}

The New York State Highway Design Manual adopted the following ramp metering warrants from the National Cooperative Highway Research Program (NCHRP) Report 155:

- Freeway operating at a level of service worse than LOS D.

- Adequate parallel surface routes must be available for the traffic diverted from the ramps.

- Sufficient ramp storage capacity must be available to prevent queues of vehicles waiting to enter the freeway from blocking local street circulation.

The New York State Department of Transportation (NYSDOT) recommends the following value for the ramp metering rate:

- One-lane ramp: metering rate range of $240-900 \mathrm{vph}$. 
- Two-lane ramp: metering range from a low of $400 \mathrm{vph}$ to a high of $1,500-1,800 \mathrm{vph}$ (Gan et al., 2011).

\subsubsection{Texas}

The Texas Manual on Uniform Traffic Control Devices follows the ramp metering warrants of MUTCD 2003. However, the Texas Department of Transportation (TxDOT) introduced the following ramp metering warrants in 2009:

- The freeway regularly operates at speeds of less than $50 \mathrm{mph}$ for at least a half-hour period during the day (presumably during the peak period).

- The ramp sustains a minimum flow rate of at least $300 \mathrm{vph}$ during the peak periods.

- The average traffic flow rate of the two rightmost lanes during the peak periods exceeds 1,600 vphpl for entrance ramps that have acceleration lanes of 500 feet or less. This threshold level increases as the length of the acceleration lane on the ramp increases.

- The combined traffic flow rate in the rightmost freeway lane plus the flow rate on the entrance ramp during peak periods exceeds a minimum of 2,300 vphpl for entrance ramps with acceleration lanes of 500 feet or less. The threshold level increases as the length of the acceleration lane on the ramp increases.

From a safety perspective, TxDOT recommends that the ramp metering application is justified based on the following three criteria:

- The rate of crashes in the immediate vicinity of the ramp exceeds the mean crash rate for comparable freeway sections in the metropolitan area. 
- The acceleration distance permits a vehicle starting from a stop at the signal to reach the prevailing speed of the freeway traffic in the merge area so as to prevent an unacceptable speed differential in the merge area. The interacting ramp and freeway traffic vehicles must be able to maintain a desirable time to collision (TTC) after the merge. A TTC value lower than a specified threshold indicates an unsafe merge condition at the ramp meter. A sufficient storage length must also exist upstream of the ramp control signal to prevent queues from impeding operations on the frontage road or surface street intersection (Balke et al., 2009).

\subsubsection{Utah}

The Utah Department of Transportation (UDOT) specifies thresholds for the total of the mainline and ramp volumes or the individual ramp volume to justify ramp metering. The total of the mainline and ramp volumes threshold depends on the number of lanes on the freeway, while the ramp volume threshold depends on the number of lanes on the ramp and the percentage of HOVs (TransCore, 2001). The thresholds are shown in Tables 2-1 and $2-2$.

Table 2-1: UDOT Total Mainline and Ramp Volume Thresholds (TransCore, 2001)

\begin{tabular}{|c|c|}
\hline Number of Lanes & Total Mainline and Ramp Volume \\
\hline 2 & 2,650 \\
\hline 3 & 4,250 \\
\hline 4 & 5,850 \\
\hline 5 & 7,450 \\
\hline 6 & 9,050 \\
\hline 7 & 10,650 \\
\hline
\end{tabular}


Table 2-2: UDOT Ramp Volume Thresholds (TransCore, 2001)

\begin{tabular}{|c|c|l|}
\hline Ramp Volumes & HOV $(\%)$ & \multicolumn{1}{|c|}{ Recommended Lane Configuration } \\
\hline$<180$ & - & Signaling not recommended \\
\hline $180 \sim 600$ & - & Single-lane metered ramp \\
\hline $600 \sim 900$ & $<10 \%$ & Single-lane metered ramp \\
\hline $600 \sim 900$ & $>10 \%$ & $\begin{array}{l}\text { Single-lane metered ramp, or } \\
\text { two-lane ramp with one lane metered and one HOV } \\
\text { lane }\end{array}$ \\
\hline $900 \sim 1080$ & $<10 \%$ & Two-lane ramp with both lanes metered \\
\hline $900 \sim 1,080$ & $>10 \%$ & $\begin{array}{l}\text { Two-lane ramp with both lanes metered, or } \\
\text { two-lane ramp with one lane metered and one HOV } \\
\text { lane }\end{array}$ \\
\hline $1,080 \sim 1,350$ & $<10 \%$ & Two-lane ramp with both lanes metered \\
\hline $1,080 \sim 1,350$ & $>10 \%$ & $\begin{array}{l}\text { Two-lane ramp with both lanes metered, or } \\
\text { three-lane ramp with two lanes metered and one HOV } \\
\text { lane }\end{array}$ \\
\hline $1,350 \sim 1,720$ & $<10 \%$ & Three-lane ramp with all lanes metered \\
\hline $1,350 \sim 1,720$ & $>10 \%$ & $\begin{array}{l}\text { Three-lane ramp with all lanes metered, or } \\
\text { three-lane ramp with two lanes metered and one HOV } \\
\text { lane }\end{array}$ \\
\hline$>1,720$ & & Consider alternate metering strategies, or no metering \\
\hline
\end{tabular}

\subsubsection{Virginia}

The Virginia Transportation Research Council specifies the following warrants to justify ramp metering (Arnold, 1998):

- The freeway has poor traffic flow conditions in the peak periods, such as speeds of less than $30 \mathrm{mph}$, low throughput per lane, and levels of service of E or F.

- There are numerous crashes on the freeway, especially in the weaving areas.

- There are obvious merging problems occurring at freeway on-ramps.

- Heavy traffic volumes at closely spaced on-ramps.

- Feasible metering rate can accommodate the ramp demand volumes from both a maximum and minimum standpoint.

- There is adequate vehicle storage on the ramp.

- A freeway management system is being planned. 


\subsubsection{Wisconsin}

The Wisconsin Department of Transportation (WisDOT) introduced the following ramp metering warrants (Wilbur Smith Associates, 2006):

- Mainline volume flow rates of at least 1,200 vphpl (approximately 20\% to $30 \%$ occupancy) coupled with slow-moving traffic along the freeway lanes.

- Ramp volume criteria: The ramp should have volumes of at least $240 \mathrm{vph}$ for one lane and $400 \mathrm{vph}$ for two lanes.

- Speed criteria: $30 \mathrm{mph}$ or less is the common minimum freeway speed to warrant ramp metering.

- Safety criteria: A reduction in crashes at the merge should be expected due to metering. Crash rates in the vicinity of the ramp of 80 crashes or more per hundred million vehicle-miles of travel are recommended as a starting point for further analysis.

- Ramp geometric criteria: These include queuing storage space, adequate acceleration distance and merge area beyond the meter, and sight distance.

- Funding criteria: An evaluation of potential funding sources should be completed to determine if there is sufficient support for the project.

- Alternate route criteria: The presence of an alternative route for motorists to avoid delays on entrance ramps created by a ramp meter may be required.

- Corridor criteria: In most implementations, ramp metering is addressed at the corridor level. It must be determined whether the section under consideration is part of a corridor. 


\subsubsection{Summary of Existing Warrants}

Ramp metering installation warrants have been developed by a number of states, as demonstrated above. As with the warrants developed in Florida, most warrants are generally simple and examine the conditions in the immediate vicinity of each ramp (local conditions) to determine if a ramp meter is warranted. Some states have fewer warrants, such as Arizona, which has only two warrants based on mainline and ramp volumes and on speed. Other states, such as Nevada and Florida, have more warrants that also consider safety, the length of acceleration lanes, ramp queue storage, level of service, platoons from intersections, and/or the availability of diversion routes. Some warrants specify LOS D as a criterion to install ramp metering. Other state warrants, such as Wisconsin, specify mainline volume flow rates of at least $1,200 \mathrm{vphpl}$, with approximately $20 \%$ to $30 \%$ occupancy and slow-moving traffic along freeway lanes.

Some states like Arizona and Nevada specify speed warrants that justify ramp metering if the traffic speed drops to less than $50 \mathrm{mph}$ for half an hour, possibly reflecting LOS D. On the other hand, other state warrants, like Virginia, specify speed drops below $30 \mathrm{mph}$ and LOS $\mathrm{E}$ or LOS $\mathrm{F}$ for the consideration of ramp metering. For the safety warrants, quantitative values were included in the Wisconsin and Florida warrants $(\geq 80$ crashes per hundred million vehicle-miles of travel). Table 2-3 summarizes the warrants presented in this section. 
Table 2-3: Summary of Ramp Metering Warrants for Traffic Criteria

\begin{tabular}{|c|c|c|c|c|c|}
\hline Criteria & & Parameter & State & \multicolumn{2}{|c|}{ Threshold } \\
\hline \multirow{6}{*}{ Freeway Volume } & \multirow{4}{*}{\multicolumn{2}{|c|}{ Mainline Volume }} & Florida & \multicolumn{2}{|c|}{$>1,200 \mathrm{vphpl}$} \\
\hline & & & Minnesota & \multicolumn{2}{|c|}{$>1,200-1,500 \mathrm{vphpl}$} \\
\hline & & & Washington & \multicolumn{2}{|c|}{$>1,500 \mathrm{vphpl}$} \\
\hline & & & Wisconsin & \multicolumn{2}{|c|}{$>1,200$ vphpl } \\
\hline & \multicolumn{2}{|c|}{ Most Right Lane } & Florida & \multicolumn{2}{|c|}{$>2,050 \mathrm{vphpl}$} \\
\hline & \multicolumn{2}{|c|}{ Two Most Right Lanes } & Texas & \multicolumn{2}{|c|}{$>1,600$ vphpl } \\
\hline \multirow{2}{*}{ Volume/Capacity } & \multirow{2}{*}{\multicolumn{2}{|c|}{ Freeway Mainline }} & California & \multicolumn{2}{|c|}{$0.6-0.8$} \\
\hline & & & Wisconsin & \multicolumn{2}{|c|}{0.7} \\
\hline \multirow{9}{*}{ Mainline Speed } & \multicolumn{2}{|c|}{ Duration of at Least Half an Hour } & MUTCD & \multicolumn{2}{|c|}{$<50 \mathrm{mph}$} \\
\hline & \multicolumn{2}{|c|}{$\begin{array}{l}\text { Duration of at Least } 30 \text { minutes for } \\
200 \text { or More Calendar Days per Year }\end{array}$} & Arizona & \multicolumn{2}{|c|}{$<50 \mathrm{mph}$} \\
\hline & Average & Mainline Speed & California & $<30$ & $\mathrm{nph}$ \\
\hline & Peak Pe & d Speed & Minnesota & $<30$ & $\mathrm{mph}$ \\
\hline & Mainlin & Speed constantly & & $<50$ & nph \\
\hline & Peak Pe & od Speed & Nevada & $<40$ & nph \\
\hline & & & Texas & $<50$ & $\mathrm{nph}$ \\
\hline & Peak Pe & od Speed & Virginia & $<30$ & $\mathrm{nph}$ \\
\hline & & & Wisconsin & $<30$ & $\mathrm{nph}$ \\
\hline & & & Nevada & & \\
\hline Level of Service & & & New York & & \\
\hline & & & Virginia & & \\
\hline Occupancy & & & Wisconsin & $>18$ & $20 \%$ \\
\hline & & \# of Mainline Lanes & & & \\
\hline & & 2 & & $>26$ & $\mathrm{vph}$ \\
\hline & & 3 & Arizona & $>42$ & vph \\
\hline Mainline and Ram & Volume & 4 & Colorado & $>58$ & vph \\
\hline (Peak Hour & & 5 & Florida & $>74$ & vph \\
\hline & & 6 & Utah & $>90$ & vph \\
\hline & & $>6$ & & $>106$ & $0 \mathrm{vph}$ \\
\hline Two Most Right La & nes of $\mathrm{Ma}$ & lline & Arizona & $>2,1$ & $\mathrm{vph}$ \\
\hline Plus Ramp Volume & (Peak Ho & & California & $>1,8$ & vph \\
\hline & & & Texas & $>2,3$ & vph \\
\hline & & \# of Ramp Lanes & & Min (vph) & Max (vph) \\
\hline & & & California & 240 & 900 \\
\hline & & & Colorado & - & 900 \\
\hline & & & Florida & 240 & 1,200 \\
\hline & & & Nevada & - & 1,100 \\
\hline & & 1 & New York & 240 & 900 \\
\hline & & & Oregon & 240 & 900 \\
\hline & & & Texas & 300 & - \\
\hline & & & Utah & 180 & 900 \\
\hline Ramp Volume & & & Wisconsin & 240 & - \\
\hline & & & California & 500 & 900 \\
\hline & & & Colorado & 900 & - \\
\hline & & & Florida & 400 & 1,700 \\
\hline & & 2 & Nevada & 1,200 & 1,900 \\
\hline & & 2 & New York & 4,00 & 1,800 \\
\hline & & & Oregon & - & 1,650 \\
\hline & & & Utah & 600 & 1,350 \\
\hline & & & Wisconsin & 400 & - \\
\hline
\end{tabular}




\subsection{Ramp Metering Strategies}

As shown in Figure 2-3, Ramp metering strategies can be classified into different categories depending on the metering selection mode, metering activation strategy, ramp metering extent, and metering algorithms. This section presents a review of these algorithms, which will provide additional information useful for the development of the method in this dissertation research.

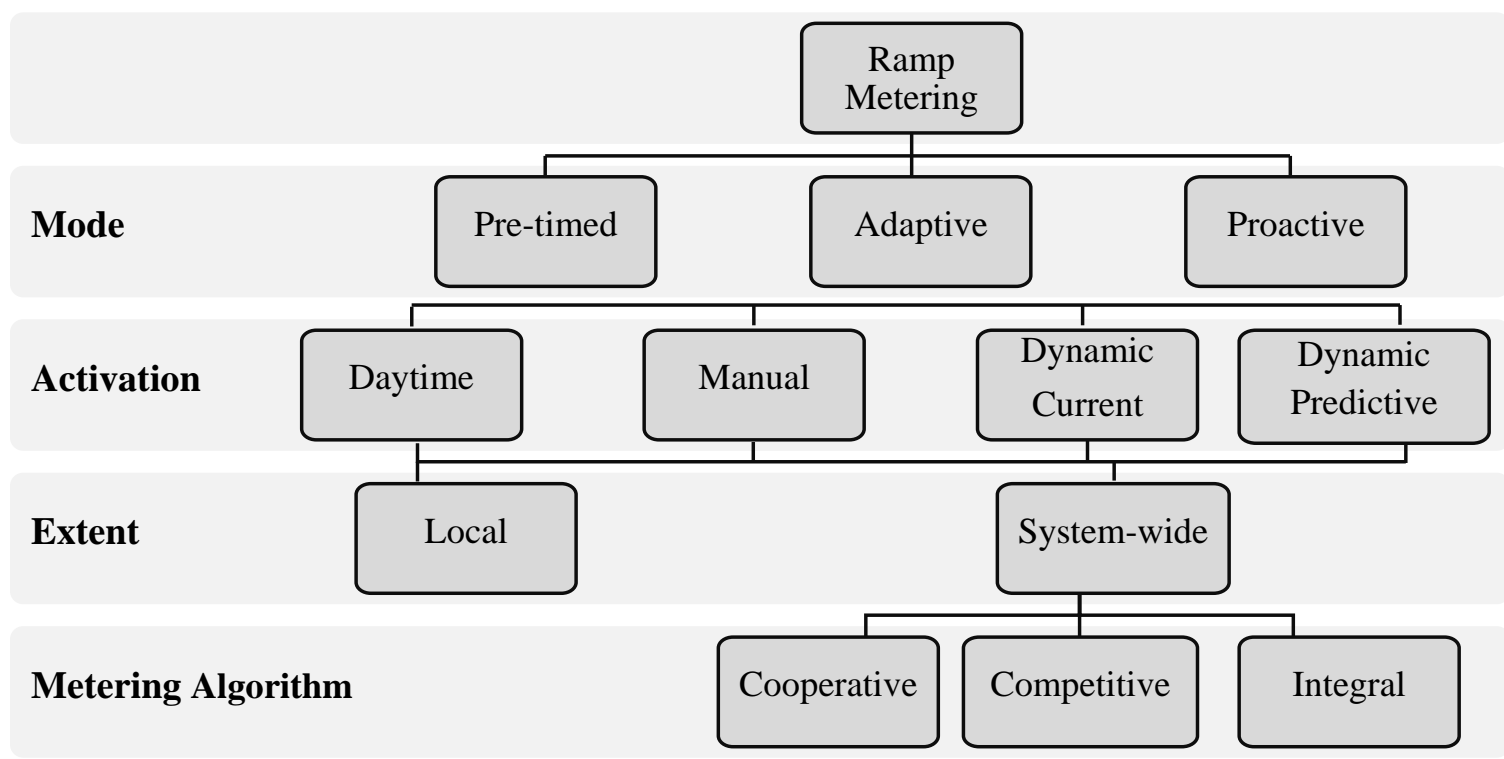

Figure 2-3: Ramp Metering Categories (Kristeleit, 2014)

\subsubsection{Metering Rate Selection Mode}

Metering rate calculations can be static, adaptive, or proactive. In static (time of day) control, the metering rate is calculated using historical data and under the assumption that traffic patterns tend to be the same over time. Adaptive (or traffic responsive) ramp calculates an appropriate ramp metering rate based on actual mainline and ramp traffic measurements. In doing so, this can address non-recurrent congestion, as well as recurrent traffic congestion, if desired. Similarly, the proactive (predictive) mode of control makes 
calculation on real-time data in order to prevent oversaturated conditions and traffic breakdown. Compared to static metering, both adaptive and proactive metering strategies require the installation and maintenance of traffic detectors along the freeway mainline and ramps.

\subsubsection{Metering Activation Strategies}

Within proactive and adaptive strategies, ramp metering can be activated either based on a schedule, manual inputs, or dynamically in response to current or predicted traffic conditions. The simplest of these activations methods is based on a fixed schedule. An example of this could be that the system is activated every day at 4:00 PM in the northbound direction. The manual strategy is more labor-intensive as it requires an operator to watch live traffic conditions via CCTV cameras and make changes accordingly. Unlike manual activation, the dynamic strategy implements an automated method which utilizes current traffic measurements or predicted traffic conditions to prevent breakdown and congestion; non-recurrent traffic conditions, such as incidents or accidents, can also trigger

the activation of dynamic ramp metering. As metering activation strategies become more advanced and increasingly more automated, the need for manual intervention is decreasing. However, these new automated methods require the deployment of more in-field traffic sensing devices, as well as more computational power.

\subsubsection{Ramp Metering Extent and Associated Algorithms}

Depending on the number of ramps being monitored by a ramp metering algorithm, it can be classified as a local algorithm, which only focuses on one ramp as an isolated element, or a system-wide (coordinated) algorithm, which considers multiple ramps. The 
objective of system-wide metering is to optimize the metering rate of each ramp in order to improve the system-wide traffic conditions and/or performance; in these types of algorithms, the function may differ based on an agency's policies.

In both local and system-wide metering, measurements of macroscopic traffic parameters on the freeway mainlines, specifically flow and occupancy and on-ramp queue lengths, are considered in the metering rate selection process to avoid freeway traffic breakdown and queue spillbacks to arterials. However, the system-wide metering requires detectors to be located on ramps and along the entire metering section. Conversely, local metering algorithms, both schedule-based and responsive, only require detectors to be located around the vicinity of a ramp area, including the subject on-ramp and freeway mainline. System-wide metering is more effective due to the fact that it can prevent and/or delay traffic breakdowns at a particular location through metering multiple upstream ramps rather than relying on metering the ramp immediately upstream of the bottleneck. This dependence on one ramp may not be enough to produce the desired effect required from these types of systems.

This section briefly discussed traffic-responsive ramp metering algorithms that have been used to select ramp metering rates. It is important to point out that this review serves to provide a review of literature related to this research's activities, as well as to explore protocols that will be implemented in the methodology developed in this dissertation. Tables 2-4 and 2-5 present comparisons of various categories of ramp metering algorithms. 
Table 2-4: Comparison of Pre-Timed and Traffic Responsive Ramp Metering Algorithms (Cambridge Systematics, 2001)

\begin{tabular}{|c|c|c|c|c|}
\hline \multirow{2}{*}{$\begin{array}{c}\text { Capabilities and } \\
\text { Requirements }\end{array}$} & \multicolumn{2}{|c|}{ Pre-timed } & \multicolumn{2}{|c|}{ Traffic Responsive } \\
\hline & Local & System-Wide & Local & System-Wide \\
\hline $\begin{array}{l}\text { Solve Local } \\
\text { /System-Wide } \\
\text { Issues }\end{array}$ & Local & System-wide & Local & $\begin{array}{l}\text { System-wide } \\
\text { (most useful for } \\
\text { corridor } \\
\text { applications) }\end{array}$ \\
\hline $\begin{array}{l}\text { Field Detection } \\
\text { Devices }\end{array}$ & No & No & Yes & $\begin{array}{l}\text { Yes (both } \\
\text { upstream and } \\
\text { downstream) }\end{array}$ \\
\hline $\begin{array}{l}\text { Communication } \\
\text { Devices }\end{array}$ & No & No & No & Yes \\
\hline Maintenance & $\begin{array}{l}\text { Periodic } \\
\text { manual update }\end{array}$ & & $\begin{array}{l}\text { High capital and } \\
\text { maintenance cost }\end{array}$ & $\begin{array}{l}\text { Highest capital } \\
\text { and maintenance } \\
\text { cost; requires } \\
\text { expert calibration } \\
\text { and } \\
\text { implementation }\end{array}$ \\
\hline $\begin{array}{l}\text { Recurrent and/or } \\
\text { Non-Recurrent } \\
\text { Effectiveness }\end{array}$ & $\begin{array}{l}\text { Recurrent } \\
\text { congestion }\end{array}$ & $\begin{array}{l}\text { Recurrent } \\
\text { congestion }\end{array}$ & $\begin{array}{l}\text { Recurrent and } \\
\text { non-recurrent } \\
\text { conditions }\end{array}$ & $\begin{array}{l}\text { Both recurrent and } \\
\text { non-recurrent } \\
\text { conditions }\end{array}$ \\
\hline $\begin{array}{l}\text { Traffic } \\
\text { Optimization }\end{array}$ & $\begin{array}{l}\text { Over- } \\
\text { restrictive } \\
\text { metering rates }\end{array}$ & $\begin{array}{l}\text { Over-restrictive } \\
\text { metering rates }\end{array}$ & $\begin{array}{l}\text { Reactive } \\
\text { improvement; no } \\
\text { optimization }\end{array}$ & $\begin{array}{l}\text { Optimal rate } \\
\text { based on real- } \\
\text { world conditions }\end{array}$ \\
\hline
\end{tabular}


Table 2-5: Summary of Ramp Metering Algorithms (Atkins, 2013)

\begin{tabular}{|c|c|c|c|c|}
\hline $\begin{array}{l}\text { Ramp Meter } \\
\text { Type }\end{array}$ & Description & Required Resources & Advantages & Disadvantages \\
\hline Fixed Time & $\begin{array}{l}\text { - Activated based on time } \\
\text { of day } \\
\text { - Time of day is based on } \\
\text { historical or predicted } \\
\text { volumes. }\end{array}$ & $\begin{array}{l}\text { - Only vehicle detection on the ramp for } \\
\text { queue management or to actuate and } \\
\text { terminate the metering cycle. } \\
\text { - Traditionally, detection has been } \\
\text { implemented in the form of induction loops. }\end{array}$ & $\begin{array}{l}\text { - Simple } \\
\text { Is able to operate even in } \\
\text { temporary lack of } \\
\text { communications, } \\
\text { detectors malfunction or } \\
\text { construction. }\end{array}$ & $\begin{array}{l}\text { Does not respond to } \\
\text { real-time traffic } \\
\text { condition. } \\
\text { - Does not respond to } \\
\text { non-recurrent traffic } \\
\text { conditions such as } \\
\text { incidents and adverse } \\
\text { weather. } \\
\text { Does not consider the } \\
\text { whole system. }\end{array}$ \\
\hline $\begin{array}{l}\text { Local Traffic } \\
\text { Responsive }\end{array}$ & $\begin{array}{l}\text { - Metering rate is } \\
\text { adjusted based on } \\
\text { current conditions of } \\
\text { freeway condition at the } \\
\text { vicinity of ramp area. }\end{array}$ & $\begin{array}{l}\text { - Demand detectors: located just upstream } \\
\text { from the stop bar, detect the presence of a } \\
\text { vehicle at the ramp meter and initiate the } \\
\text { ramp metering cycle. } \\
\text { - Passage Detectors: located just downstream } \\
\text { from the stop bar to detect and count the } \\
\text { number of vehicles entering the freeway } \\
\text { (used to determine the duration of green } \\
\text { time) } \\
\text { - Ramp queue detectors: located near the } \\
\text { ramp intersection and the adjacent arterial. } \\
\text { Mainline: located upstream of the entrance } \\
\text { ramp gore point. }\end{array}$ & $\begin{array}{l}\text { Responses to real-time } \\
\text { traffic conditions at the } \\
\text { vicinity of the ramp } \\
\text { area. } \\
\text { Does not require } \\
\text { communication to TMC. }\end{array}$ & $\begin{array}{l}\text { Does not respond to } \\
\text { traffic conditions in the } \\
\text { rest of system. }\end{array}$ \\
\hline $\begin{array}{l}\text { System-Wide } \\
\text { Traffic } \\
\text { Responsive }\end{array}$ & $\begin{array}{l}\text { The metering rate of } \\
\text { each ramp is optimized } \\
\text { in order to improve } \\
\text { system-wide } \\
\text { conditions. }\end{array}$ & $\begin{array}{l}\text { - Demand detectors, passage detectors, ramp } \\
\text { queue detectors, (similar to local } \\
\text { algorithms). } \\
\text { - Mainline: located upstream of the entrance } \\
\text { ramp gore point. System-wide metering } \\
\text { operations can use mainline detectors } \\
\text { downstream of ramps. } \\
\text { - Off-ramp passage detectors } \\
\text { - Unmetered on-ramp passage detectors }\end{array}$ & $\begin{array}{l}\text { Responses to real-time } \\
\text { traffic conditions } \\
\text { throughout the system. } \\
\text { - Is able to prevent } \\
\text { bottleneck. } \\
\text { - Has the most potential } \\
\text { benefits among all } \\
\text { metering operations. }\end{array}$ & $\begin{array}{l}\text { - } \text { Requires } \\
\text { - Hammunication to TMC. } \\
\text { - } \text { some ramps over others, } \\
\text { creating inequity issues. }\end{array}$ \\
\hline
\end{tabular}




\subsubsection{Local Ramp Metering Algorithms}

The three widely referenced local metering algorithms are the demand-capacity, percent-occupancy, and ALINEA algorithms. These three algorithms will be explored in the remainder of this section.

\section{Demand-Capacity Algorithm}

The demand-capacity algorithm is one of the initial algorithms used in trafficresponsive ramp metering and can be considered a fundamental basis for other metering algorithms. This algorithm utilizes real-time freeway flow or occupancy measurements from locations up and downstream of the ramp. The metering rate is calculated as the difference between upstream freeway flow and downstream capacity, or as a function of the difference between upstream occupancy and desired occupancy (Kristeleit, 2014).

The advantage of this algorithm is its simplicity. However, the level of congestion of the freeway may not be determined only using the upstream local freeway occupancy. Another version of this algorithm, developed in the Netherlands, manages the metering rate based on flow and speed data to keep the actual flow below the critical limit.

Smargdis et al. showed that this algorithm can be partially sensitive to nonmeasurable disturbances such as merging difficulties, shockwaves, and slow vehicles (Smargdis et al., 2004). The National Cooperative Highway Research Program (NCHRP) Report 3-87 suggests improving this algorithm by including the probability of breakdown for the activation and/or metering rate calculation (Elefteriadou et al., 2009). This means that the ramp metering rate is set to keep the demand significantly lower than the capacity, as is done with the simple demand-capacity algorithm. 


\section{Percent-Occupancy Algorithm}

This algorithm depends solely on upstream occupancy measurements to determine the level of congestion and, as such, does not require downstream capacity measurements. The algorithm utilizes a linear relationship between the metering rate and upstream occupancy. Equation 2-3 demonstrates the form used to calculate the metering rate. In this equation, $K_{l}$ is the freeway capacity. $K_{2}$ is the slope of a straight line that relates occupancy to flow in the uncongested part of the fundamental diagram. The values of both $K_{1}$ and $K_{2}$ are preset values for each location (Hasan, 1999).

$$
r(k)=K_{1}-K_{2} o_{\text {in }}(k-1)
$$

where,

$$
\begin{aligned}
r(k) & =\text { metering rate at time interval } k, \\
K_{1} & =\text { a constant value of freeway capacity }(\mathrm{veh} / \mathrm{hr}), \text { and } \\
o_{\text {in }}(k-1) & =\text { the last measured upstream occupancy value }(\%) .
\end{aligned}
$$

\section{ALINEA Algorithms}

The Asservissement Linéaire d'Entrée Autoroutière (ALINEA) algorithm was developed by Papageorgiou in 1997 and was initially deployed in Paris, Amsterdam and Munich (Kristeleit, 2014). ALINEA is a local traffic-responsive control algorithm with a feedback regulator. The idea of this algorithm is to keep the occupancy under a static, predefined critical occupancy value. The calculated metering rate is expected to keep the traffic flow under the capacity level of the downstream segment, as indicated by the occupancy measurements. The metering rate is calculated using Equation 2-4. In this algorithm the critical or desired occupancy can be set by determining the occupancy of the downstream segment, when it approximately reaches its capacity. 


$$
r(k)=r(k-1)+K R\left[\hat{o}-o_{\text {out }}(k-1)\right]
$$

where,

$$
\begin{aligned}
r(k) & =\text { metering rate at time interval } k \\
K R & =\text { a constant regulator parameter }(\mathrm{veh} / \mathrm{hr}) \\
o_{\text {out }}(k-1) & =\text { the last measured upstream occupancy value }(\%), \\
\hat{o} & =\text { the desired value for downstream occupancy (predefined). }
\end{aligned}
$$

The ALINEA algorithm has been frequently referenced and used in many ramp metering studies. Over time, multiple extensions of it have been developed to deal with different issues and overcome challenges. FL-ALINEA, UF-ALINEA, UP-ALINEA, XALINEA/Q and MALINEA are some of the more common extensions of the ALINEA algorithm. These extensions will be briefly discussed in this section.

\section{FL-ALINEA}

The FL-ALINEA algorithm was developed to overcome possible difficulties with occupancy measurements and selecting appropriate occupancy values. This extension modifies the original ALINEA equation by substituting occupancy with downstream flow measurements. Generally, it has been recommended to keep the critical flow at least $10 \%$ below capacity.

\section{UF-ALINEA}

This is a modification to the FL-ALINEA algorithm described above, which estimates the downstream flow instead of measuring it. In order to accomplish this, the onramp flow and upstream mainline flow are considered. 


\section{UP-ALINEA}

In some conditions, only upstream occupancy is available, and the ALINEA algorithm needs to be modified to calculate downstream occupancy based on the upstream measurements. This is done in an extension of the original algorithm, called the UPALINEA algorithm. To calculate downstream occupancy, additional measurements of the entering flow from the on-ramp to the freeway and freeway upstream flow measurements are required.

Assuming $q_{\text {out }}=q_{\text {in }}+q_{\text {ramp }}$, the downstream occupancy is calculated as shown below, using Equation 2-5:

$$
o_{\text {out }}(k)=o_{\text {in }}(k)\left[1+\frac{q_{\text {ramp }}(k)}{q_{\text {in }}(k)}\right] \times \frac{\lambda_{\text {in }}}{\lambda_{\text {out }}}
$$

where,

$o_{\text {out }}(k)=$ downstream occupancy at the time $k$,

$o_{\text {in }}(k)=$ upstream occupancy at the time $k$,

$q_{\text {ramp }}(k)=$ measured ramp volume $(\mathrm{vph})$ at the time $k$,

$q_{\text {in }}(k)=$ upstream measured freeway volume (vph) at the time $k$, and

$\lambda_{\text {in }}, \lambda_{\text {out }}=$ the number of mainstream lanes for the upstream and downstream segments.

\section{$X-A L I N E A / Q$}

Ramp metering may cause the formation of large queues on the ramp, which in turn may affect the surface street. The X-ALINEA/Q algorithm was developed to account for ramp queues. X-ALINEA/Q requires measuring the ramp demands and queue lengths. 


\section{MALINEA}

The MALINEA algorithm was proposed by Oh and Sisiopiko in 2001 (Oh and Sisiopiku, 2001). MALINEA measures upstream occupancy of the freeway segment and the time lag between upstream and downstream measurements in order to incorporate the upstream conditions in the metering rate calculation. MALINEA uses the following equation (Elefteriadou et al., 2009):

$$
r(t+1)=\left[o_{u}(t+1)-o_{u}(t)\right] \times \frac{K}{A}+r(t)
$$

where,

$$
\begin{aligned}
& r(t+1)=\text { metering rate to be applied in the next time period, } \\
& o_{u}(t+1)=\text { desirable upstream occupancy in the next time period, } \\
& o_{u}(t)=\text { measured occupancy at the upstream detector for the last time period, } \\
& r(t)=\text { the current metering rate, and } \\
& A, K=\text { slope of occupancy upstream and downstream of the on-ramp, and the } \\
& \quad \text { parameter used in ALINEA, respectively. }
\end{aligned}
$$

\subsubsection{System-Wide Ramp Metering Algorithms}

As indicated in the literature, system-wide ramp metering algorithms have been categorized as cooperative, competitive, or integral. In cooperative ramp metering, the calculated metering rates are based on local conditions and are adjusted according to system-wide considerations. Competitive algorithms calculate ramp metering rates at both the system-wide and local levels. From these two calculations, the competitive method selects the most restrictive case. Similarly, the integral algorithm calculates both rates and 
then incorporates them in the metering rate calculation simultaneously to determine the optimal metering rates (Bertini and Ahn, 2006).

\section{Cooperative Algorithms}

\section{The Helper Algorithm}

The helper algorithm was developed in 1981 in Denver, Colorado and includes a local traffic responsive algorithm enhanced with a system override feature (Kristeleit, 2014). In this algorithm, the freeway corridor is divided into groups, with each group containing one to seven metered ramps (Lipp et al., 1991). This algorithm initially determines the metering rate for each of the ramps using a local traffic-responsive algorithm and simultaneously monitors the on-ramp queue using the queue detectors. If the occupancy on a queue detector for a specific on-ramp exceeds the predefined threshold, the subject ramp is identified as a "critical ramp." Once a critical ramp is identified within its group, the system override feature of this algorithm is activated. This feature increases the metering rate of the critical ramp while reducing the metering rate of the upstream ramps to mitigate the congestion in the vicinity of the critical ramp (Bertini and Ahn, 2006).

\section{The Linked Ramp Algorithm}

The linked ramp algorithm was first deployed in San Diego, California in 1968 and is commonly referred to as the San Diego Ramp Metering System (SDRMS). This algorithm utilizes historical traffic flow data to calculate the maximum and minimum metering rates at each ramp. The maximum metering rate is calculated based on the local capacity, which is estimated from historical data, and the metering rate is the difference between the target traffic flow (considering capacity) and upstream traffic flow. Therefore, the algorithm operates as local and once the demands lead to calculating rates that are 
below the minimum rates, the cooperative feature of the Linked algorithm is activated, resulting in metering upstream ramps (Kristeleit, 2014).

\section{Competitive Algorithms}

\section{The FLOW Algorithm}

The FLOW algorithm is a bottleneck-based algorithm developed by Jacobson et al. in 1989. This algorithm calculates both local and bottleneck metering rates, then selects whichever is more restrictive. The local metering rate is calculated using the percentoccupancy algorithm. The metering rates are selected from a look-up table that relates the upstream occupancy to the metering rate of the ramp. The look-up table is produced from historical volume-occupancy relationships (Jacobson et al., 1989).

To estimate the bottleneck metering rate, the bottleneck locations on the freeway with an influence zone of at least one ramp must first be identified. Then, all of the metered on-ramps within the zone are weighted based on their distances from the bottleneck and historical ramp volumes. This algorithm requires loop detectors upstream and downstream of the influence zone, as well as all metered and unmetered on- and off-ramps. The bottleneck algorithm is activated once both of the following conditions are met:

- The downstream occupancy exceeds a predefined threshold.

- The total entering volume (sum of upstream freeway and on-ramps volume) exceeds the total exiting volume (sum of vehicles exiting the section and offramps).

Following these conditions, the metering rates are calculated based on the difference of the total entering and exiting volumes, as well as the weighting factors for the ramps. 
As it is possible that the bottleneck influence areas may overlap, each ramp may have more than one bottleneck metering rate. Also, the most restrictive metering rate, between the local and bottleneck, is selected for the subject ramp. The FLOW algorithm also includes a queue control feature to prevent queue spillback onto the surface street (Hasan, 1999).

\section{Zone Algorithm}

Initially, the zone algorithm was implemented as a pre-timed metering system in the St. Paul Metropolitan/Minneapolis but was later upgraded to a traffic-responsive metering system. In this algorithm, as the name implies, the freeway is divided into multiple zones with low incidents upstream and a potential bottleneck downstream. Each zone includes the freeway mainline, off-ramps, and metered and unmetered on-ramps. The zone metering algorithm is designed to keep the level of traffic lower than the desired threshold by managing flows entering a zone. The downstream bottleneck capacity is the critical factor for managing a zone's inflowing and outflowing traffic. The basic equation describing the general concept of this algorithm for a metering rate calculation is the shown in Equation 2-7 (Hourdakis and Michalopoulos, 2002):

$$
M+A+U \leq B+X+S
$$

where,

$M=$ total volume entering the mainline from all entrance ramps in a given zone (release rate),

$A=$ arrival volume at the upstream boundary of a zone, 
$U=$ total volume entering a zone from unmetered entrance ramps,

$B$ = capacity of downstream mainline boundary of a zone,

$X=$ total exit volume from a zone, and

$S=$ available storage, or spare capacity in the beginning of each time interval.

In 2000, The Minnesota Department of Transportation (MnDOT) evaluated this metering algorithm on Highway 169 and I-394. The study concluded that the algorithm improved travel time by $6 \%$ to $16 \%$, while reducing the fuel consumption and emissions by $2 \%$ to $47 \%$.

The Stratified Zone Metering Algorithm (SZM) was developed and implemented as an enhancement to the zone metering algorithm; this modification incorporated the definition of overlapping zones. A zone can be defined between any two mainline detector stations and is typically set to be 0.5 to 3 miles in length. Therefore, each primary zone in the conventional version is subdivided in the SZM. Each subdivision is defined as a set of successive detector stations. As illustrated in Figure 2-4, the higher-level subdivisions are larger zones, and they may overlap. The metering rates are calculated and reported at 30second intervals. With these results, ramp metering is calculated to avoid mainline congestion and on-ramp queue spillbacks onto arterials.

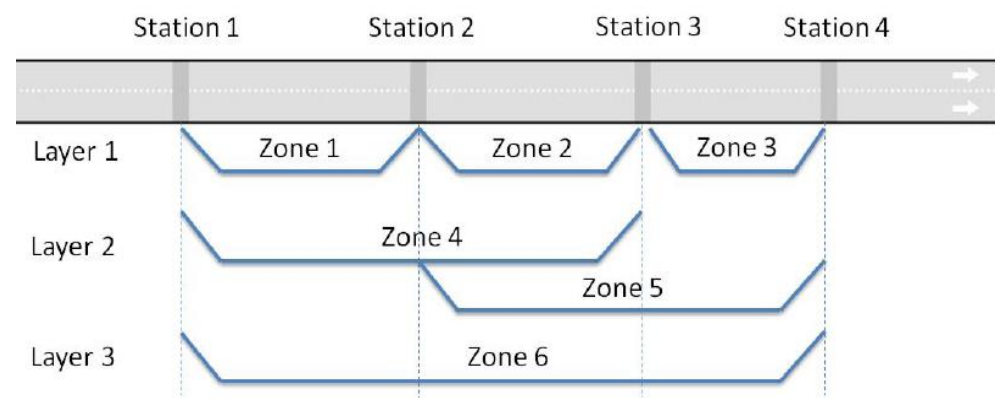

Figure 2-4: Zone and Layer Structure in SZM (Elefteriadou et al., 2009) 


\section{The SWARM Algorithm}

The System-Wide Area Ramp Metering (SWARM) algorithm divides the freeway into contiguous sections bounded by bottleneck locations that are identified by loop detector measurements; each section may include multiple on and off-ramps. For each section, the SWARM 1 and SWARM 2 modes produce two metering rate values, and the more restrictive metering rate will be selected.

In the SWARM 1 mode (the system-wide level), the density at the bottleneck location is forecasted using a linear regression of the immediate past's data and the application of the Kalman filtering process. The idea of the algorithm is to keep the realtime density below a predetermined threshold value. Excess density is defined as the difference between the forecasted density and threshold density. The necessary volume reduction for the section can be calculated using the Equation 2-8:

$$
\text { Required density }=\text { current density }-\left(\frac{\text { excess density }}{\mathrm{T}_{\text {crit }}}\right)
$$

where,

$$
\mathrm{T}_{\text {crit }}=\text { forecasting time span (minutes) }
$$

Volume reduction $=($ local density - requiered density $) \times$

$$
\text { (number of lanes) } \times \text { (distance to the next station) }
$$

The volume reduction (ramp metering rate) is proportionally distributed to the upstream on-ramps of the section according to their demand and queue storage, which define the weighting factor for each of the ramps used in calculating the ramp metering rates. 
In the SWARM 2 mode (local level), any traffic-responsive local metering algorithm can be used to convert the measured headway upstream of the ramp to an estimated density, which is then used to define the metering rate. This mode also determines the available storage zone and calculates the metering rate to maintain LOS D with a maximum density of $35 \mathrm{pc} / \mathrm{mi} / \mathrm{ln}$ (Bertini and Ahn, 2006).

SWARM is a predictive algorithm, and its performance is highly dependent on the accuracy of the prediction. This predictive feature enables the algorithm to prevent bottlenecks. However, inaccurate prediction may lead to poor results (Elefteriadou et al., 2009). Zhang et al. (2001) evaluated the performance of SWARM in 2001, with a five-step ahead prediction and reported very poor results compared to the ALINEA algorithm, zone algorithm, and bottleneck algorithm (Zhang et al., 2001).

\section{Seattle Bottleneck Algorithm}

The Seattle bottleneck metering algorithm calculates both of the local and bottleneck metering rates using the upstream mainline occupancy at each ramp obtained for local-responsive detector data and bottleneck information for bottleneck metering. Then, the lowest metering rate, between the local and bottleneck, is assigned to each ramp.

The local metering rate is set as the difference between the real-time upstream volume and estimated capacity. The capacity is estimated based on the volume-capacity relationship, which is calculated using historical data upstream of the ramp. Jacobson et al. provided an example of a curve using historical data to determine the local metering rate depending on the mainline occupancy (Jacobson et al., 1989).

The bottleneck metering rate is calculated considering system-wide conditions and capacity constraints. These calculations are based on the real-time demand-capacity 
relationship. This algorithm is activated once the downstream occupancy exceeds the predefined threshold (usually 18\%) and the entering volume exceeds the exiting volume between the two detectors. In this case, the upstream volume should be reduced by the number of the vehicles stored within the section. This volume reduction is distributed to all of the non-critical upstream ramps by weighting factors. The weighting factors depend on the ramp demand and the distance between the subject ramp and downstream bottleneck.

Once the metering rate is set as the lowest value of local and bottleneck metering rates, the rates need to be adjusted considering the queues on the ramp, a ramp volume adjustment, and an advance queue override. The queue adjustment is applied to consider the presence of queue at the ramp queue detector. The ramp volume adjustment takes the driver violations and inattention into account by automatically correcting the metering rate, while the number of vehicles entering the freeway from the ramp is less or more than the specified metering rate. The queue override adjustment increases the metering rate to a high value and is activated once the ramp queue reaches the worst acceptable queue. NCHRP Report 3-87 suggests enhancing this algorithm by considering the probability of a breakdown threshold for ramp metering activation and the local metering rate calculation (Elefteriadou et al., 2009).

\section{Integral Algorithms}

\section{METALINE}

METALINE is an extension of the ALINEA algorithm described earlier and was developed by Papageorgiou et al. in 1990 (Papageorgiou et al., 1990). In this algorithm, the fluctuation in the measured occupancy for each freeway segment and the difference 
between the critical occupancy and the measured occupancy determines the metering rate for each ramp. Metering rate, measured occupancy, and desired occupancy are presented in the form of a vector, as illustrated in Equation 2-10 (Elefteriadou et al., 2009):

$$
\vec{r}(k)=\vec{r}(k-1)-K_{1}[\vec{o}(k)-\vec{o}(k-1)]-K_{2}\left[\vec{O}(k)-\overrightarrow{O^{c}}\right]
$$

where,

$$
\begin{aligned}
& \vec{r}(k)=\text { vector of metering rates for the m controlled ramps at time step } k, \\
& \vec{o}(k)=\text { vector of } \mathrm{n} \text { measured occupancies within the directional freeway segment at time } \\
& \quad \text { step } k, \\
& \vec{O}(k)=\text { measured occupancy, } \\
& \overrightarrow{O^{c}} \quad=\text { desired occupancy (occupancy at capacity), and } \\
& K_{1}, K_{2}=\text { gain matrices. }
\end{aligned}
$$

\section{Model Predictive Control Algorithm}

The Model Predictive Control (MPC) Algorithm is an online predictive metering algorithm incorporating a cost criterion into the optimization process, as well as constrained inputs and outputs (Camacho and Bordons, 1995 and Maciejowski, 2002). MPC utilizes a receding horizon strategy to minimize a predefined objective function, which results in optimization of traffic operation. This algorithm predicts the traffic parameters for a determined prediction horizon $\left(N_{p}\right)$ based on a traffic model and in each sample step $\mathrm{k}$ determines the metering rate, which minimizes the objective function for the time period $\left[k \Delta T_{c t r l},\left(k+N_{p}\right) \Delta T_{c t r l}\right] . \Delta T_{c t r l}$ is the controller time step which defines the rate for updating the control signal and is usually set as one minute. In order to manage the computational burden, a control horizon $\left(N_{c}\right)$ smaller than $\mathrm{N}_{\mathrm{p}}$ is defined. The metering rate 
is only allowed to change at this time period $\left[k \Delta T_{c t r l},\left(k+N_{c}\right) \Delta T_{c t r l}\right]$ and remains unchanged thereafter. In this receding horizon framework, the metering rate is set as the first calculated rate. After implementation of this rate, the traffic measurements will be updated and fed to the next sample step $(k+1)$. The whole process is iterated for each step.

It is very important to select proper values for $N_{p}$ and $N_{c}$. Larger $N_{p}$ values enable the algorithm to predict further events, but also increases the computational complexity. Selecting a smaller control horizon will increase the number of metering rates to be optimized, and also increases accuracy. Therefore, there should be a proper tradeoff between the accuracy and the computational of complexity of the algorithm (Bellemans et al., 2006).

\section{Fuzzy Logic Algorithm}

The fuzzy logic algorithm was developed and implemented in Washington State and was adopted in Florida. The first implementation in Florida was onI-95 in Miami-Dade County. The algorithm incorporates both objective and subjective knowledge to improve traffic operations. Here, the subjective knowledge is represented in linguistic form. Unlike other ramp metering algorithms, fuzzy logic algorithm can handle nonlinear systems with unknown models. The main advantage of the fuzzy logic algorithm is the ability to handle nonlinearity and uncertainties in addition to the ability of utilizing incomplete and inaccurate data, while also balancing mainline congestion and ramp queues. Furthermore, the fuzzy logic controller does not require extensive system modeling and is easy to adjust.

This algorithm utilizes a set of rules that must be developed by experts. These rules are adjustable. This enables the fuzzy controller to adapt to various situations and compensate for poor or inaccurate measurements. Many successful implementations of a 
variety of fuzzy logic controllers have been noted in Amsterdam, Miami and Seattle, which confirms its validity. In 1999, Bogenberger proposed an adaptive fuzzy controller that incorporates genetic algorithms and neural networks (Bogenberger and May, 1999). Figure 2-5 illustrates the structure of a fuzzy logic ramp metering system.

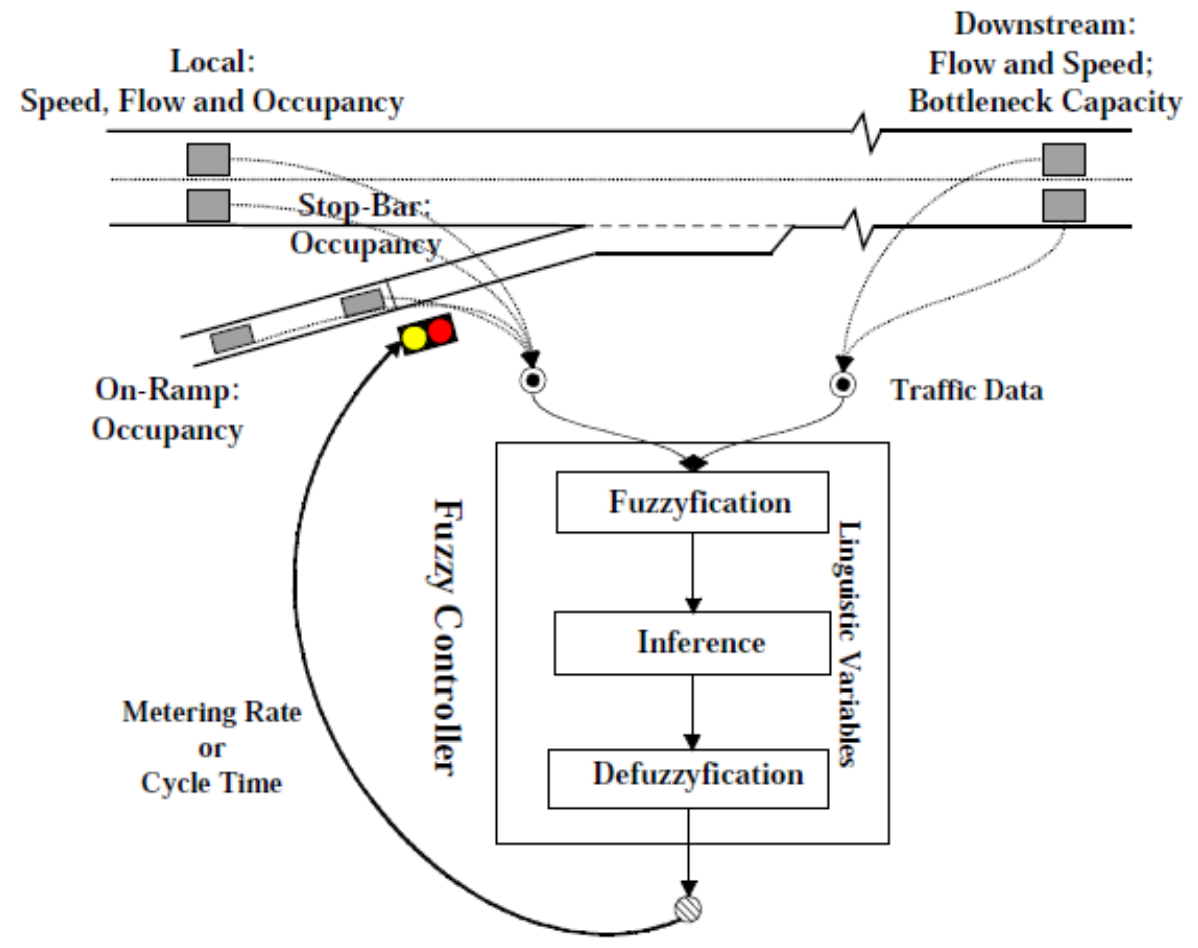

Figure 2-5: Fuzzy Logic Ramp Metering Structure (Bogenberger et al., 2001)

The fuzzy logic algorithms incorporate three main steps of fuzzification, rule activation and defuzzification. In the fuzzification step, each of the numerical inputs is classified into fuzzy classes, and the degree of membership for each class is determined. In 2001, a new approach to fuzzy controller was proposed and is referred to as Adaptive and Coordinated Control of Entrance Ramps with Fuzzy Logic (ACCEZZ) (Bogenberger et al., 2001).The general fuzzy ramp controller used in the ACCEZZ models has a total of seven inputs: local flow, speed and occupancy on the mainline immediately upstream of the on ramp, downstream speed and volume/capacity (v/c) ratio, on-ramp queue, and check in 
occupancy. Each input value corresponds to one or more of the predefined classes of the subject variable. The shape, distribution, and dynamic range of these fuzzy classes are subject to a tuning process. In this case, a degree of membership is assigned to each class. The degree of membership for each class indicates how much each input belongs to that class. The degree of membership is on a scale of 0 to 1 , where 1 indicates that an input belongs $100 \%$ to the subject class. The second step is to use the fuzzy classes and their degree of membership from the previous step to find the appropriate rule to apply. The assigned weight for each rule indicates the relative importance of it compared to other rules. Following this, the third step is to calculate the metering rate based on the outcomes of the previous step and to report a single value as the metering rate. This process of transformation from linguistic rules to a quantitative value as the metering rate is called the defuzzification process. The final metering rate is calculated as the weighted average of the metering rate and degree of membership.

The ACCEZZ models use the same fuzzy controller procedure and dynamically adjust the input and output fuzzy sets by redefining the linguistic variables. This adjustment can address inaccurate data or changes in traffic patterns and is automatically done by learning procedures such as the neural network algorithm. The ACCEZZ family of models include a two-step process of bottleneck performance measurement and a dynamic freeway traffic model. The first step is to monitor the entire traffic system by incorporating traffic system and a queuing model. The second step is to capture the dynamic traffic state evolution and coordinate all of the ramps to reach the network level optimum status.

\section{Comparison of Metering Algorithms}

The metering algorithms described above are summarized in Table 2-6. 
Table 2-6: Metering Algorithms Summary

\begin{tabular}{|c|c|c|c|}
\hline \multicolumn{2}{|c|}{ Extent } & Algorithm & Metering Rate Calculation Method \\
\hline \multirow{3}{*}{\multicolumn{2}{|c|}{ Local }} & $\begin{array}{l}\text { Demand- } \\
\text { Capacity }\end{array}$ & $\begin{array}{l}\text { - Based on difference between upstream freeway flow and } \\
\text { downstream capacity, or } \\
\text { - Based on difference between upstream occupancy and } \\
\text { desired occupancy. }\end{array}$ \\
\hline & & $\begin{array}{l}\text { Percent- } \\
\text { Occupancy }\end{array}$ & $\begin{array}{l}\text { - Based on the difference between upstream freeway } \\
\text { occupancy and occupancy at capacity. }\end{array}$ \\
\hline & & ALINEA & $\begin{array}{l}\text { - Based on the difference between downstream freeway } \\
\text { occupancy and desired occupancy. }\end{array}$ \\
\hline \multirow{9}{*}{$\begin{array}{l}\text { System } \\
\text {-Wide }\end{array}$} & \multirow[t]{2}{*}{ Cooperative } & Helper & $\begin{array}{l}\text { - Based on upstream occupancy of critical ramp, one of } \\
\text { seven predefined metering rate categories is selected. } \\
\text { - If the ramp queue from queue detector exceeds the } \\
\text { threshold, the metering rate will be increased and the } \\
\text { upstream ramp metering rate would decrease. }\end{array}$ \\
\hline & & $\begin{array}{l}\text { Linked } \\
\text { Ramp }\end{array}$ & $\begin{array}{l}\text { - Based on the difference between upstream freeway flow } \\
\text { and target flow. } \\
\text { - If the metering rate falls below a predefined threshold, the } \\
\text { upstream ramp will have the same metering rate or less. }\end{array}$ \\
\hline & \multirow{4}{*}{ Competitive } & FLOW & $\begin{array}{l}\text { - Calculates both local and bottleneck metering rates and } \\
\text { picks the more restrictive one. } \\
\text { - Local metering rate is derived based on occupancy. } \\
\text { - Bottleneck metering rate is based on the difference of the } \\
\text { total entering and exiting volumes and the weight factors } \\
\text { for the ramps (based on ramp distance from the bottleneck } \\
\text { and historical ramp volume). }\end{array}$ \\
\hline & & Zone & $\begin{array}{l}\text { - The zone is defined as the area between boundaries of free } \\
\text { flow in upstream and bottleneck in downstream. } \\
\text { - Metering rate is calculated as the difference of entering } \\
\text { and exiting flow compared to the bottleneck capacity. }\end{array}$ \\
\hline & & SWARM & $\begin{array}{l}\text { - Calculates both local and system-wide metering rates and } \\
\text { picks the more restrictive one. } \\
\text { - Local metering rate based on upstream density. } \\
\text { - System-wide metering rate based on the difference } \\
\text { between real-time density and predefined threshold. }\end{array}$ \\
\hline & & $\begin{array}{l}\text { Seattle } \\
\text { Bottleneck }\end{array}$ & $\begin{array}{l}\text { - Calculates both local and system-wide metering rates and } \\
\text { picks the more restrictive one. } \\
\text { - Local metering rate based on upstream occupancy. } \\
\text { - System-wide metering rate based on the difference } \\
\text { between the downstream volume and bottleneck capacity. }\end{array}$ \\
\hline & \multirow[b]{3}{*}{ Integral } & METALINE & $\begin{array}{l}\text { - Based on the difference between the critical occupancy } \\
\text { and the measured occupancy. }\end{array}$ \\
\hline & & $\begin{array}{l}\text { Model } \\
\text { Predictive } \\
\text { Control }\end{array}$ & $\begin{array}{l}\text { - Predicts traffic parameters for a predefined time horizon } \\
\text { and calculates metering rate by optimization process based } \\
\text { on the selected objective function. }\end{array}$ \\
\hline & & Fuzzy Logic & $\begin{array}{l}\text { - Based on local speed, occupancy, flow, queue occupancy } \\
\text { and downstream speed and predefined linguistic rules the } \\
\text { metering rate is defined. } \\
\text { - The rules compare the current condition to the desired } \\
\text { condition and regulate to eliminate this difference and } \\
\text { reach desired condition. }\end{array}$ \\
\hline
\end{tabular}




\subsubsection{Useful Concepts from Metering Algorithms}

Based on the review of the existing literature concerning adaptive ramp metering algorithms, it was possible to identify concepts that can be adopted for use as part of the methodology for identifying the warrants that will be used in this dissertation. For example, the Zone, FLOW, Seattle Bottleneck, and SWARM algorithms divide the freeway into multiple zones, where each zone has the potential to have a bottleneck downstream. The downstream bottleneck capacity is used as the regulating factor for managing the traffic entering and leaving a zone in the Zone, FLOW, and Bottleneck algorithms, whereas the density of the bottleneck is used as the controlling parameter in the SWARM algorithm to maintain level of service D. This idea can be adopted in this dissertation to identify which ramps should be metered for a zone controlled by a bottleneck. The adopted method may utilize volume thresholds below capacity to constrain the incoming volume in order to reduce the probability of breakdown. The equations used in some algorithms can be used to detect congestion based on occupancy.

The concept of multiple overlapping zones, as used in the Stratified Zone and FLOW Algorithm, can also be helpful. The method developed in this dissertation can be applied to zones controlled by different bottlenecks. A ramp may be assigned to overlapping zones if it is determined that it is required to be metered to address the congestion on more than one zone and the contribution of each ramp in the ramp metering algorithm can be defined by weighting each ramp based on the distance to the bottleneck and the ramp's demand level. 


\subsection{Additional Considerations for Ramp Metering}

There are several environmental and operational components that may also impact traffic flow on a freeway or ramps. These components need to be considered in the ramp metering process as they can severely impact the performance of ramp metering and the transportation network as a whole. This section summarizes some of these components.

\subsubsection{Incidents}

Traffic incidents tend to affect traffic operations by changing the roadway environment and driver behaviors. Roadway environments can also be affected by capacity reductions due to lane or shoulder closure, and changes in traffic control strategies, including ramp metering, incident management, and dynamic message sign activation. Driver behavior may be affected at the microscopic level (tactical and operational) by incident occurrence, such as lane changing, car following, speed, gap acceptance, and accelerating behavior. Incident occurrence may also cause changes at the strategic level, such as route shift, mode shift, or change in the time of trip (Hadi et al., 2011). The occurrence of incidents may require activation of ramp metering and more restrictive metering rates.

Incident impacts on capacity drop are well studied. Goolsby (1971) studied the capacity reduction due to incidents and concluded that an incident blocking one lane out of three lanes reduces capacity by about $50 \%$. He also concluded that incident blocking two out of three lanes reduces the capacity by about 79\% (Goolsby, 1971).

The HCM 2000 provides estimates of the expected reduction in capacity as a function of the number of blocked lanes (or shoulder) and the number of lanes of the highway section under consideration. The values recommended in the HCM 2000 can be 
used as the average capacity reduction during incidents; for instance, for a three-lane freeway segment, these values were a reduction of $17 \%$ for shoulder blockage incidents, $51 \%$ for one-lane blockage incidents, and $83 \%$ for two-lane blockage incidents. These values are $15 \%, 42 \%$, and $75 \%$ for a four-lane freeway segment, respectively (HCM, 2000).

Qi and Smith (2001) suggested that the capacity reduction caused by one out of a three-lane blockage can be modeled as a beta distribution with an average of $63 \%$ and a standard deviation of 14\% (Qi and Smith, 2001). This average capacity reduction is higher than that reported in prior research, which showed about a 50\% reduction. They also found that the capacity reduction due to incidents with two of three lanes blocked can be modeled as a beta distribution with an average of $77 \%$ and a standard deviation of $12 \%$; this closely resembled previously reported values (79\%).

Knoop et al. (2009) found that in the case of a blocked driving lane, the queue discharge rate for each available lane was reduced by $50 \%$. They also found that the queue discharge rate was reduced by $30 \%$ when the driving lanes were open but there was an incident on the shoulder or in the opposite direction of travel (Knoop et al., 2009).

Hadi et al. (2007) adjusted the parameters of three widely used microscopic simulation tools to determine their abilities to replicate the reported reductions in capacities due to traffic incidents. From the results, they concluded that it was possible to fine-tune the parameters of the three simulation tools to simulate the drops in capacities due to incident lane blockage (Hadi et al., 2007).

Hadi et al. (2011) investigated the capacity drop for incidents using traffic management data and concluded that after incident occurrence with one-lane closure on a 
three-lane freeway, the capacity dropped by $54 \%$ to $60 \%$. During the lane blockage period, another capacity drop occurred due to the arrival of fire trucks that blocked other lanes. After the incident cleared, the queue began to dissipate at a queue discharge rate that was $19 \%$ to $39 \%$ lower than the capacity before the incident occurred. The reduction in capacity during incidents was partly due to the rubbernecking effects (Hadi et al., 2011).

\subsubsection{Adverse Weather}

Adverse weather is one of seven main sources of congestion, as identified by the FHWA. Non-ideal driving conditions such as rain, snow, fog, and high-speed wind can affect driver behaviors, vehicle performance, and thus traffic flow characteristics including capacity, speed, travel time, and safety (FHWA, 2015). Ramp metering activation and metering strategies should accommodate such changes during adverse weather. Ibrahim and Hall (1994) investigated freeway speed reductions under adverse weather conditions and concluded that the speed was reduced by $3 \%$ to $5 \%$ for light precipitation (both rain and snow), $14 \%$ to $15 \%$ for heavy rain, and $30 \%$ to $40 \%$ for heavy snow, respectively. The authors mentioned that these values could be different depending on the regional characteristics and could not be generalized for dissimilar locations (Ibrahim and Hall, 1994).

An empirical study was conducted by the FHWA (2006) to examine the impact of adverse weather, including precipitation and visibility, on freeway free flow speed, speed at capacity, capacity, and jam density. These parameters were measured based on loop detector data from Baltimore, the Twin Cities, and Seattle. Interestingly, the results showed that the jam density was not impacted by weather conditions, but free-flow speed and speed 
at capacity decreased as the rain intensity increased. However, the study found that the capacity reduction did not change with rain intensity. Rather, it remained constant at a value of $10 \%$ to $11 \%$ of the capacity with no weather event. A $2.0 \%$ to $3.6 \%$ reduction in free flow speed and an $8 \%$ to $10 \%$ reduction of speed at capacity was reported for light rain conditions (less than $0.0039 \mathrm{in} / \mathrm{hr}$ ). In this study free-flow speed was found to decrease by $6 \%$ to $9 \%$ and the speed at capacity by $8 \%$ to $14 \%$ due to heavy rain $(0.63 \mathrm{in} / \mathrm{hr})$ (FHWA, 2006).

Stralen et al. (2014) investigated the impacts of adverse weather on the probability of traffic breakdown. This work incorporated the impacts on supply and demand as they related to adverse weather and traffic conditions using a panel mixed-logit model. The average breakdown probability for dry weather was $50 \%$, while the average breakdown probability during heavy rain was $77.4 \%$ (Stralen et al., 2014).

Li et al. (2014) assessed travel time reliability during rainfall events in Florida. They calibrated the rainfall intensity distribution according to zip codes and hourly precipitation, and then evaluated travel time reliability based on the probability of rainfall. The final results showed a $6 \%$ to $12 \%$ speed reduction for freeway and arterial facilities respectively, depending on the rain intensity level (Li et al., 2014).

The HCM 2010 presented capacity reduction percentages for freeway facilities under three levels of rain: light, medium and heavy. These values represent a $2 \%$ capacity reduction for light rain, $7.2 \%$ for medium rain, and 14.1\% for heavy rain (HCM, 2010). 


\subsubsection{Diversion}

Traffic diversion due to ramp metering was initially discussed to address the concern of traffic deterioration on parallel streets due to additional demands on these streets. However, there are also instances where diversion away from congested ramps and merge areas can cause improvements in traffic conditions. Improving traffic conditions on the freeway by proper ramp metering can cause drivers with longer trips to use the freeway instead of local streets. Therefore, traffic diversion due to ramp metering does not always worsen the performance of parallel local streets. When the ramp metering increases the capacity of freeway bottlenecks, both freeway and local streets benefit from the additional capacity. The true impact of ramp metering on the network and different types of roads is complicated and requires thorough network analysis such as using dynamic traffic assignments.

The diversion effect of ramp metering can be interpreted as negative or positive, depending on the traffic conditions local streets. When the local streets are underutilized, the diversion from the freeways to local streets will improve network traffic conditions. However, if parallel streets are operating near capacity conditions and the ramp metering causes diversion from the freeway to these roads, the performance of parallel streets will undoubtedly suffer. A related study by Kang and Gillen (1999) reported no more than a $5 \%$ to $10 \%$ diversion to the local streets (Kang and Gillen, 1999). However, other studies in Los Angeles, Denver, Seattle and Detroit reported no significant diversion from the freeway to local streets (Piotrowicz and Robinson, 1995).

Considering the advantages and disadvantages of diversion on the network performance, ramp metering strategies can be classified as diversionary or non- 
diversionary. On the other hand, traffic diversion resulting from ramp metering can be modal, temporal, or spatial (Wu, 2001). Modal diversion refers to considering other modes of transportation and carpooling or transit. Temporal diversion represents changing the time of travel to avoid delay and long queues on the ramp. This type of diversion helps to distribute the peak flow over a longer period, which results in a more effective utilization of freeway capacity. Spatial diversion addresses the cases where vehicles change their routes of travel by either selecting a downstream unmetered ramp or completely diverting to parallel local streets.

Haj-Salem and Papageorgiou (1995) conducted a study in Paris and reported that ramp metering caused about a $20 \%$ increase in travel time for parallel local streets, which carried 5\% of the network flow. However, considering the whole corridor, the travel time was reduced by 7\% (Haj-Salem and Papageorgiou, 1995). A similar field study in Twin Cities, Minnesota, reported contradictory results in a stated preference study. The survey showed that about $75 \%$ of travelers mentioned that they were willing to use alternate routes to avoid delays on ramps. However, the data showed no significant diversion to alternative routes or to other transportation modes (Wu, 2001).

A study on the northbound Dan Ryan Expressway in Chicago showed that having only four metered ramps did not cause enough diversion to avoid the freeway overload, but the point of congestion propagation was shifted ( $\mathrm{Wu}, 2001)$.

\subsubsection{Vehicle Class}

Truck acceleration capability affects the required acceleration length on ramps and, therefore, affects the metering performance. Yang et al. (2016) investigated the 
acceleration capability of three types of trucks using video data collection. The results showed that existing acceleration lane length characteristics affected the acceleration behaviors. The observed speed profile illustrated a two-stage behavior. First, the acceleration rate decreases with an increase in speed. Then, as the truck reaches the merging point, the acceleration increases to catch up with the freeway stream. The results showed that the default values for acceleration rate in the ITE (Institute of Transportation Engineers) Traffic Engineering Handbook and the AASHTO (American Association of State Highway and Transportation Officials) Green Book need to be updated. This study suggested average acceleration rates of $2.82 \mathrm{ft} / \mathrm{s}^{2}$ for light, $2.46 \mathrm{ft} / \mathrm{s}^{2}$ for medium trucks, and $1.96 \mathrm{ft} / \mathrm{s}^{2}$ heavy trucks, respectively. Also, it recommended that the $15^{\text {th }}$ percentile acceleration performance data, which is approximately $30 \%$ lower than the measured average acceleration capability, should be considered when calculating the acceleration lane length (Yang et al., 2016).

\section{$2.4 \quad$ Summary}

It is crucial to select ramps to meter to realize the benefits of the ramp metering strategy. Many states around the country have developed their specific warrants for ramp metering installation. These warrants consider only the traffic, geometry, and safety conditions in the immediate vicinity of the subject on-ramp (local conditions). Ramp metering algorithms, as implemented during operations to reduce the impacts of traffic bottlenecks, can be categorized as local or system-wide algorithms. Local algorithms only target a single ramp as an isolated element. On the other hand, system algorithms consider multiple ramps as a system and calculate the metering rates of each on-ramp to address the 
congestion and breakdown at the bottleneck locations to benefit the entire system. Systemwide algorithms are proven to be more effective than local algorithms because they distribute the metering burden to several ramps instead of relying on the metering of the single on-ramp immediately upstream of the bottleneck, which may not be sufficient and can cause long queues on the on-ramp. Moreover, the existing local warrants only consider recurrent conditions to justify ramp metering installation, with no consideration of the benefit of metering during non-recurrent events such as incidents and adverse weather. Previous studies showed that non-recurrent conditions contribute significantly to the congestion and unreliability of the transportation system. This reveals a gap between existing ramp metering warrants and the ramp metering operation algorithms, which are used during operations. This dissertation aims to bridge this gap by developing a methodology to address the system-wide traffic conditions, in addition to taking nonrecurrent conditions into consideration. 


\section{CHAPTER 3 METHODOLOGY}

The review of the literature highlighted a gap between the existing ramp metering warrants and the ramp metering operation algorithms, which are used during operation. This study aims to develop a methodology for considering system-wide conditions in the decisions to select ramps for metering. A ramp may not be a candidate for ramp signal installation according to its local traffic conditions; however, it can play a significant role in addressing the traffic congestion at a system bottleneck located miles downstream of the ramp. The methodology developed in this dissertation research can be used in conjunction with existing local warrants for the installation of metering to bridge the gap between the installation decision and operation and management policies and strategies. The proposed ramp selection methodology considers both recurrent and non-recurrent conditions (e.g., incident and rainfall). This chapter describes the proposed methodology of this research. The first section is dedicated to introducing the overall methodology. The detailed description is presented in the following sections.

\subsection{Methodology Outline}

A critical component of both off-line and real-time warrants is the collection and processing of the data for use as inputs to these warrants. Thus, the first step in the proposed framework is to identify the potential parameters for warrant development, as well as the associated data items needed to estimate these parameters. These parameters and associated data items may be related to the traffic operations, geometry, safety, and environmental conditions of the system. However, this dissertation is mostly focused on traffic-related 
parameters, combined with incident and weather conditions. Once the parameters are identified, the next step is to collect, filter, integrate and cluster the required data for the study.

Prior to developing the methodology, the traffic data for the study area is used to assess the need for developing the methodology in addition to the existing local warrants. For this purpose, the first step is the identification of the system bottlenecks. Then, the selection of metering locations based on system performance is compared to the selection based on local performance using a microscopic simulation software. If the performance of a system-based selection is proven to be more effective than the selection based on local performance, this will give a strong indication of the need for a system-based selection. Otherwise, the existing local warrants will be considered sufficient to control the performance of the system.

The next step is to develop methods for the off-line and real-time selection of ramp metering locations and activation decisions during recurrent and non-recurrent conditions, based on system data from multiple sources. The data will be used to identify bottleneck characteristics for use as main inputs to the decision process. These characteristics can include bottleneck demand and capacity.

\subsection{Introduction of the Study Area and Required Data}

\subsubsection{Case Study}

A case study is used in this dissertation to demonstrate and test the developed warrants. As shown in Figure 3-1, the area of the case study is an I-95 section in Broward County, Florida. This segment, with a total length of about 14 miles, starts from Hallandale 
Beach Boulevard and ends at Commercial Boulevard, including ten on-ramps from arterials. The study is limited to the northbound direction of this segment. The analysis is conducted for the morning and afternoon peak periods (7:30-10:00 AM and 2:30-7:00 PM).

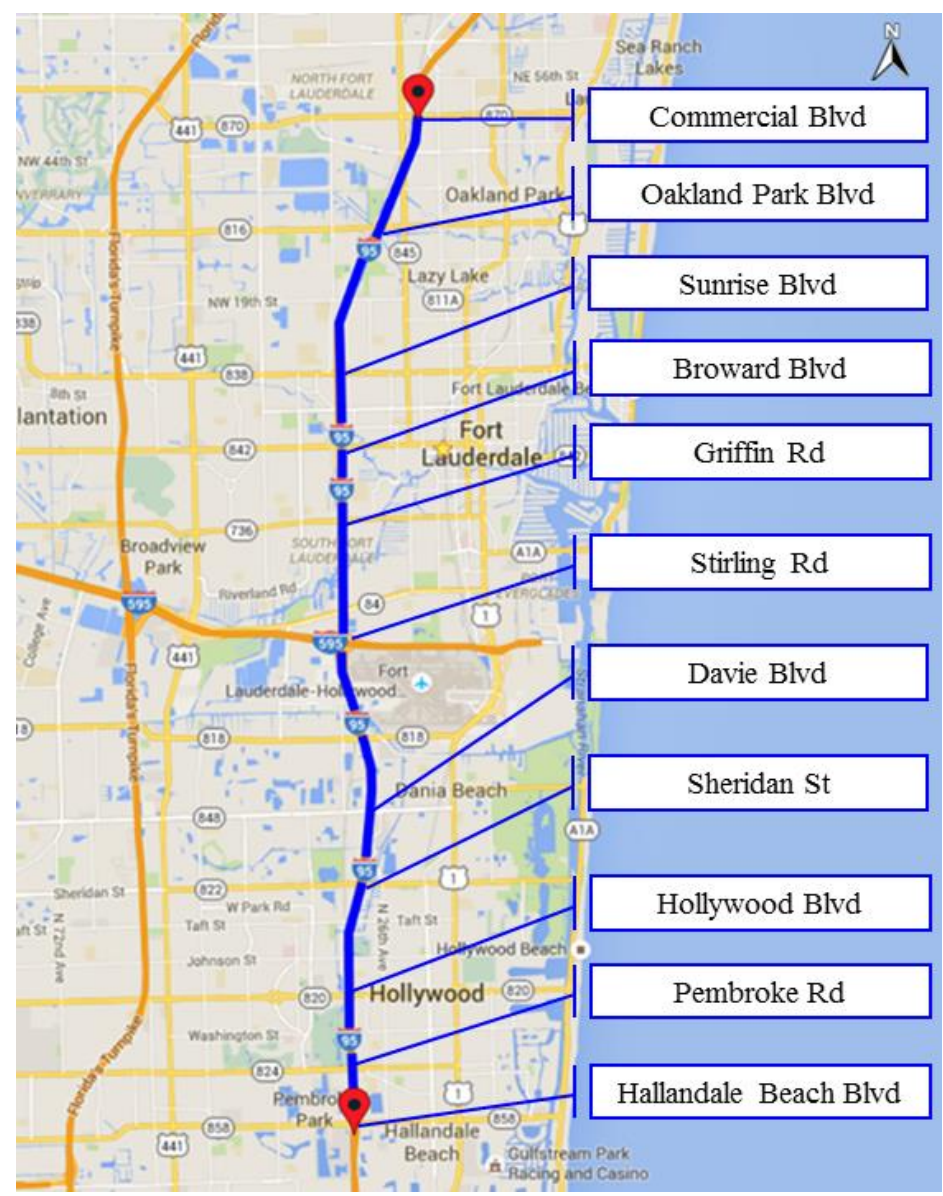

Figure 3-1: Study Area, I-95 Northbound in Broward County, Florida

\subsubsection{Traffic Data}

Traffic data was collected for the study area, including mainline peak hour volume, mainline peak hour speed, peak hour ramp volume, detector occupancy, and peak hour volume for the rightmost lane of the freeway mainline. The traffic data for the mainline was collected for the morning peak hours for a 12-month period from the Regional Integrated Transportation Information System (RITIS), the traffic management data 
warehouse of the Florida Department of Transportation (FDOT). Since there is no detector installed for the on-ramps, ramp volumes were collected from the Florida Transportation Information (FTI) database. The FTI database is a planning level data and is only collected for three days a year per location, while the traffic management data is collected continuously throughout the year.

\subsubsection{Incident and Adverse Weather Data}

Incident and adverse weather data are used to filter normal days without any nonrecurrent conditions such as a crash or rain. This information was collected from the traffic management data warehouse of the FDOT.

\subsection{Assessment of the Need for Developing System-Based Methodology}

An assessment was conducted to determine the need for system-based warrants, in addition to the existing local warrants. First, this study applies the existing local ramp metering warrants to the ramps in the case study area to determine which ramps to meter according to these warrants. Second, a system-based method is used to select ramps for metering. Then, the study compares the results obtained when metering only the ramps justified according to the existing warrants (referred to as locally justified ramps) with the results obtained when combining the metering of these ramps with metering the ramps justified according to system-wide consideration (system justified ramps). VISSIM microscopic simulation modeling was used for the comparison. The following subsections discuss these steps in further detail. 


\subsubsection{Applying Existing Ramp Metering Warrants}

Since the case study area is in the state of Florida, the ramp metering warrants in Florida are used as the base warrants for comparison (Gan et al., 2011). The flowchart illustrated in Figure 2-1 represents the steps for applying the warrants. This flowchart is applied to each of the on-ramps in the study area to check which ramps are identified to be metered according to the warrants. Since the main purpose of this study is to examine the warrants based on their traffic operation impacts, only the traffic warrants, which are shaded in gray in Figure 2-1, are considered when selecting the "locally justified ramps."

\subsubsection{Selecting Ramps Based on System Bottlenecks}

This section describes the methodology used to select ramps for metering based on a system bottleneck capacity (system justified ramps). The methodology considers the stochastic nature of the capacity of the freeway bottlenecks and involves two main steps. The first is to derive the stochastic distribution of capacity at the freeway bottlenecks. The second is to select the ramps for metering based on different capacity percentiles (Fartash et al., 2017)

\subsubsection{Stochastic Capacity Analysis}

The capacity of the freeway is treated as a constant value in the current version of the Highway Capacity Manual (HCM, 2016) and other traffic engineering guidelines. In 1996, Ponzlet showed that capacity can vary depending on environmental conditions such as light and pavement conditions, as well as other operational conditions (Ponzlet, 1996). Other studies addressed the stochastic nature of freeway capacity and showed that even under constant external conditions, various values of capacity can be observed 
(Elefteriadou et al., 1995, Lorenz and Elefteriadou, 2000, and Okamura et al., 2000). These studies showed that there is a variation in the demand level, of which the flow of a freeway segment breaks down into stop-and-go operations.

To consider the bottleneck stochastic capacity in this research, first the recurrent bottleneck location is identified based on data from days with no events, such as incidents, bad weather, and work zones. The bottlenecks are identified by detecting low speeds being propagated upstream, with free-flowing (or near free-flowing) conditions occurring downstream. This identification is accomplished by examining the historical speed profiles at multiple locations upstream and downstream of the bottleneck (FHWA, 2015). The FHWA recently introduced a tool for Congestion and Bottleneck Identification (CBI), which can identify bottleneck locations and their characteristics using numerical and graphical performance measures. Previous research suggested that a 5-minute time interval is the best compromise between the accuracy and simplicity of empirical analyses of breakdown at bottlenecks (Elefteriadou and Lertworawanich, 2003, and Brilon et al., 2005). These studies utilize a speed value ranging between $45 \mathrm{mph}$ and $55 \mathrm{mph}$ to indicate the beginning of the breakdown. This dissertation research uses the CBI tool methodology mentioned above, with an average value of $45 \mathrm{mph}$ as a threshold for bottleneck identification for 5-minute analysis time intervals.

The next step in considering the stochasticity of freeway capacity at bottlenecks is to estimate the capacity distribution function using empirical analysis. In this dissertation, the Product Limit Method (PLM) by Kaplan and Meier (Kaplan and Meier, 1958) is utilized to estimate the distribution. PLM is used to estimate the probability of survival past 
given time points (Kaplan and Meier, 1958). In this case, the death refers to breakdown, and the lifetime variable is the capacity. Based on this method, the distribution function of the capacity could be derived, as shown in Equation 3-1:

$$
F_{c}(q)=1-\prod_{i: q_{i}<q} \frac{k_{i}-d_{i}}{k_{i}} ; i \in B
$$

where,

$$
\begin{aligned}
F_{c}(q) & =\text { distribution function of capacity } \mathrm{c}, \\
q & =\text { traffic volume }(\mathrm{vph}), \\
q_{i} & =\text { traffic volume for interval } i(\mathrm{vph}), \\
k_{i} & =\text { number of intervals with a traffic volume of } q \geq q_{i}, \\
d_{i} & =\text { number of intervals with breakdown occurrence at a volume of } q_{i}, \text { and } \\
B & =\text { set of breakdown intervals. }
\end{aligned}
$$

Set B includes traffic volumes with higher average speeds than threshold speeds at time interval $\mathrm{i}$, and in the following time interval $(\mathrm{i}+1)$, the average speed drops below the threshold speed. Note that if the traffic is congested at the downstream cross section during the time interval of $\mathrm{i}$ or $\mathrm{i}-1$, this case is excluded from set $\mathrm{B}$, because interval i does not contain any information for the capacity assessment at the observation point (Brilon et al., 2005).

In this research, after excluding the days with incident and weather events, the PLM method is applied to one year of archived speed and flow data. It should be noted that the PLM is a non-parametric method that does not require assumptions regarding the distribution function type. A maximum likelihood function is used to find the best-fit distribution. 


\subsubsection{Selecting Ramps for Metering based on System Bottlenecks}

To select the ramps to be metered based on a system bottleneck, all ramps in the investigated segment of the freeway ahead of the bottleneck are included in an optimization process based on a linear programming formulation adopted from the model used as part of the FREQ analysis model (Leiman et al., 1991). The linear programming formulation requires the bottleneck capacity as an input, in addition to the origin-destination demands between the mainline entry points, on-ramps, off-ramps, and mainline exit point within a considered system. The output of the model is the optimized metering rates for all ramps in the subject system. The objective of the optimization is to maximize the vehicle throughput. The objective function used in this study is adopted from the one used in the FREQ model (May, 1976). However, the constraints are modified to fit the case study under consideration and data format. Additional constraints to account for other factors such as queuing capacity on the ramps, agency preferences, and so on could be added to the formulation as needed. The objective function and constraints of the linear programming are presented in Equation 3-2. Figure 3-2 illustrates a schematic representation of the variables of linear programming formulation.

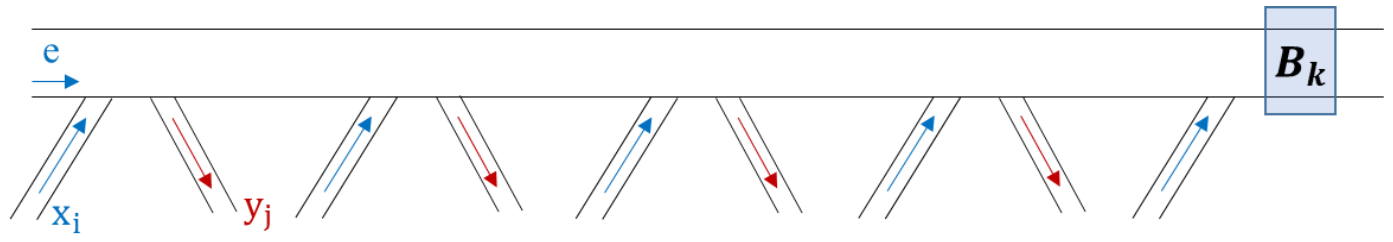

\section{Figure 3-2: Schematic Demonstration for the Variables of Linear Programming Formulation}

Please note that the formulation of Equation 3-2 is extended later in this chapter and used as part of the methodology developed in this dissertation (see Section 3.4). 


$$
\text { Objective Function: } \operatorname{MAX} \sum_{i=1}^{n} x_{i}
$$

Subject to:

$$
\begin{array}{ll}
\sum_{i=1}^{n} x_{i}+e-\sum_{j=1}^{l} y_{j} \leq B_{k} & , k=1,2, \ldots, m, \\
x_{i, \min } \leq x_{i} \leq V_{i} & , i=1,2, \ldots, n
\end{array}
$$

where,

$$
\begin{aligned}
x_{i} & =\text { optimum ramp metering rate for on-ramp } i(\mathrm{vph}), \\
n & =\text { number of the on-ramps upstream of the subsection } k, \\
l & =\text { number of the off-ramps upstream of the subsection } k, \\
y_{j} & =\text { ramp demand for off-ramp } j(\mathrm{vph}), \\
e & =\text { upstream mainline volume, } \\
B_{k} & =\text { capacity of subsection } k(\mathrm{vph}), \\
m & =\text { number of subsections, } \\
V_{i} & =\text { demand rate at on-ramp } i, \text { and } \\
x_{i, \text { min }} & =\text { minimum metering rate for on-ramp } i .
\end{aligned}
$$

The first constraint in the above equation limits the mainline volume at a subsection $k$ to the total of the entering flow from the upstream on-ramps and mainline minus the exiting flow from the upstream off-ramps to be less than the capacity of subsection $k$. The value of the capacity can be selected from the capacity distribution as a desired percentile based on agency specifications. The second constraint requires the metering rate to be more than the minimum metering rate and less than the demand of the subject ramp. In this dissertation, the minimum metering rate is calculated based on the estimated queue storage 
capacity of the subject on-ramp. The current Florida ramp metering warrants uses Equation 3-3 to calculate the estimated queue length and minimum storage length $\left(L_{s}\right)$ (Gan et al., 2011). Note that the storage length is the distance from the starting point of the ramp from the arterial to the stop line on the on-ramp. Equation 3-4 is used to represent the minimum metering rate $x_{i, \min }$ for each on-ramp i.

$$
\begin{gathered}
L_{s}=0.25 V-0.00007422 V^{2} \\
x_{i, \min }(v p h)=V_{i}(v p h)-L_{s}(\text { meter }) \times \frac{1 \text { vehicle }}{6.1(\text { meter })}=V_{i}-0.04098360 V_{i}+ \\
0.00001216 V_{i}^{2}=0.9590164 V_{i}+0.00001216 V_{i}^{2}
\end{gathered}
$$

where,

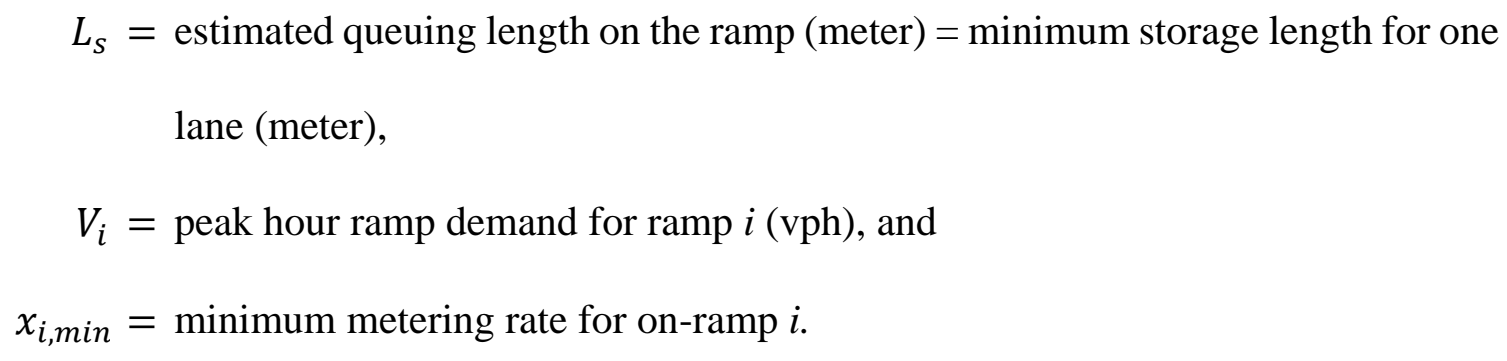
lane (meter),$$
V_{i}=\text { peak hour ramp demand for ramp } i(\mathrm{vph}), \text { and }
$$$$
x_{i, \min }=\text { minimum metering rate for on-ramp } i \text {. }
$$

If the resulting metering rate from applying the above methodology for a ramp is lower than the actual ramp volume, the ramp is considered for metering. Otherwise, the ramp is not justified to be metered.

\subsubsection{Comparison Based on Simulation}

The case study area was modeled in the VISSIM microscopic simulation to assess the need for selecting ramps to install metering equipment based on system-wide conditions. The methodology based on Equations 3-2 and 3-4, as described above, was applied to calculate the metering rates for the scenarios when selecting ramps based on 
existing local warrants and system bottleneck consideration. In order to assess the potential improvements of considering the system bottleneck, the simulation results were used to estimate performance measures, including travel time on the on-ramps and travel time on the freeway mainline. The "average speed" on the freeway mainline for each 15-minute time interval was also used in the comparison.

The travel times on the freeway mainline and the on-ramps are used to calculate the benefits of the system justified approach compared to the locally justified approach in terms of delay savings. The delay savings, calculated as the difference between the travel times, installation, operations and maintenance costs of the two approaches, are used to calculate the benefit-cost ratio. The costs are estimated based on information obtained from FDOT District Four, and the present worth of the ramp metering deployment is calculated based on initial costs and the recurrent benefits and costs during the project life cycle.

\subsection{Developed Methodology for Identification of Ramps for Metering}

The method developed in this study to select ramps for metering is based on a linear programming formulation that has been implemented in the past to estimate the ramp metering rate. The formulation was used as part of the FREQ freeway traffic analysis tool (Leiman et al., 1991, and May, 1976). The method was extended in this study to consider the stochasticity of the demands and capacity, combined with derived models to estimate the impacts of ramp metering on bottleneck characteristics and performance measures. The linear programming formulation can be set to optimize the ramp metering operation to maximize the throughput of the system without violating constraints such as the minimum and maximum rates on each ramp and ramp queue lengths. To select the ramps to be 
metered, all ramps in a study area are included in the linear programming optimization. The linear programming formulation requires bottleneck capacity as an input, in addition to the origin-destination demands between the mainline entry points, on-ramps, off-ramps, and mainline exit point of the considered system.

The output of the model is the optimized metering rates for all ramps in the study area. The objective of the optimization is to maximize the vehicle throughput to keep the flow as close as possible but lower than the capacity to prevent breakdown. The objective function and constraints of the linear programming are presented in Equation 3-5. It is notable that objective function is the same as Equation 3-2 with added constraints.

$$
\text { Objective Function: } M A X \sum_{i=1}^{n} x_{i}
$$

Subject to:

$$
\begin{array}{ll}
\sum_{i=1}^{n} \beta_{i} x_{i}+e-\sum_{j=1}^{l} \gamma_{j} y_{j} \leq B_{k} & , k=1,2, \ldots, m, j=1,2, \ldots, l \\
x_{i, \text { min }} \leq x_{i} \leq V_{i} & , i=1,2, \ldots, \mathrm{n} \\
x_{i, \text { min }}=V_{i}-\alpha S_{i} & , i=1,2, \ldots, \mathrm{n} \\
\text { where, } &
\end{array}
$$

$$
\begin{aligned}
x_{i}= & \text { optimum ramp metering rate for on-ramp } i(\mathrm{vph}), \\
\beta_{i}= & \text { portion of vehicles entering from on-ramp } i \text { which pass through the bottleneck } \\
& \text { location, } \\
n= & \text { number of the on-ramps upstream of the subsection } k, \\
l & =\text { number of the off-ramps upstream of the subsection } k, \\
y_{j}= & \text { ramp demand for off-ramp } j(\mathrm{vph}), \\
\gamma_{j} & =\text { portion of the upstream mainline volume }(e) \text { which exit from off-ramp } j,
\end{aligned}
$$




$$
\begin{aligned}
e & =\text { upstream mainline volume }(\mathrm{vph}), \\
B_{k}= & \text { capacity of subsection } k(\mathrm{vph}), \\
m= & \text { number of subsections, } \\
V_{i}= & \text { demand rate at on-ramp } i(\mathrm{vph}), \\
S_{i}= & \text { available storage at on-ramp } i(\mathrm{vph}), \\
x_{i, m i n}= & \text { minimum metering rate for on-ramp } i(\mathrm{vph}), \text { and } \\
\alpha= & \text { user-specified portion of the maximum queue accommodated by the storage } \\
& \text { length. }
\end{aligned}
$$

The first constraint in Equation 3-5 requires that the mainline volume at subsection $k$ (the total of the entering flow from the upstream on-ramps and mainline minus the exiting flow from the upstream off-ramps) be less than the capacity of this subsection. In this study, the capacity and demand values utilized in the formulation are considered as stochastic variables and are generated from their distributions using the Monte Carlo simulation, as discussed in detail in the next section. The linear programming formulation is assessed with the values generated from each experiment of the Monte Carlo analysis. The second constraint in the formulation requires the metering rate to be higher than the minimum metering rate and less than the demand of the subject ramp. The third constraint defines the minimum metering rate for each on-ramp as the difference between the demand of the on-ramp and a multiplier of the available queue storage $\left(S_{i}\right)$. The queue storage in feet is converted to vehicles by assuming that each queued vehicle and the associated distance headway occupies 25 feet and considering the ramp queue length and the number of lanes on the ramp. If the queue storage considering the distance between the metering stop line and the gore is known, then this storage should be used in the formulation. In reality, 
meeting this storage requirement is a function of a number of factors, including on-ramp demand, traffic flow arrival pattern, metering rate and algorithm, upstream signal control, and right turn-on-red vehicles (Tian et al., 2016). Based on the review of the literature presented earlier, one of the approaches to determine the minimum storage length on the on-ramp is to consider that the storage length should be able to accommodate at least $10 \%$ of the on-ramp demand (Gan et al., 2011). In this study, initially it is assumed that each onramp queue storage is set to accommodate at least $10 \%$ of the demand, therefore, the minimum metering rate for each ramp is calculated as $90 \%$ of the demand on the on-ramp.

An absolute minimum metering rate of four vehicles per minute (240 vehicles per hour) was also set for all of the on-ramps, as recommended in the literature. These percentages are user inputs and can change based on an agency's policy. The abovementioned linear programming formulation calculates the excessive entering flow from on-ramps, which needs to be eliminated using ramp signals. This excessive volume equals to $\sum_{i=1}^{n} V_{i}-\sum_{i=1}^{n} x_{i}$. The regular linear programming distributes the excessive volume evenly between the on-ramps. However, this is not appropriate for the purpose of this research since the user may want to ensure that congestion can be addressed by metering the on-ramp(s) that are closer to the bottleneck before metering additional ramps. Thus, a modified programming formulation was deployed in this project to perform the selection of the ramps for metering starting from the ramp that is the closest to the system bottleneck location. If this ramp is unable to accommodate the excessive demand above capacity at the bottleneck, considering the constraints on the process listed in Equation 35, the metering is extended to the upstream ramp. This extension continues until the excessive volume is distributed between the ramps required to be metered. The metering 
rate is set to produce an equal demand to capacity ratio on the on-ramps selected for metering.

\subsubsection{Off-Line Ramp Selection for Recurrent Conditions}

Figure 3-3 represents a simplified summary of the main steps of the developed methodology to identify the locations that benefit from ramp metering.

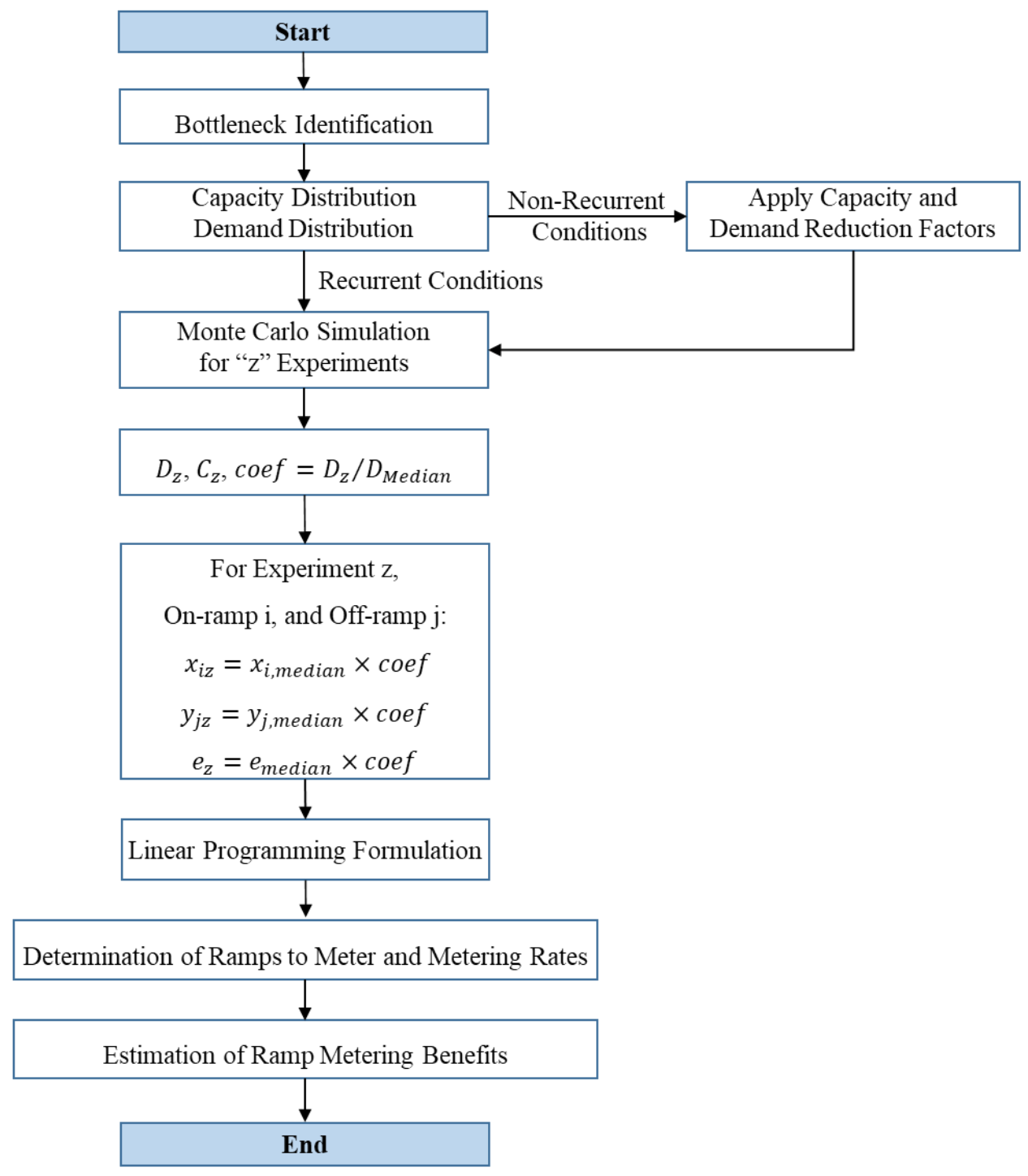

Figure 3-3: Main Steps of the Developed Methodology 
The bottleneck location is identified as described in Section 3.3.2.1, and the capacity distribution is derived as described in the same section. Section 3.4.1.1 describes the methodology used to derive the demand distributions at the bottleneck location. Monte Carlo simulation is described in detail in Section 3.4.1.2. Capacity and demand distributions are used as the inputs to the Monte Carlo simulation to generate 1,000 experiments. Each experiment represents one realization of the real-world demand and capacity values. The generated demand value for each experiment is divided by the median demand value to calculate the demand fluctuation coefficient. This coefficient was later multiplied to the on- and off-ramp volumes as well as the mainline volume to replicate the demand fluctuation in the real-world conditions (Fartash et al., 2018). These 1,000 experiments were inputted to the linear programming formulation described in Section 3.4.

The results of the linear programming formulation were used to conduct the benefit-cost analysis as described in Section 3.4.3. Section 3.4.2 describes the required modifications to select the ramps to meter under non-recurrent conditions.

\subsubsection{Stochastic Demand Analysis}

Similar to capacity, traffic demand also has a stochastic nature, which is considered in this dissertation research. To derive the stochastic distributions of freeway demands, the historical detector volume data for the same period used in the capacity analysis discussed in the previous section is analyzed. As aforementioned, the volume and speed data are analyzed only for the event-free time intervals. The RITIS data is filtered to capture the event-free time intervals. Therefore, all time intervals with events such as incident, adverse weather, and work zone are excluded from further analysis. As the fluctuations for the 5- 
minute demand values are high, the data were aggregated to 15-minute intervals. Therefore, the volume for each 15-minute interval was simply calculated as the summation of the volumes for the three corresponding 5-minute time intervals, and the speed for each 15minute interval is the average of the speed for three corresponding 5-minute time intervals. If there is no queue at the bottleneck location, the demand is equal to the traffic volume measured at the bottleneck detection station. However, if there is a queue at the bottleneck location, the demand is calculated as the summation of the volume and the estimated additional number of the vehicles queued in the time interval, since the traffic volume by itself reflects the capacity and not the demand. If the speed for the considered time interval is lower than the speed threshold (45 mph), a queue occurrence is identified at the detection station. The distance between each of the two detectors is divided into two equal lengths, and each length is assigned to the nearest detector. If the aggregated speed over the 15minute time interval for a detector is less than the speed threshold, the queue length is assumed to be equal to the assigned length of that detector. Therefore, the demand for each time interval is calculated using Equation 3-6:

$$
D_{i}=F_{i}+Q_{i}-Q_{i-1}
$$

where,

$$
\begin{aligned}
D_{i} & =\text { demand for time interval } i(\mathrm{vphpl}), \\
F_{i} & =\text { flow for time interval } i,(\mathrm{vphpl}), \\
Q_{i} & =\text { the entire queue length for time interval } i(\mathrm{vphpl}), \text { and } \\
Q_{i-1} & =\text { the entire queue length for time interval } i-1(\mathrm{vphpl}) .
\end{aligned}
$$




\subsubsection{Generating Analysis Scenarios Using Monte Carlo Simulation}

In the real world, as a result of the variations in demands and capacity, different days involve different operation scenarios, as described earlier. In this study, different analysis scenarios representing different days are generated using a Monte Carlo process to account for the stochastic nature of demand and capacity that result in variations in system performance between days even with the presence of no incidents, weather events, and/or construction activities. Monte Carlo is a popular statistical analysis method used for considering the impacts of stochastic variables and is capable of dealing with various stochastic distribution types and a large number of variables (Mahadevan, 1996). As described earlier, statistical distributions were fitted to the historical traffic data for capacity and demands measurements for the year 2015.

The Monte Carlo simulation utilizes random sampling to conduct a large number of experiments. In each experiment, instances of input random variables (capacity and demand in this case) are generated based on their distributions to represent one realization of traffic conditions on the investigated facility. Then, the linear programming formulation and its extension described earlier is applied for each realization, and the outputs from all realizations are further analyzed to support the decision-making process. The results are the ramps that need to be metered and the metering rate for each on-ramp and each realization. Performing this process for a large number of experiments will generate a set of output variables that generate distributions of these variables which can be used in the analysis. To obtain the distribution of the outcome, 1,000 Monte Carlo experiments were performed. Note that the ramp metering rates produced as part of the process are not expected to be used in real-world applications in many cases, since an adaptive ramp 
metering will most likely be used. However, the process generates the ramps to be metered and rates that can be used to have an initial assessment of ramp metering impacts. In addition, it allows for the calculation of queue lengths on the on-ramps and provides inputs for the benefit-cost analysis of ramp metering, as discussed later in this document.

\subsubsection{Off-Line Ramp Selection for Non-Recurrent Conditions}

This dissertation research aims to investigate the installation and activation of ramp metering by considering both recurrent and non-recurrent conditions. Thus, this section summarizes the effort conducted to select the ramps that need to be metered during incident and rainfall events. The process is basically similar to that used for recurrent conditions, as described in Section 3.4.1. The only difference is including the impacts of non-recurrent events (incident and rainfall) on the capacity (and possibly demand) inputs to the ramp selection formulation. The following sections discuss the details of these impacts and the methodology to incorporate them in this research.

\subsubsection{Incident Impact on Capacity}

According to the latest version of the HCM, once a lane is blocked due to an incident, the remaining lanes will not function at full capacity (HCM, 2016). Table 3-1 illustrates the remaining capacity of the unblocked lanes for different combinations of the total number of lanes and the number of blocked lanes, as presented in the HCM. These values of capacity drop are used to modify the capacity distribution derived using data collected under normal (event-free) conditions. For example, for an incident that results in one lane blockage out of four lanes, the capacity of the remaining three lanes drops to $77 \%$ 
of its original value. Therefore, the remaining capacity of the section will reduce to $\% 57.75$ of its original value $(3 \times 0.77 / 4=0.5775)$.

Table 3-1: Remaining Capacity Ratio for Open Lanes after Closure due to Incident Occurrence (HCM, 2016)

\begin{tabular}{|c|c|c|c|c|c|c|}
\hline $\begin{array}{c}\text { Directional } \\
\text { Lanes }\end{array}$ & $\begin{array}{c}\text { No } \\
\text { Incident }\end{array}$ & $\begin{array}{c}\text { Shoulder } \\
\text { Blocked }\end{array}$ & $\begin{array}{c}\text { 1 Lane } \\
\text { Blocked }\end{array}$ & $\begin{array}{c}\text { 2 Lanes } \\
\text { Blocked }\end{array}$ & $\begin{array}{c}\text { 3 Lanes } \\
\text { Blocked }\end{array}$ & $\begin{array}{c}\text { 4 Lanes } \\
\text { Blocked }\end{array}$ \\
\hline 2 & 1.00 & 0.81 & 0.70 & N/A & N/A & N/A \\
\hline 3 & 1.00 & 0.83 & 0.74 & 0.51 & N/A & N/A \\
\hline 4 & 1.00 & 0.85 & 0.77 & 0.50 & 0.52 & N/A \\
\hline 5 & 1.00 & 0.87 & 0.81 & 0.67 & 0.50 & 0.50 \\
\hline 6 & 1.00 & 0.89 & 0.85 & 0.75 & 0.52 & 0.52 \\
\hline 7 & 1.00 & 0.91 & 0.88 & 0.80 & 0.63 & 0.63 \\
\hline 8 & 1.00 & 0.93 & 0.89 & 0.84 & 0.66 & 0.66 \\
\hline
\end{tabular}

\subsubsection{Incident Impact on Demands}

The impact of incidents on diversion has been investigated in previous studies. Hadi et al. performed an empirical analysis on a 7-mile section in the I-95 corridor in Miami, Florida between the Golden Glades Interchange and SR-836 by analyzing 188 incident cases. The average diversion rates were estimated for various combinations of the total number of lanes and the number of blocked lanes due to incidents (Hadi et al., 2013). Table 3-2 shows the diversion rates for each case of lane blockages. These values are used in this research to calculate the remaining demand after incident occurrence. For example, for an incident that results in one lane blockage out of four lanes, the adjusted demand for the whole segment is assumed to decrease by $11.07 \%$. This diversion percentage can be varied by the analyst based on local conditions. In addition, it is possible to set diversion as a stochastic variable in the Monte Carlo simulation based on variations in the diversion percentage, as reported in the previous studies. 
Table 3-2: Estimated Diversion Rates due to Incident Occurrence (Hadi et al., 2013)

\begin{tabular}{|c|c|c|}
\hline Directional Lanes & Number of Lanes Blocked & Average Diversion Rate (\%) \\
\hline 3 & 1 & 14.81 \\
\hline 3 & 2 & 10.68 \\
\hline 3 & 3 & 30.27 \\
\hline 4 & 1 & 11.07 \\
\hline 4 & 2 & 16.88 \\
\hline 4 & 3 & 24.61 \\
\hline 4 & 4 & 34.83 \\
\hline 5 & 1 & 8.60 \\
\hline 5 & 2 & 9.87 \\
\hline 5 & 3 & 17.30 \\
\hline
\end{tabular}

To assess ramp metering requirements under incident conditions, different incident scenarios can be considered. For example, for a segment with four lanes, the incident scenarios may include shoulder-only incidents, or one-lane, two-lane, or three-lane blocked incidents. The capacity of the mainline in the case of a three-lane blockage is expected to be $13 \%$ of the original capacity based on the information provided in Table $3-1$. The demand drops by only $24.61 \%$, according to Table 3-2. Such scenarios with excessive demand-to-capacity ratios are not expected to benefit from ramp metering, and thus, are excluded from further analysis.

\subsubsection{Rainfall Impact on Capacity}

According to the HCM, rainfall reduces the capacity of the freeway, and the intensity of the impact corresponds to the intensity of the rainfall in terms of inches per hour (in/hr) (HCM, 2016). The HCM sixth edition presents the remaining capacity of the freeway segment for two categories of rain: medium and heavy, corresponding to the intensity of the rainfall (HCM, 2016). Table 3-3 illustrates the presented values in the HCM for the remaining capacity for medium and heavy rain events according to the free-flow 
speed of a freeway segment. The free-flow speed of the case study area is $75 \mathrm{mph}$; therefore, the remaining capacity percentage is 0.90 and 0.82 for the medium and heavy rain categories, respectively.

Table 3-3: Remaining Capacity Ratio for Rainfall (HCM, 2016)

\begin{tabular}{|c|c|c|c|c|c|c|}
\hline \multirow{2}{*}{ Rain Category } & \multirow{2}{*}{ Rain Intensity } & \multicolumn{5}{|c|}{ Free-Flow Speed of the Freeway } \\
\cline { 3 - 7 } & & $\mathbf{5 5} \mathbf{~} \mathbf{p h}$ & $\mathbf{6 0} \mathbf{~ m p h}$ & $\mathbf{6 5} \mathbf{~} \mathbf{p h}$ & $\mathbf{7 0} \mathbf{~} \mathbf{p h}$ & $\mathbf{7 5} \mathbf{~ m p h}$ \\
\hline Medium Rain & $>0.10-0.25 \mathrm{in} / \mathrm{hr}$ & 0.94 & 0.93 & 0.92 & 0.91 & 0.90 \\
\hline Heavy Rain & $>0.25 \mathrm{in} / \mathrm{hr}$ & 0.89 & 0.88 & 0.86 & 0.84 & 0.82 \\
\hline
\end{tabular}

To address rainfall conditions, the two scenarios of the medium and heavy rains are considered. The method used to estimate the required number of ramps, metering rate, and resulting queue lengths is similar to the method used for recurrent conditions and incident conditions. The only difference is that the capacity values for each scenario are adjusted by the remaining capacity ratios presented in Table 3-3. In the case study of this dissertation, the rain is assumed to not affect the demands. However, this can be added if information of such impacts is available.

Table 3-4 summarizes the coefficients used to modify the demand and capacity values for each incident and rain scenario, using the approach described above.

Table 3-4: Diversion and Capacity Adjustment Coefficients for Non-Recurrent Scenarios on a 4-Lane Freeway Segment

\begin{tabular}{|c|c|c|}
\hline Event & $\begin{array}{c}\text { Remaining Capacity } \\
\text { for the Segment }(\mathbf{v p h})\end{array}$ & $\begin{array}{c}\text { Remaining Demand } \\
\text { for the Segment }(\mathbf{v p h})\end{array}$ \\
\hline Shoulder Only Incident & $0.85 \times(4$ lanes $) \times$ original capacity $(\mathrm{vphpl})$ & original demand \\
\hline 1 Lane Blocked Incident & $0.77 \times(3$ lanes $) \times$ original capacity $(\mathrm{vphpl})$ & $(1-0.1107) \times$ original demand \\
\hline 2 Lanes Blocked Incident & $0.50 \times(2$ lanes $) \times$ original capacity $(\mathrm{vphpl})$ & $(1-0.1688) \times$ original demand \\
\hline Medium Rain & $0.90 \times(4$ lanes $) \times$ original capacity $(\mathrm{vphpl})$ & original demand \\
\hline Heavy Rain & $0.82 \times(4$ lanes $) \times$ original capacity $(\mathrm{vphpl})$ & original demand \\
\hline
\end{tabular}




\subsubsection{Benefit-Cost Analysis for Ramp Metering Deployment}

This step involves estimating the anticipated benefits of ramp metering. The benefits of the proposed methodology are evaluated in terms of delay savings. For this purpose, the queuing theory equations are used to calculate the delays for both freeway mainline and the on-ramps (May, 1990). The queue and associated delay on the mainline forms due to breakdown occurrence at the bottleneck locations. The queues that form due to metering are those that occur on the on-ramps due to ramp demands exceeding the ramp capacities with metering. The delay savings for each scenario or event type is calculated based on the difference between the delays in the absence of ramp metering and with the ramp metering application. The duration of rainfall is assumed to be one hour. Based on previous analysis of incident data from the case study corridor, the average incident durations utilized in the analysis are 40 minutes for shoulder incidents and 50 minutes for incidents with lane blockages (Hadi et al., 2007). The total delay on the freeway mainline and each on-ramp (TD) is calculated using Equation 3-7 and is based on queuing theory analysis (May, 1990).

$$
\begin{gathered}
T D=\frac{t_{R} t_{Q}\left(\lambda-\mu_{R}\right)}{2} \\
t_{Q}=\frac{t_{R}\left(\mu-\mu_{R}\right)}{\mu-\lambda}
\end{gathered}
$$

where,

$$
\begin{aligned}
\lambda= & \text { arrival rate (demand) }(\mathrm{vph}), \\
\mu= & \text { capacity rate under recurrent condition }(\mathrm{vph}), \\
\mu_{R}= & \text { reduced capacity rate under metering for ramps or under non-recurrent } \\
& \text { conditions for the mainline }(\mathrm{vph}),
\end{aligned}
$$


$t_{R}=$ event duration (hr), and

$t_{Q}=$ time in queue duration (hr).

The delay savings can be converted to monetary values to be incorporated into benefit-cost analyses. The costs are estimated based on information obtained from FDOT District Four, and the present worth of the ramp metering deployment is calculated based on initial costs and the recurrent benefits and costs during the project life. The utilized methodology described above can be used to conduct benefit-cost analysis of the ramp metering deployment and associated decisions, such as which ramps to meter and when to activate. The methodology can be used to assess the benefits of selecting ramps based on local conditions versus the selection based on system conditions.

\subsubsection{Real-Time Ramp Selection for Activation}

NCHRP Report 3-87 recommends considering the probability of breakdown as a measure to activate ramp metering or be incorporated into the metering algorithms to calculate the metering rate (Elefteriadou et al., 2009). For this purpose, the first step is to develop the breakdown probability model. This model is supposed to estimate the probability of breakdown occurrence for any specific traffic flow (either the freeway flow or total flow of freeway and on-ramp). The model is developed based on an analysis approach referred to as lifetime data analysis statistics. This approach is usually used to estimate the time until failure for mechanical parts. In traffic studies, it can provide the probability that a particular flow will not lead to breakdown. The maximum pre-breakdown volume is interpreted as the lifetime. The Product Limit Method (PLM) was used to achieve the distribution of lifetime. Figure 3-4 illustrates a sample of probability of breakdown 
derived in NCHRP Report 3-87 for a four-lane bottleneck at the I-95 NB ramp from $103^{\text {rd }}$ Street in Miami-Dade County.

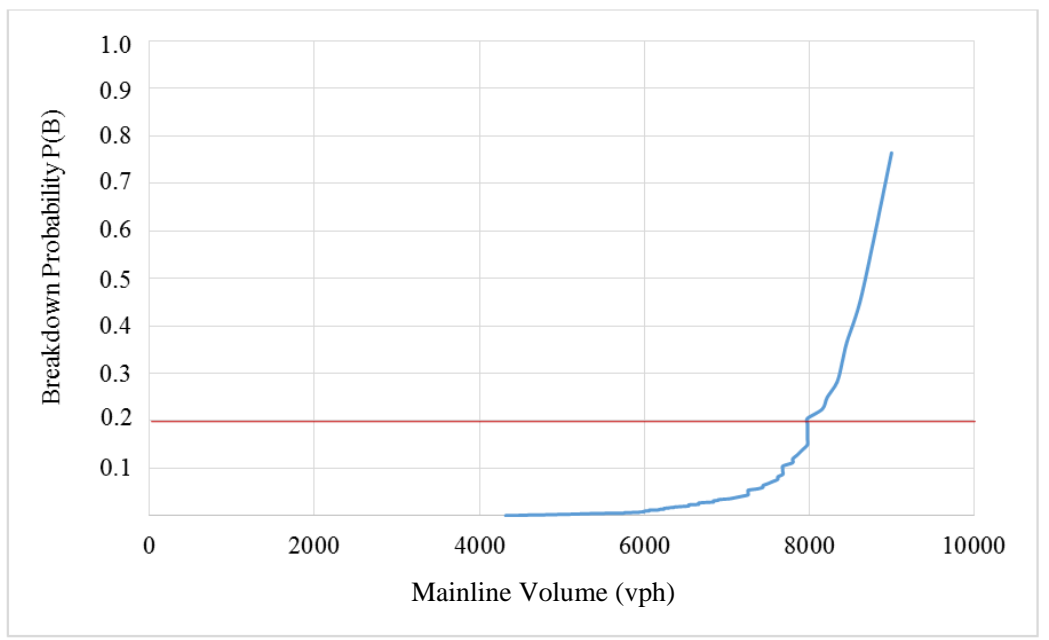

\section{Figure 3-4: Breakdown Probability Model for I-95 NB ramp from 103rd St.} (Elefteriadou et al., 2009)

NCHRP Report 3-87 proposed a $20 \%$ probability of breakdown as the threshold; that is, once the upstream flow reaches a value corresponding to $20 \%$ or more of a probability of breakdown, the ramp meter is activated. This method is quite simple and only requires immediate upstream and on-ramp volumes or immediate downstream volumes or occupancy as the inputs. However, it does not allow for the determination of how many ramps and which ramps need to be metered; it only determines the activation time. Moreover, this method is only applicable to recurrent traffic conditions and does not support activation time for non-recurrent conditions.

As described in Section 3.3.2.1, the PLM method referenced in the above discussion was used in this dissertation to derive the capacity distribution. The maximum flow before breakdown occurrence was interpreted as the capacity. Therefore, the 
probability of breakdown for the bottleneck can be estimated based on the stochastic distribution of capacity considering the estimated demands.

The proposed methodology for off-line selection of the ramps to meter can be extended to real-time activation of ramp signals. In addition to the stochastic capacity distribution, there is a need to predict the demands to estimate the probability of having a $\mathrm{D} / \mathrm{C}$ ratio higher than 1.0 in the next 15 -minute time interval. For this purpose, a simplified prediction model is used by deriving factors based on the historical demand data for 15minute intervals for the prediction of the demands on a freeway mainline for the next 15 minutes. For the purpose of this research, the prediction is based on the ratio of the demand in the next 15 minutes over an instantaneous demand. This ratio was derived from historical demand distributions for the morning and afternoon peak periods. The $80^{\text {th }}$ percentile demand for each 15-minute interval was used for the analysis. More complex travel demand prediction methods can also be used to provide the input to the proposed ramp selection methodology.

The constraints of the formulation may be updated based on the preference of the operating agency on storage utilizations. This method can provide the ramp metering activation for the ramps in addition to the total number of ramps to be metered. The capacity input to the formulation is assumed to be the $20^{\text {th }}$ percentile capacity. Since realtime activation is based on the forecasted demand value for each 15-minute interval, the Monte Carlo simulation in not required.

Another approach that uses the outcome of the proposed formulation of this dissertation research is to provide a look-up table derived off-line that relates the number 
of ramps to be metered to the predicted $\mathrm{D} / \mathrm{C}$ values at the activation decision stage, rather than running the ramp metering formulation in real time. Therefore, by predicting the demand value for the next 15 minutes and calculating the forecasted D/C ratio value for the next 15 minutes, the specific ramps to be metered can be determined, as well as the time of their activation.

The developed distributions for demand prediction and look-up table and the comparison results of these three approaches (probability of breakdown, using the formulation, and using the look-up table) are presented in Chapter 4.

\subsection{Summary}

This chapter described a methodology to select the ramps to meter based on traffic conditions at the system bottlenecks under recurrent and non-recurrent conditions. This methodology takes the stochastic nature of the demand and capacity into consideration. For this purpose, the demand and capacity distributions are derived based on historical traffic data and are used as inputs to a Monte Carlo simulation process that provides the required inputs to the ramp selection formulation utilized as part of the developed methodology.

To select the ramps to be metered based on system-wide traffic conditions, a linear programming formulation is utilized. The application of this formulation ensures that the ramps selected for metering will support the applications of metering strategies that have the potential to prevent breakdown at bottleneck locations by keeping the bottleneck flow below the capacity and limiting the entering flow from the ramps upstream of the bottleneck locations, while considering the queuing storage capacities of on-ramps. This formulation ensures the selection of the smallest subset of ramps for metering that meets 
the formulation constraints. As such, the selection of ramps for metering and the associated rates starts from the closest on-ramp to the bottleneck location. If the constraints are not met with the metering of this ramp, the subset of ramps to be metered is extended to the upstream ramp. This extension continues until the excessive volume above the bottleneck capacity is distributed between the ramps required to be metered, while meeting all of the constraints. The metering rate is set to produce an equal demand to capacity ratio on the metered ramps.

This methodology is extended to determine the ramps that need to be metered during incident and rainfall conditions by modifying the capacity and demand inputs based on the impacts of non-recurrent events (incidents and weather). The benefits of systemwide metering are calculated in terms of delay savings and can be used to support the decisions to select a subset of on-ramps for metering. The results can be used to conduct benefit-cost analysis of the ramp metering deployment and associated decisions such as which ramp to meter and when to activate.

The proposed methodology is also extended for real-time activation of ramp metering. The results of the off-line ramp selection are utilized to produce a look-up table for real-time activation of the ramps based on real-time data and demand prediction for the next 15 minutes. Moreover, the activation based on the probability of breakdown for the recurrent condition is compared with the use of the look-up table, as well as using the proposed methodology for off-line selection of the ramps with substitution of the Monte Carlo simulation results with real-time traffic data as the input. 


\section{CHAPTER 4 \\ RESULTS}

This chapter presents the results of each step of the methodology, including the inputs and outputs of each step. The results of the assessment used to develop a systembased methodology for selecting ramps for metering are first presented, followed by the results of the proposed methodology for recurrent and non-recurrent conditions. Then, the results of real-time activation are presented.

\subsection{Assessment of the Need to Develop System-Based Warrants}

The first step was to determine the bottlenecks and the associated stochastic capacities. By analyzing the speed profile of the corridor, it was determined that the main recurrent bottleneck is located upstream of the I-95 on-ramp from Commercial Boulevard in Fort Lauderdale, Florida. The capacity distribution of the bottleneck was assessed by utilizing the PLM method described earlier. The results of the PLM method estimation and the fitted Weibull distribution based on the maximum likelihood method are shown in Figure 4-1. As illustrated in Figure $4-1$, the $30^{\text {th }}, 50^{\text {th }}, 80^{\text {th }}$ and $95^{\text {th }}$ percentiles of the bottleneck capacity are equal to 2,239 vphpl, 2,300 vphpl, 2,373 vphpl, and 2,428 vphpl, respectively. It is interesting to note that the $50^{\text {th }}$ percentile capacity is $2,300 \mathrm{vphpl}$, which is close to the deterministic capacity estimated by the HCM 2016 (2,318 vphpl). However, it should be considered that this may not be the case at other locations. As mentioned in the methodology section, the VISSIM microscopic simulation was used to evaluate the impacts of ramp metering when considering local and system-wide conditions in selecting ramps for metering. The model was first calibrated in accordance with the real-world flow 
data for each capacity percentile at the bottleneck location to ensure that the simulation replicates the actual network and operation. As part of the calibration, the driving behavior parameters of VISSIM were fine-tuned and the resulting capacities were entirely compatible with the results in Figure 4-1.

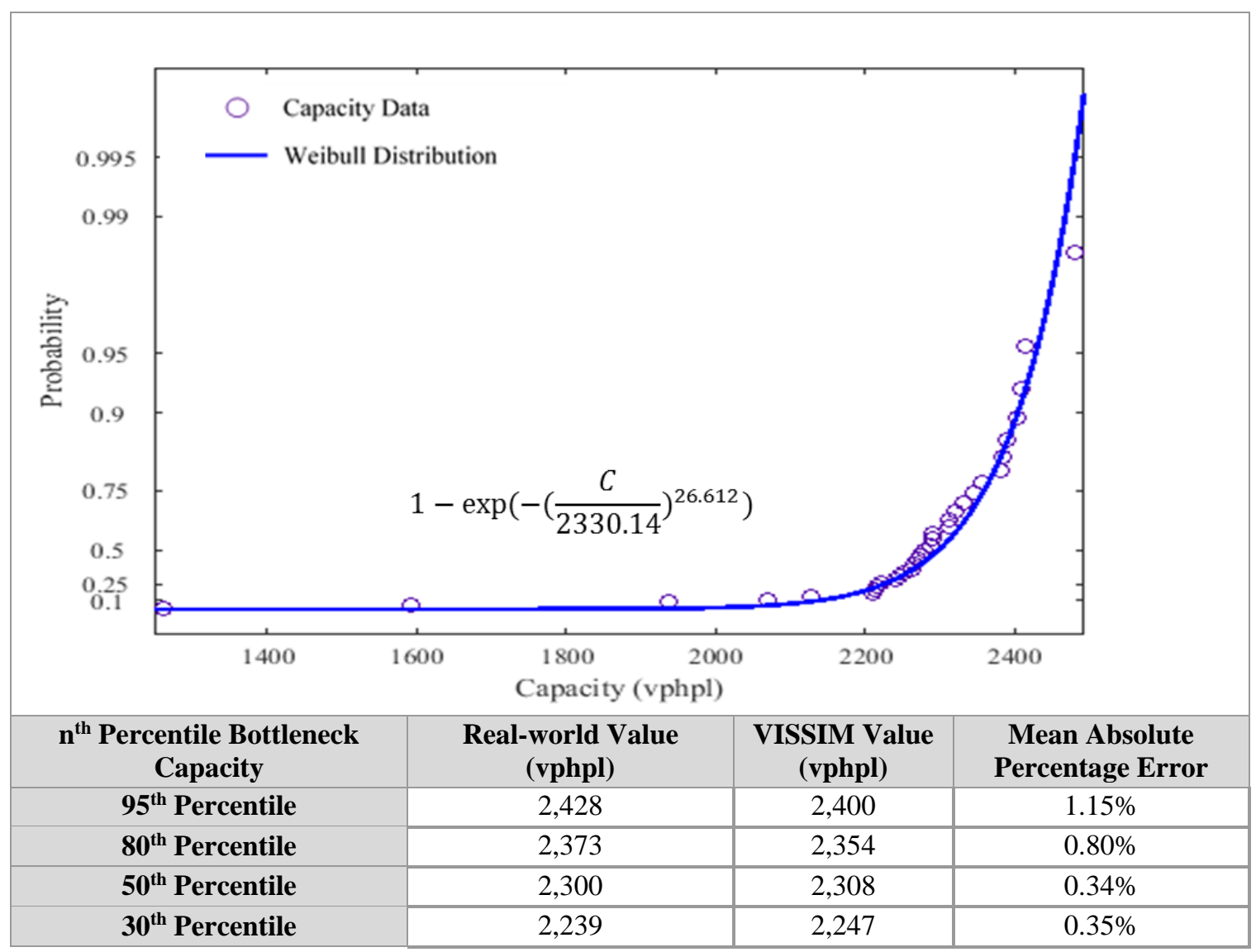

Figure 4-1: Stochastic Capacity Distribution for Bottleneck Location and VISSIM Calibration Results

Table 4-1 compares the results of the selection of ramps for metering with those obtained using the existing Florida Warrants. As shown in the table, only four out of ten ramps are justified to be metered based on the existing Florida traffic warrants. When considering the system bottleneck, eight out of the ten ramps are warranted to be metered 
with the $95^{\text {th }}$ and $80^{\text {th }}$ percentile capacity, and nine are warranted with the $50^{\text {th }}$ and $30^{\text {th }}$ percentile capacity at the bottleneck.

Table 4-1: List of Warranted Ramp Metering based on Existing Florida Warrants and System-Wide Consideration

\begin{tabular}{|c|c|c|c|c|c|}
\hline \multirow[b]{2}{*}{ I-95 On-ramp at } & \multirow[b]{2}{*}{$\begin{array}{c}\text { Locally } \\
\text { Justified } \\
\text { Ramps }\end{array}$} & \multicolumn{4}{|c|}{ System Justified Ramps } \\
\hline & & $\begin{array}{c}95^{\text {th }} \\
\text { Percentile } \\
\text { Bottleneck } \\
\text { Capacity }\end{array}$ & $\begin{array}{c}80^{\text {th }} \\
\text { Percentile } \\
\text { Bottleneck } \\
\text { Capacity }\end{array}$ & $\begin{array}{c}50^{\text {th }} \\
\text { Percentile } \\
\text { Bottleneck } \\
\text { Capacity }\end{array}$ & $\begin{array}{c}30^{\text {th }} \\
\text { Percentile } \\
\text { Bottleneck } \\
\text { Capacity }\end{array}$ \\
\hline Oakland Park Blvd & $\checkmark$ & $\checkmark$ & $\checkmark$ & $\checkmark$ & $\checkmark$ \\
\hline Sunrise Blvd & $x$ & $\checkmark$ & $\checkmark$ & $\checkmark$ & $\checkmark$ \\
\hline Broward Blvd & $x$ & $x$ & $x$ & $\checkmark$ & $\checkmark$ \\
\hline Griffin Rd & $\checkmark$ & $\checkmark$ & $\checkmark$ & $\checkmark$ & $\checkmark$ \\
\hline Stirling Rd & $x$ & $\checkmark$ & $\checkmark$ & $\checkmark$ & $\checkmark$ \\
\hline Davie Blvd & $x$ & $x$ & $x$ & $x$ & $x$ \\
\hline Sheridan St & $\checkmark$ & $\checkmark$ & $\checkmark$ & $\checkmark$ & $\checkmark$ \\
\hline Hollywood Blvd & $x$ & $\checkmark$ & $\checkmark$ & $\checkmark$ & $\checkmark$ \\
\hline Pembroke Rd & $x$ & $\checkmark$ & $\checkmark$ & $\checkmark$ & $\checkmark$ \\
\hline Hallandale Beach Blvd & $\checkmark$ & $\checkmark$ & $\checkmark$ & $\checkmark$ & $\checkmark$ \\
\hline
\end{tabular}

The VISSIM results for the average speed for each 15-minute time interval along the freeway mainline is presented in the speed contours for unmetered, locally justified metering and system justified metering scenarios. These contours illustrate the start times of traffic breakdowns, as well as the severity of the speed drops by color-coding. Figure 42 represents the speed contours for the $95^{\text {th }}$ and $80^{\text {th }}$ percentile capacities, and Figure $4-3$ shows the contours for the $50^{\text {th }}$ and $30^{\text {th }}$ percentile capacities of the bottlenecks.

As can be seen from Figure 4-2, in the case of the $95^{\text {th }}$ percentile capacity, metering ramps based on existing warrants (locally justified ramps) was able to prevent the breakdown, but there was still an experienced speed drop at the bottleneck location. Metering the additional system justified ramps resulted entirely in the prevention of the speed drop at the bottleneck. In the case of the $80^{\text {th }}$ percentile capacity at the bottleneck, Figure 4-2 shows that metering the locally justified ramps postponed the breakdown for 15 
minutes. The metering of the system justified ramps postponed the breakdown by 30 minutes, resulting in a decrease in the spatial extent of the queue.

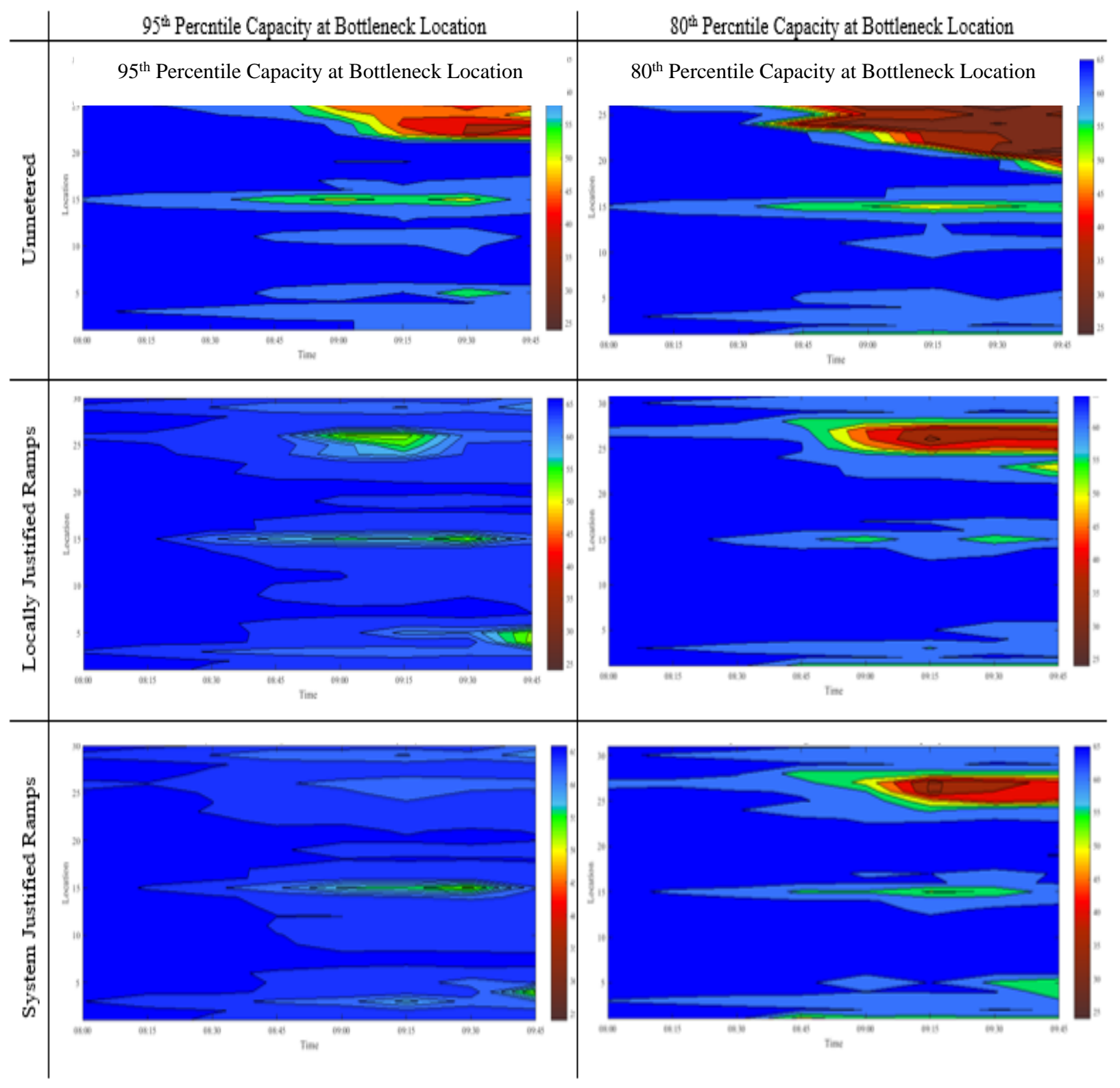

Figure 4-2: Speed Contours for Freeway Mainline $\left(95^{\text {th }}\right.$ and $80^{\text {th }}$ Percentile Capacity at the Bottleneck) 


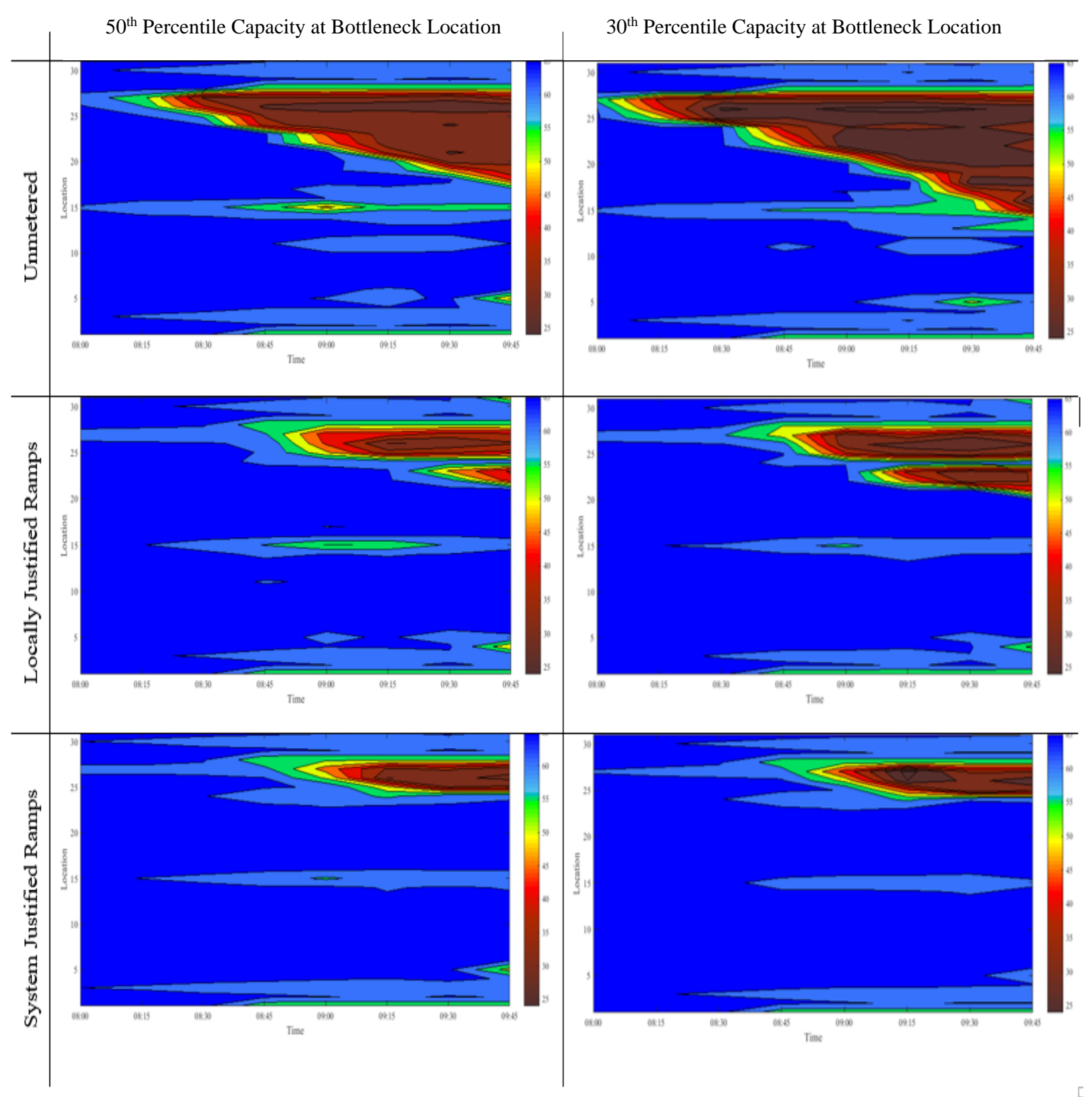

\section{Figure 4-3: Speed Contours for Freeway Mainline $\left(5^{\text {th }}\right.$ and $30^{\text {th }}$ Percentile Capacity at the Bottleneck)}

In the case of the $50^{\text {th }}$ and $30^{\text {th }}$ percentile capacities at the bottleneck shown in

Figure 4-3, the lower capacity resulted in an earlier and more severe breakdown. This makes it difficult to prevent breakdowns with ramp metering, as evaluated in this research. However, in both cases, the locally justified metering could postpone the breakdown at the bottleneck. Nonetheless, the system justified metering could further postpone the 
breakdown and is also able to further limit the physical extent of the breakdown propagation. It should be mentioned that the comparison in this dissertation utilized timeof-day metering to simplify the comparison. The implementation of adaptive metering may be able to prevent the breakdown or at least delay it more than identified in this evaluation, even with the $50^{\text {th }}$ and $30^{\text {th }}$ bottleneck capacities.

Figures 4-4 and 4-5 illustrate the results of the travel time on the freeway mainline and on-ramps, respectively. The mainline travel time is the average value for the travel time along the area, which is most affected by the bottleneck (end of the queue spillback and speed drop area due to the breakdown at the bottleneck).

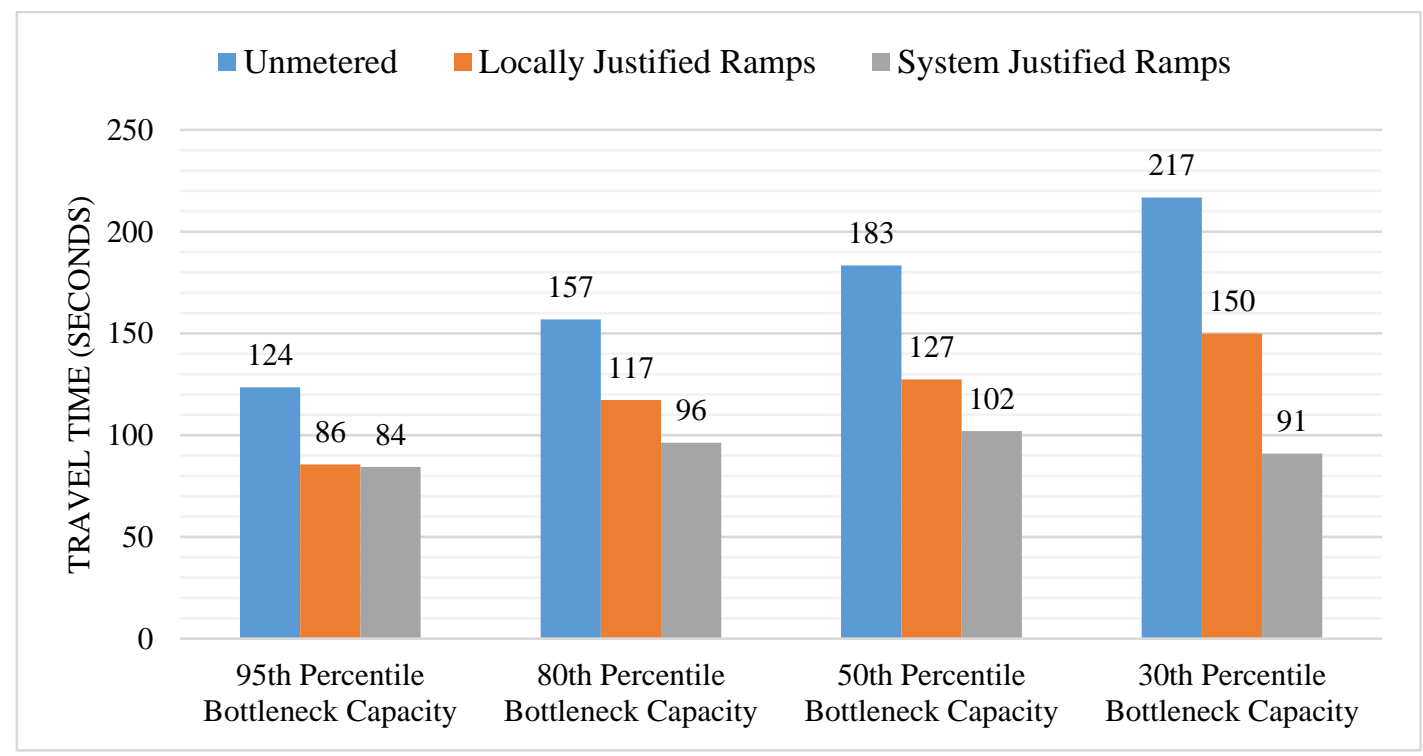

\section{Figure 4-4: Travel Time on the Freeway Mainline with Different Percentiles of Bottleneck Capacity and Metering Scenarios}

As shown in Figure 4-4, the application of ramp metering for locally justified ramps reduced the travel time by an average of $29.4 \%$ compared to the unmetered conditions. Whereas, metering the system justified ramps reduced the travel time by an average of $43.4 \%$, compared to unmetered conditions and $14 \%$ compared to only metering the locally 
justified ramps. Matched paired t-tests were conducted to identify the statistical significance of the diffrence between mainline travel time for the three different scenarios. The results showed that the difference between the unmetered conditions and metering the locally justified ramps is statistically significant (p-value $=0.002<0.05)$ at the $5 \%$ significance level. Also, the difference between metering system justified and metering locally justified ramps is statistically significant ( $\mathrm{p}$-value $=0.044<0.05$ ) at the $5 \%$ significance level.

The average travel time for all on-ramps in the corridor are plotted in Figure 4-5. The figure shows that, a main benefit of the system justified metering is the distribution of the long ramp queues observed when using locally justified metering on the additional system justified ramps. As illustrated in Figure 4-5, metering only locally justified ramps leads to a significant increase in travel time for the four metered ramps in Broward County, Florida (Oakland Park Boulevard, Griffin Road, Sheridan Street and Hallandale Beach Boulevard). In the case of system justified metering, the burden is distributed between more ramps, therefore, the impact on the four aforementioned ramps is significantly decreased. Paired t-tests were conducted to identify the statistical significance of the diffrence between the overall travel times for all of the on-ramps. The results show that application of locally justified ramps increased the overall travel time on the on-ramps compared to the unmeterd conditions by $118 \%$, and this difference is staistically significant ( $\mathrm{p}$-value $=0.006<0.05$ ) at the 5\% significance level. Also, the decrease in the overall travel time on the on-ramps resulting from metering the system justified ramps (29.3\% reduction compared to locally justifed ramps) is statistically significant ( $\mathrm{p}$-value $=0.002<0.05)$ at the $5 \%$ significance level. 

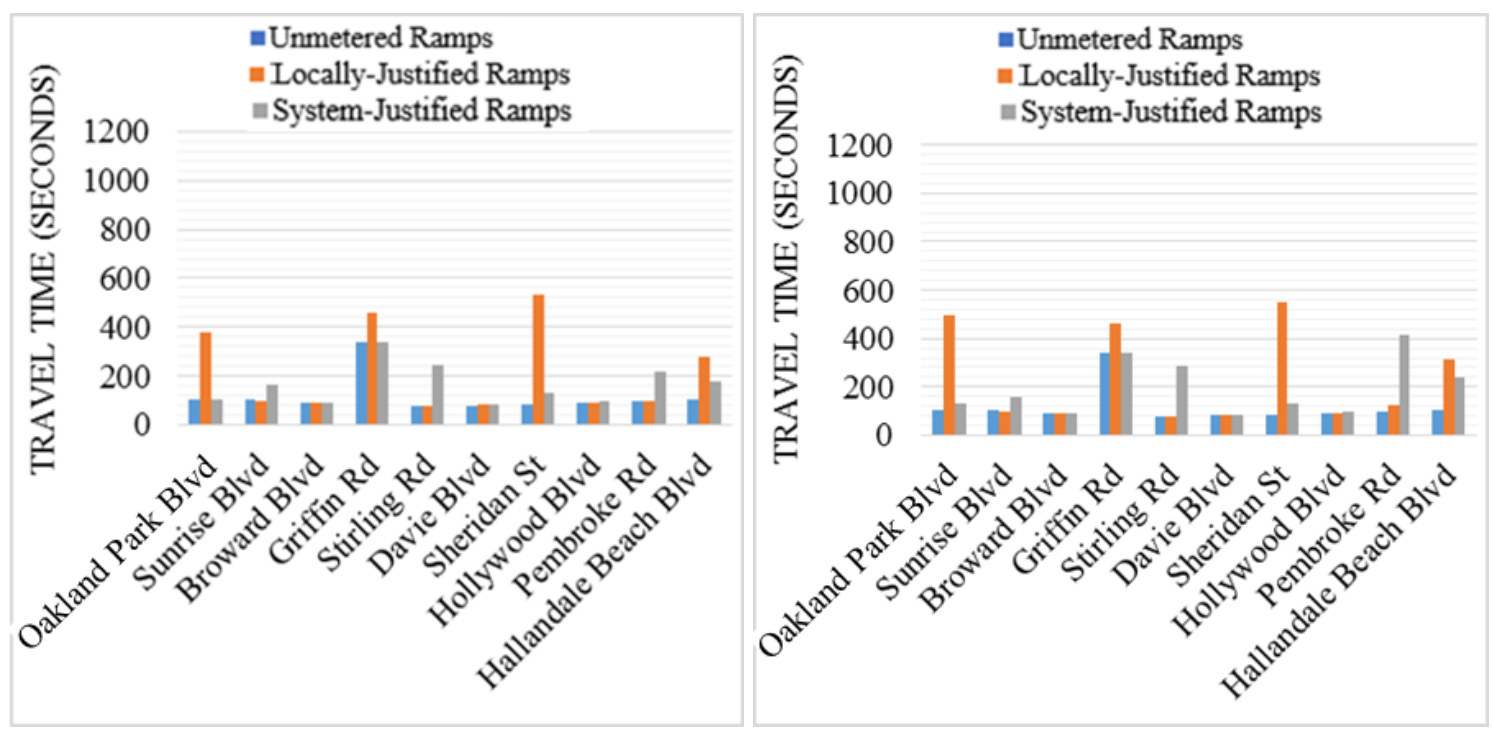

a) $95^{\text {th }}$ Percentile Bottleneck Capacity

b) $80^{\text {th }}$ Percentile Bottleneck Capacity
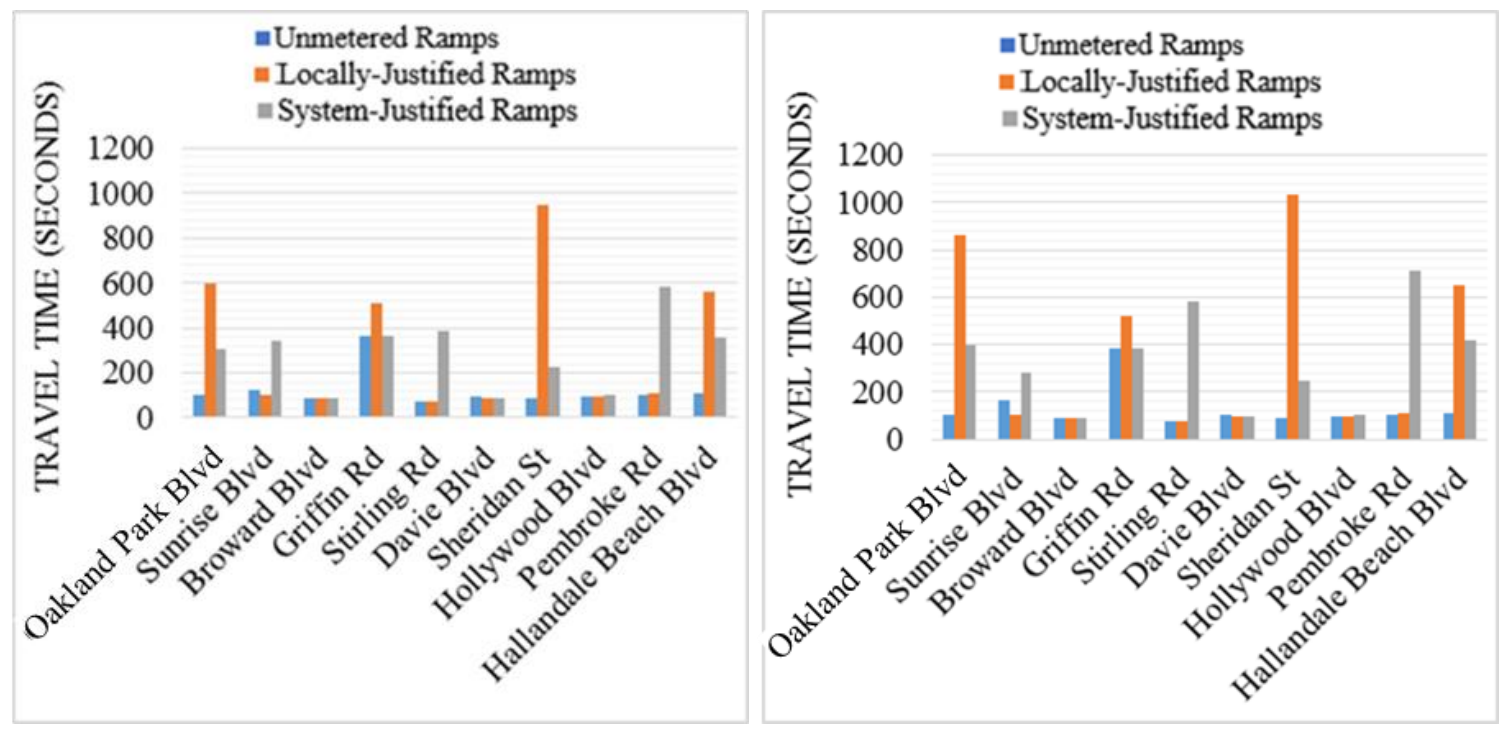

c) $50^{\text {th }}$ Percentile Bottleneck Capacity

d) $30^{\text {th }}$ Percentile bottleneck Capacity

\section{Figure 4-5: Travel Time on the On-ramps}

The difference of the average travel times per vehicle on the freeway mainline and the on-ramps is the delay savings for the system justifed approach compared to the locally justified approach. This value is multiplied by the corresponding volumes to calculate the total delay savings in veh-hr. This involves multiplying the delay savings of the mainline traffic by the mainline traffic volume and the delay savings of each on-ramp by the on- 
ramp flow. The monetary value of the delay savings is calculated by multiplying the delay savings in veh-hr by the value of time, assumed to be $\$ 13.0$ per passenger-hr, and by a passenger occupancy of 1.2 passengers/vehicle based on previous studies in the region. The annual benefit of the system-wide metering in the case study area is calculated assuming three hours of ramp metering for 46 business days in the morning and afternoon (six hours in total). According to the data from the year 2015, 46 of the days experienced recurrent conditions without an incident or rainfall event. The project life is assumed to be seven years, and the interest rate is assumed to be $6 \%$. Table 4-2 includes the parameters for the benefit-cost analysis. The results show that the benefit-cost ratio of the system justified metering compared to the locally justified metering is about 2.06 .

Table 4-2: Delay Savings due to System Justified vs. Locally Justified Ramp Metering and the Associated Benefit-Cost Analysis

\begin{tabular}{|l|l|c|}
\hline \multicolumn{1}{|c|}{ Parameters } & $\begin{array}{c}\text { 50 } \\
\text { Percentile } \\
\text { Capacity }\end{array}$ \\
\hline \multirow{3}{*}{ Benefit } & Total Delay Saving (veh-hr) & 2,572 \\
\cline { 2 - 3 } & Difference in Total Number of the Ramps (Local vs. System) & 5 \\
\hline \multirow{2}{*}{ Cost } & Difference in Capital Cost (\$) & $1,812,000$ \\
\cline { 2 - 3 } & Difference in Maintenance Cost (\$) & 66,240 \\
\hline \multirow{2}{*}{$\begin{array}{l}\text { Interest } \\
\text { Parameters }\end{array}$} & Interest Rate Benefit-Cost Ratio & $6 \%$ \\
\cline { 2 - 3 } & Project Life & 7 years \\
\hline
\end{tabular}

\subsection{Off-Line Ramp Selection for Recurrent and Non-Recurrent Conditions}

The results presented in Section 4.1 confirm the benefit of adding system-based warrants to the existing local warrants. This section presents the results from the application of the proposed methodolgy for the off-line selection of the ramps under recurrent and non-recurrent conditions. 


\subsubsection{Application of Monte Carlo Simulation}

Application of the Monte Carlo simulation requires the capacity and demand distributions for the analysis period. The capacity distribution derived based on the realworld data collected from the case study freeway facility is presented in Figure 4-1. The demand distributions for the morning and afternoon peaks are presented in Figure 4-6 for the main bottleneck location of the case study facility.

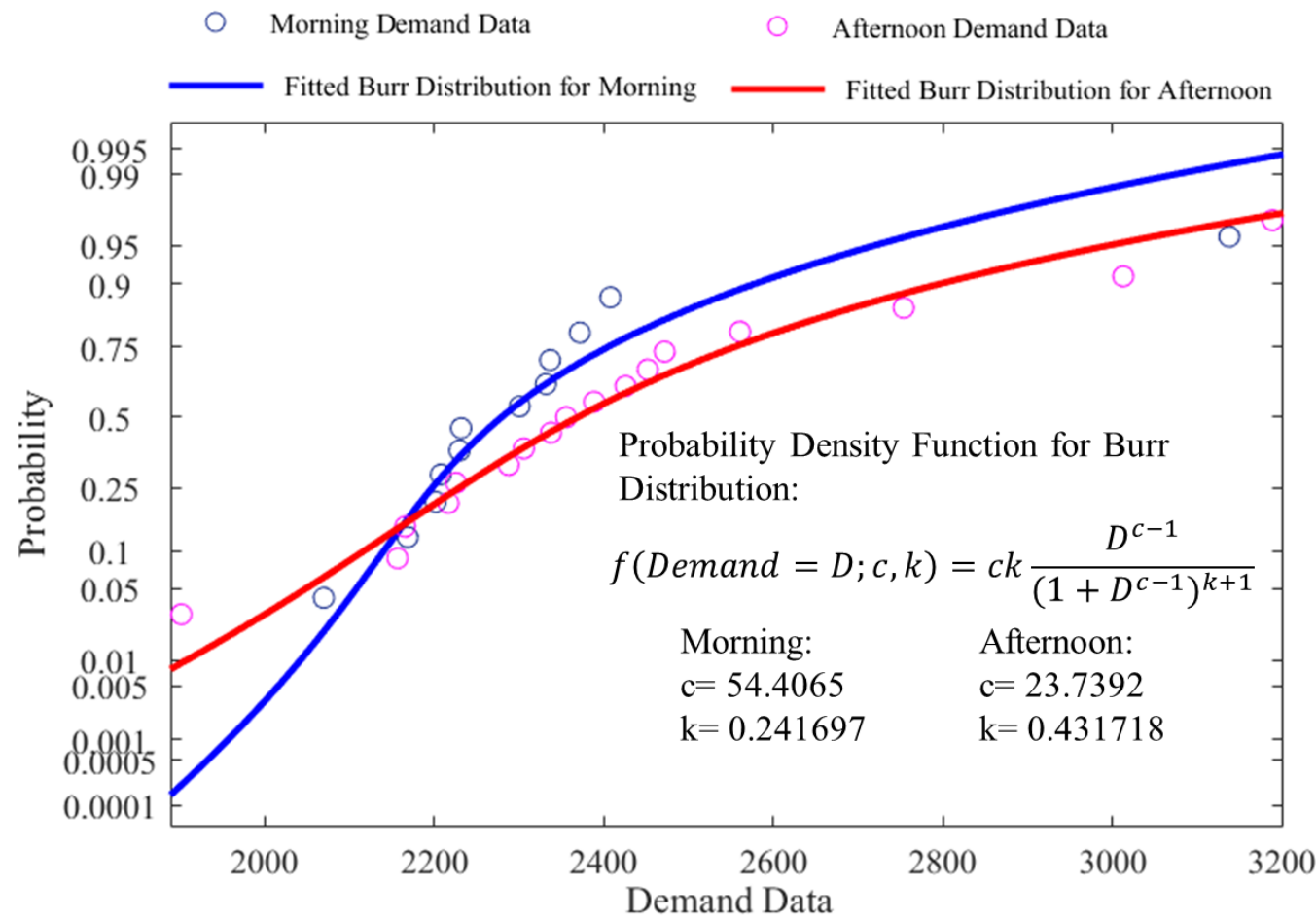

Figure 4-6: Demand Distribution for the Morning and Afternoon Peaks

\subsubsection{Demand to Capacity Ratio Distributions Derived Based on Monte Carlo Results}

A total of 1,000 independent Monte Carlo experiments were conducted which produced different demand and capacity values for the morning and afternoon peak periods. Each of these experiments presents a day with specific demand and capacity. The distribution of the demand/capacity (D/C) ratio was generated based on the experiment results. Figure 4-7 shows the Cumulative Density Functions (CDF) fitted to the D/C values 
for the morning and afternoon peak hours during recurrent conditions. According to these distributions, it is estimated that the median $\mathrm{D} / \mathrm{C}$ ratio is about 0.995 in the morning peak and 1.039 in the afternoon for no incident conditions. The $85^{\text {th }}$ percentile $\mathrm{D} / \mathrm{C}$ ratios are 1.108 and 1.184 for the two peaks, respectively.

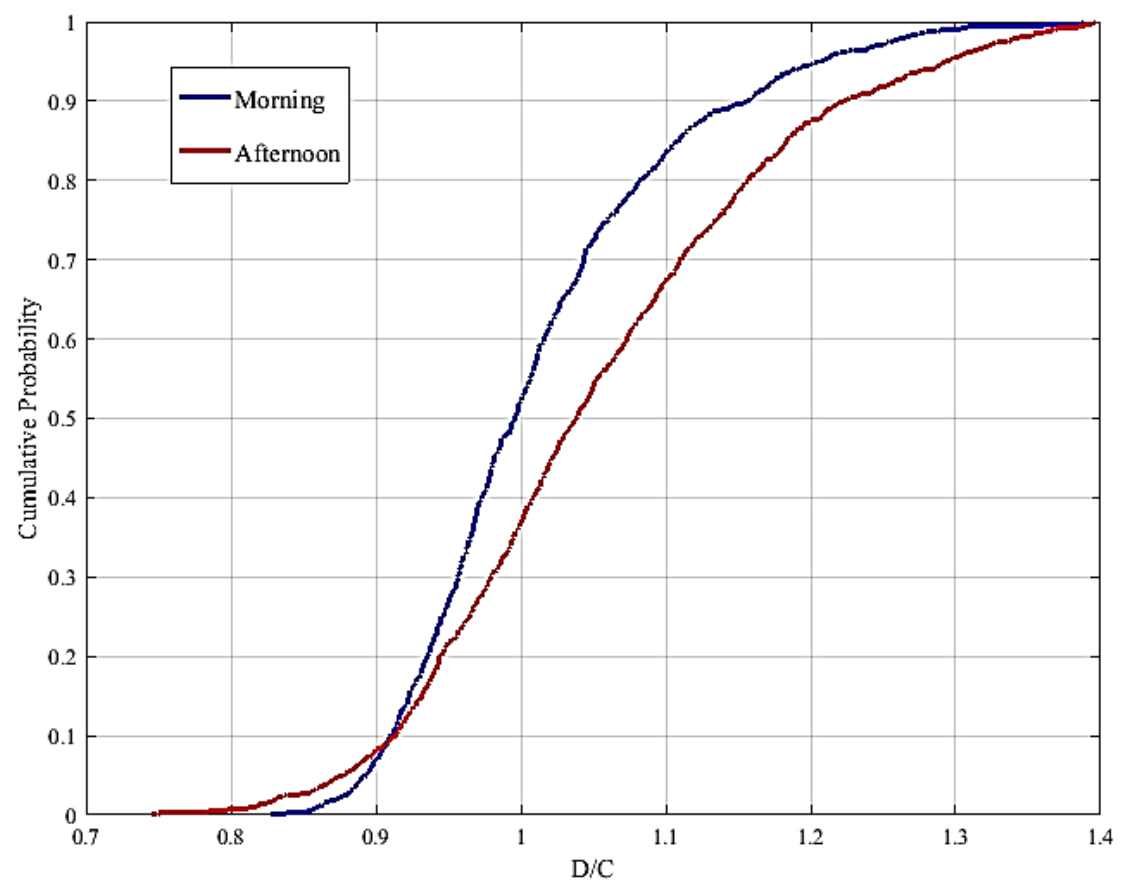

Figure 4-7: Cumulative Probability of the D/C Ratios for the Morning and Afternoon Peaks during Recurrent Conditions

The capacity and demand values for each Monte Carlo experiment are generated from the capacity and demand distributions in Figures 4-1 and 4-6, respectively. As stated earlier, a total of 1,000 independent experiments with different demand and capacity values were generated for the morning and afternoon peaks, and the D/C value was calculated for each experiment. Based on the calculated frequencies, the histograms for the morning and afternoon peaks were obtained, as shown in Figures 4-8 and 4-9, respectively. 


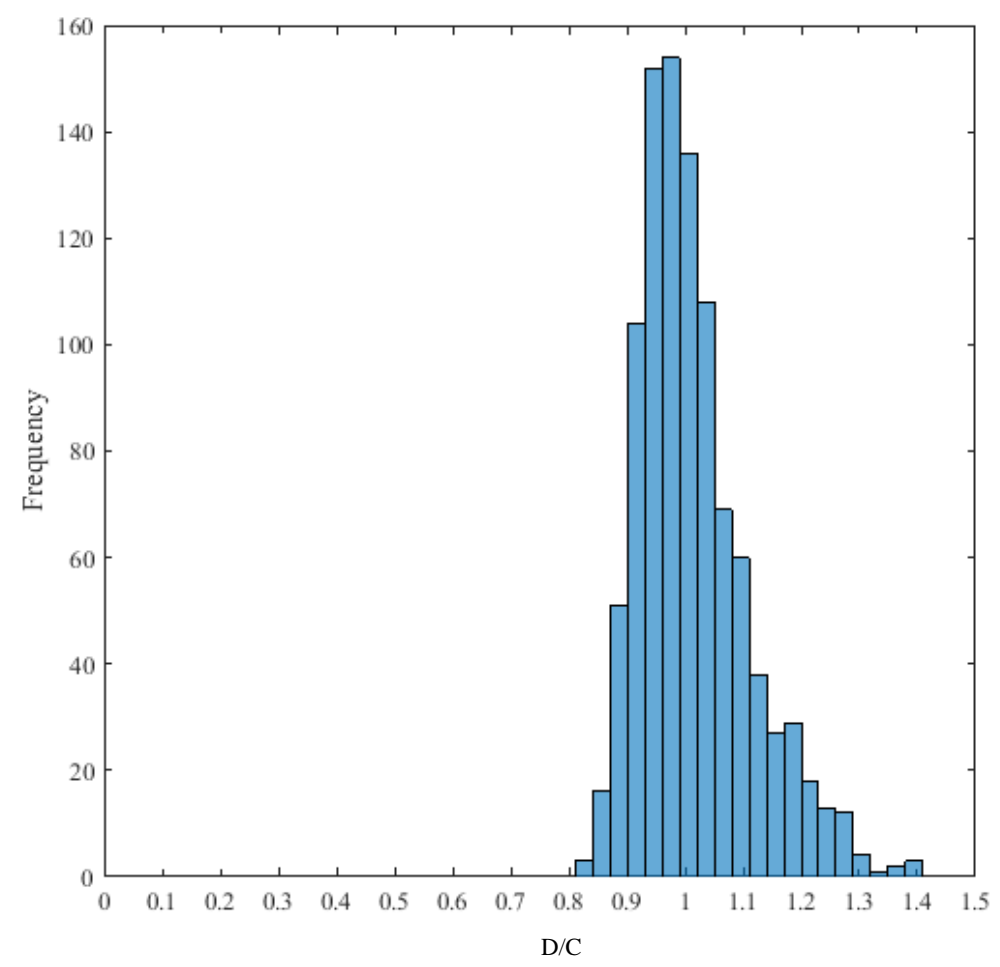

Figure 4-8: Simulated D/C Histogram for the Morning Peak during Recurrent Conditions

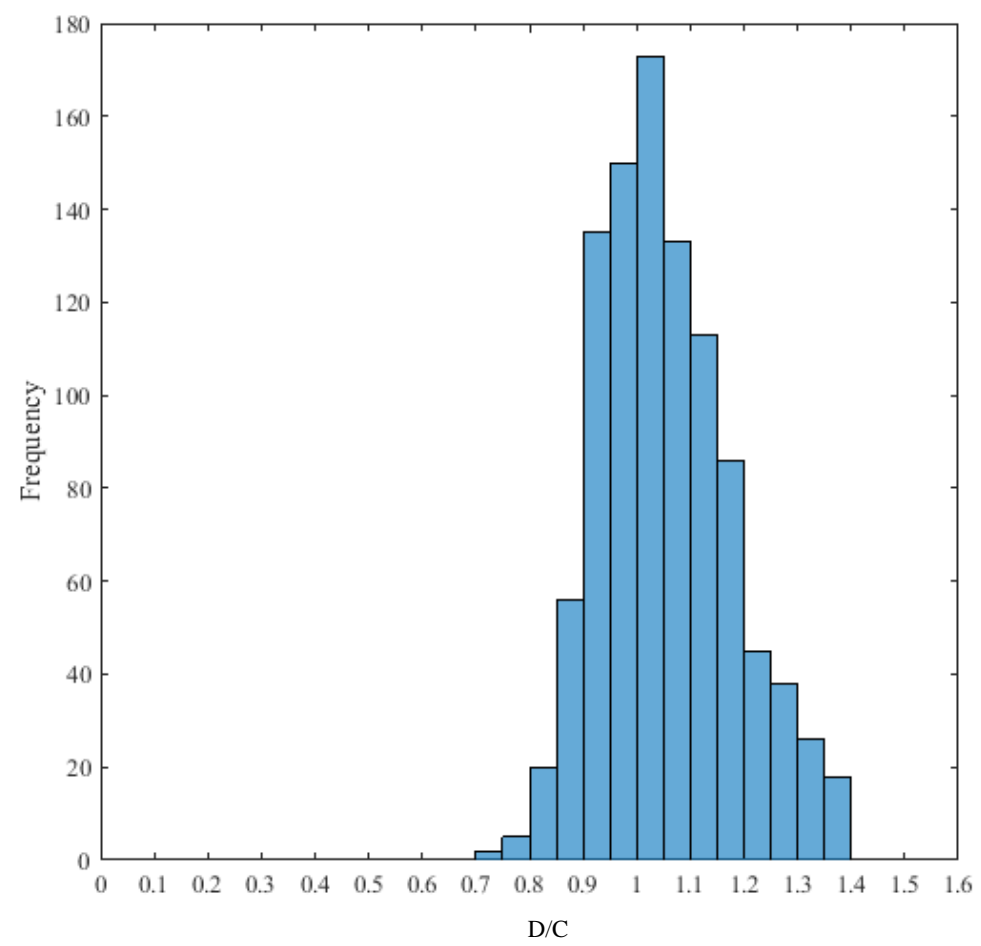

Figure 4-9: Simulated D/C Histogram for the Afternoon Peak during Recurrent Conditions 


\subsubsection{Determining the Number of Ramps to Meter}

The capacity and demand values from the 1,000 experiments (representing days) of the Monte Carlo simulation were used as inputs to the ramp metering selection formulation for the morning and afternoon periods. The outputs from the ramp selection formulation is the number of the ramps to be metered upstream of the bottleneck and the queue lengths on each ramp, which can be calculated as a function of the estimated ramp metering rates. The statistical analysis of the total number of ramps to be metered are presented in Table 4-3 for the morning and afternoon peaks.

Table 4-3: Total Number of Ramps to Meter for Recurrent and Non-Recurrent Conditions

\begin{tabular}{|c|c|c|c|c|c|c|c|c|c|c|c|c|}
\hline \multirow[b]{3}{*}{$\begin{array}{c}\text { Number of } \\
\text { Metered Ramps }\end{array}$} & \multirow{2}{*}{\multicolumn{2}{|c|}{$\begin{array}{l}\text { Recurrent } \\
\text { Condition }\end{array}$}} & \multicolumn{6}{|c|}{ Non-Recurrent (Incident) } & \multicolumn{4}{|c|}{ Non-Recurrent (Rainfall) } \\
\hline & & & \multicolumn{2}{|c|}{$\begin{array}{l}\text { Shoulder } \\
\text { Blocked }\end{array}$} & \multicolumn{2}{|c|}{$\begin{array}{c}\text { 1 Lane } \\
\text { Blocked }\end{array}$} & \multicolumn{2}{|c|}{$\begin{array}{l}2 \text { Lanes } \\
\text { Blocked }\end{array}$} & \multicolumn{2}{|c|}{ Medium Rain } & \multicolumn{2}{|c|}{ Heavy Rain } \\
\hline & $\begin{array}{l}\stackrel{\infty}{\Xi} \\
\stackrel{\Xi}{\Xi} \\
\sum\end{array}$ & 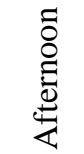 & $\begin{array}{l}\stackrel{\infty}{\circ} \\
\stackrel{\Xi}{\Xi} \\
\stackrel{0}{\Sigma}\end{array}$ & 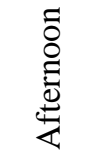 & $\begin{array}{l}\stackrel{\infty}{\doteq} \\
\stackrel{\Xi}{\Xi} \\
\stackrel{0}{\Sigma}\end{array}$ & 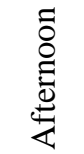 & $\begin{array}{l}\stackrel{\infty}{:} \\
\stackrel{\Xi}{\Xi} \\
\stackrel{0}{\Sigma}\end{array}$ & 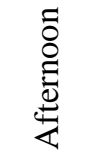 & $\begin{array}{l}\stackrel{\infty}{\Xi} \\
\stackrel{\Xi}{\Xi} \\
\stackrel{0}{\Sigma}\end{array}$ & 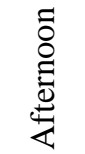 & $\begin{array}{l}\stackrel{\infty}{\Xi} \\
\sum_{\Sigma}^{0}\end{array}$ & 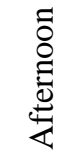 \\
\hline $\mathbf{0}$ & 523 & 370 & 0 & 0 & 0 & 0 & 0 & 0 & 0 & 0 & 0 & 0 \\
\hline 1 & 0 & 0 & 0 & 0 & 0 & 0 & 0 & 0 & 0 & 0 & 0 & 0 \\
\hline 2 & 3 & 15 & 19 & 18 & 0 & 3 & 0 & 0 & 1 & 7 & 0 & 1 \\
\hline 3 & 78 & 40 & 22 & 10 & 1 & 4 & 0 & 0 & 28 & 19 & 0 & 2 \\
\hline 4 & 63 & 50 & 47 & 15 & 1 & 3 & 0 & 0 & 61 & 25 & 0 & 4 \\
\hline 5 & 57 & 25 & 54 & 7 & 4 & 4 & 0 & 0 & 54 & 19 & 4 & 7 \\
\hline 6 & 64 & 85 & 109 & 51 & 7 & 14 & 0 & 0 & 147 & 77 & 23 & 25 \\
\hline 7 & 18 & 24 & 43 & 18 & 17 & 15 & 0 & 0 & 53 & 21 & 11 & 10 \\
\hline 8 & 30 & 18 & 98 & 12 & 26 & 7 & 0 & 0 & 71 & 18 & 30 & 12 \\
\hline 9 & 35 & 74 & 68 & 33 & 46 & 33 & 0 & 0 & 96 & 90 & 54 & 33 \\
\hline 10 & 129 & 299 & 540 & 827 & 898 & 908 & 1000 & 1000 & 437 & 647 & 878 & 895 \\
\hline Total & 1000 & 1000 & 1000 & 1000 & 1000 & 1000 & 1000 & 1000 & 948 & 924 & 1000 & 989 \\
\hline
\end{tabular}

As shown in Table 4-3, the results from the simulation indicate that 129 of the 1,000 experiments with no incidents or weather events require the metering of all 10 ramps between Hallandale Boulevard and Commercial Boulevard in the morning peak, and 299 of the 1,000 days require metering all ramps in the afternoon peak. About half of the days 
in the morning peak and two third of the days in the afternoon peak require two or more ramps to meter.

The ramp metering selection procedure was applied for incident and weather events at the bottleneck location; the results are presented in Table 4-3. The results are based on the ramp selection formulation for incidents occurring at Commercial Boulevard in the northbound direction in the morning and afternoon peaks, in terms of the total number of ramps that need to be metered in 1,000 scenarios for each incident lane blockage type. It should be mentioned that a one-hour incident duration is assumed in this analysis. To address rainfall conditions, the two scenarios of the medium and heavy rains are considered. The results show that with lane blockage incidents and heavy rain during the peak hours, all ten ramps will have to be activated in most cases.

\subsubsection{Estimation of Ramp Queue Lengths}

For a specific on-ramp, the maximum queue length on the on-ramp is calculated as the difference between the calculated metering rate and the demand. The average queue length is half of this value, according to queuing theory equations. This value is converted to feet, assuming that each queued vehicle and the associated distance headway occupies 25 feet and considering the number of lanes available for storage on the on-ramp. Table 44 shows the average queue length (in feet) of each on-ramp in the morning and afternoon peaks for the recurrent and non-recurrent conditions. The queue length results are shown for the $50^{\text {th }}$ and $85^{\text {th }}$ percentiles of the D/C ratios from the Monte-Carlo simulation. The analyst can examine the queue length results, and if the queue length of specific ramps 
needs to be decreased, the analyst can increase the constraint on the queue lengths of these specific ramps in the formulation presented in Equation 3-5.

\section{Table 4-4: Cumulative Probability of Average Queue Length (Feet) for Recurrent and Non-Recurrent Conditions}

\begin{tabular}{|c|c|c|c|c|c|c|c|c|c|c|c|c|}
\hline Conditions & 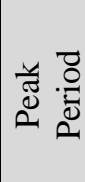 & 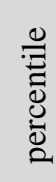 & $\begin{array}{l}\vec{E} \\
\frac{\pi}{\pi} \\
\text { J }\end{array}$ & 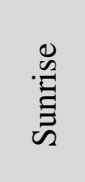 & 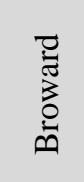 & 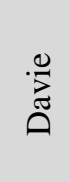 & $\stackrel{\Xi}{\Xi}$ & $\stackrel{\infty}{:}$ & $\begin{array}{l}\frac{\pi}{0} \\
\frac{\pi}{D} \\
\frac{E}{n}\end{array}$ & 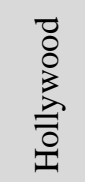 & $\begin{array}{l}\text { v } \\
\text { o } \\
\text { है } \\
\text { D. }\end{array}$ & 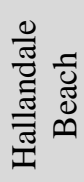 \\
\hline \multirow{4}{*}{ Recurrent Condition } & \multirow{2}{*}{ AM } & 50 & 150 & 0 & 0 & 0 & 0 & 375 & 0 & 0 & 0 & 0 \\
\hline & & 85 & 1037 & 700 & 475 & 262 & 0 & 850 & 1600 & 1150 & 1350 & 1312 \\
\hline & \multirow{2}{*}{ PM } & 50 & 487 & 0 & 0 & 0 & 0 & 850 & 875 & 825 & 775 & 0 \\
\hline & & 85 & 975 & 1075 & 1162 & 687 & 1037 & 1137 & 1212 & 1137 & 1100 & 1512 \\
\hline \multirow{4}{*}{$\begin{array}{l}\text { Medium } \\
\text { Rain }\end{array}$} & \multirow{2}{*}{ AM } & 50 & 812 & 562 & 762 & 650 & 0 & 765 & 1437 & 1037 & 1237 & 1212 \\
\hline & & 85 & 1125 & 775 & 1062 & 900 & 887 & 862 & 1625 & 1175 & 1400 & 1375 \\
\hline & \multirow{2}{*}{ PM } & 50 & 850 & 937 & 1012 & 600 & 900 & 1000 & 1037 & 1000 & 962 & 1312 \\
\hline & & 85 & 987 & 1100 & 1187 & 700 & 1050 & 1162 & 1200 & 1162 & 1112 & 1517 \\
\hline \multirow{4}{*}{$\begin{array}{l}\text { Heavy } \\
\text { Rain }\end{array}$} & \multirow{2}{*}{ AM } & 50 & 912 & 637 & 862 & 734 & 725 & 787 & 1487 & 1075 & 1287 & 1326 \\
\hline & & 85 & 1150 & 787 & 1087 & 925 & 900 & 887 & 1662 & 1187 & 1425 & 1400 \\
\hline & \multirow{2}{*}{ PM } & 50 & 862 & 962 & 1037 & 612 & 925 & 1012 & 1062 & 1012 & 987 & 1350 \\
\hline & & 85 & 1000 & 1112 & 1200 & 712 & 1075 & 1175 & 1225 & 1175 & 1337 & 1550 \\
\hline \multirow{4}{*}{$\begin{array}{l}\text { Shoulder Blocked } \\
\text { Incident }\end{array}$} & \multirow{2}{*}{ A } & 50 & 650 & 450 & 615 & 525 & 512 & 500 & 950 & 675 & 812 & 800 \\
\hline & & 85 & 712 & 487 & 662 & 562 & 550 & 537 & 1025 & 737 & 875 & 862 \\
\hline & \multirow{2}{*}{ PM } & 50 & 475 & 525 & 562 & 337 & 500 & 550 & 575 & 550 & 537 & 737 \\
\hline & & 85 & 537 & 600 & 650 & 387 & 587 & 637 & 662 & 637 & 612 & 850 \\
\hline \multirow{4}{*}{$\begin{array}{c}\text { One Lane Blocked } \\
\text { Incident }\end{array}$} & \multirow{2}{*}{ AM } & 50 & 750 & 525 & 712 & 600 & 600 & 587 & 1100 & 787 & 937 & 925 \\
\hline & & 85 & 812 & 562 & 775 & 650 & 637 & 625 & 1187 & 850 & 1025 & 1000 \\
\hline & \multirow{2}{*}{ PM } & 50 & 750 & 525 & 712 & 600 & 600 & 587 & 1100 & 787 & 937 & 925 \\
\hline & & 85 & 675 & 762 & 825 & 487 & 725 & 800 & 850 & 812 & 775 & 1075 \\
\hline \multirow{4}{*}{$\begin{array}{l}\text { Two Lanes Blocked } \\
\text { Incident }\end{array}$} & \multirow{2}{*}{ AM } & 50 & 987 & 687 & 937 & 800 & 787 & 775 & 1462 & 1050 & 1250 & 1237 \\
\hline & & 85 & 1150 & 787 & 1075 & 925 & 900 & 887 & 1662 & 1187 & 1425 & 1400 \\
\hline & \multirow{2}{*}{ PM } & 50 & 862 & 950 & 1037 & 612 & 912 & 1000 & 1050 & 1012 & 945 & 1337 \\
\hline & & 85 & 962 & 1062 & 1150 & 687 & 1025 & 1125 & 1187 & 1125 & 1087 & 1500 \\
\hline
\end{tabular}

\subsubsection{Benefit-Cost Analysis of Ramp Metering Deployment}

The utilized methodology described in Chapter 3 can be used to conduct benefitcost analysis of the ramp metering deployment and associated decisions, such as which ramps to meter and when to activate. A summary of calculated delay savings of ramp metering is presented in Table 4-5 for recurrent and non-recurrent conditions calculated using the queuing theory equations presented in Chapter 3. As aforementioned, the delays 
are calculated for the two peak periods. The duration of the rainfall is assumed to be one hour, and the duration of the incident to be 40 minutes for shoulder incidents and 50 minutes for lane-blockage incidents. Table 4-5 indicates that ramp metering can provide significant benefits in terms of mobility and reliability, as indicated by the $50 \%$ and $85 \%$ delay savings. During recurrent conditions, the median delays decreased by 859 veh-hrs (about 7.8 minutes/veh) and 1,174 veh-hrs (about 10.3 minute/vehicles) during the AM and PM peak hours, respectively. The delay savings are even more during shoulder and onelane blockage incidents and rain events that occur during the peak hours, as shown in Table 4-5. In the case of two-lane blockage incidents, ramp metering is not capable of preventing the breakdown; therefore, the queue forms on the mainline and reduces the delay savings.

The following discussion illustrates the use of the delay savings results in the benefit-cost analysis of the ramp metering deployment. The monetary value of the delay savings is calculated by multiplying the median delay savings in veh-hr by the value of time assumed to be $\$ 13.0$ per passenger-hr and passenger occupancy of 1.2 passengers/vehicle based on previous studies in the region. The annual benefit of the system-wide metering in the case study area is calculated assuming $48 \%$ and $63 \%$ of the days with no events have recurrent congestion in the morning and afternoon peaks, respectively, as obtained from the Monte Carlo analysis discussed earlier. It was assumed that $12 \%$ and $5 \%$ of the weekdays had additional delays due to incident and rain events, respectively. The project life is assumed to be seven years, and the interest rate is assumed to be $6 \%$. Table 4-5 includes the parameters for the benefit-cost analysis. The results show that benefit-cost ratio of the analysis is about 9.4 . 
Table 4-5: Delay Savings due to Ramp Metering with Recurrent and Non-Recurrent Conditions and the Associated Benefit-Cost Analysis

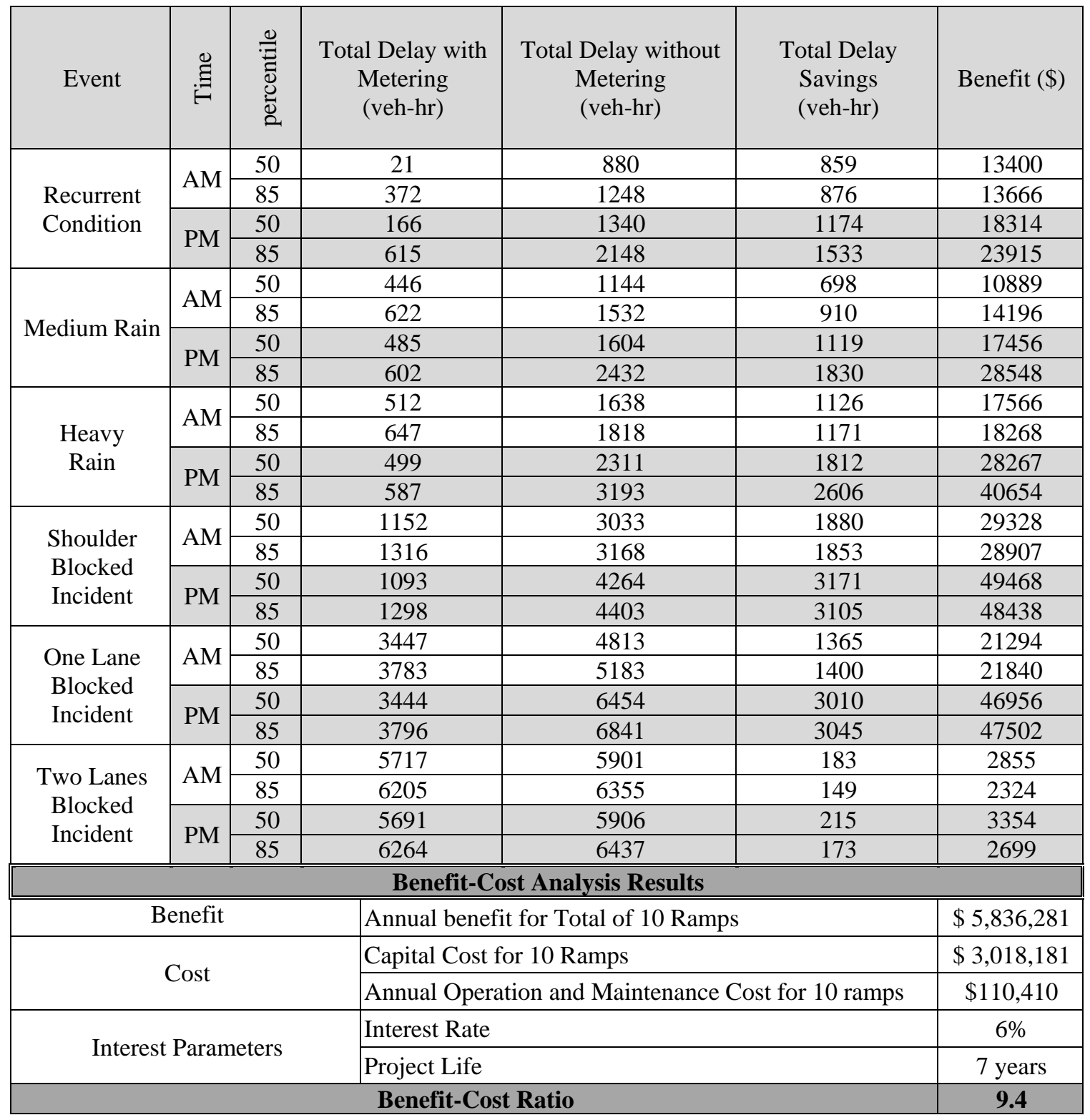

\subsection{Real-Time Ramp Selection for Application}

The historical demand distributions for the morning and afternoon peak periods are illustrated in Figures 4-10 and 4-11, respectively. The demand values are presented for different percentiles for each 15-minute interval. 


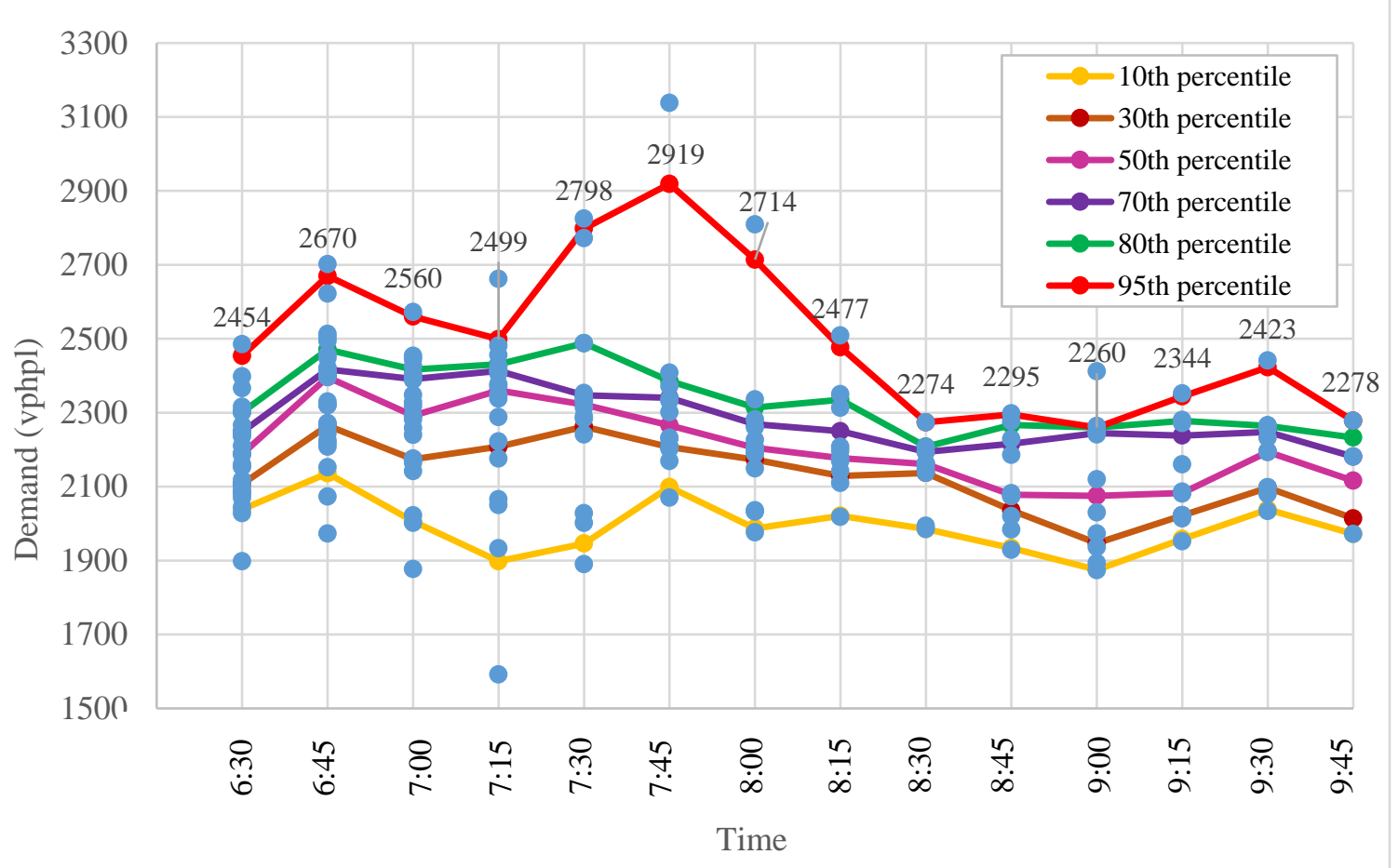

Figure 4-10: Historical Demand Distribution for the Morning Peak Period

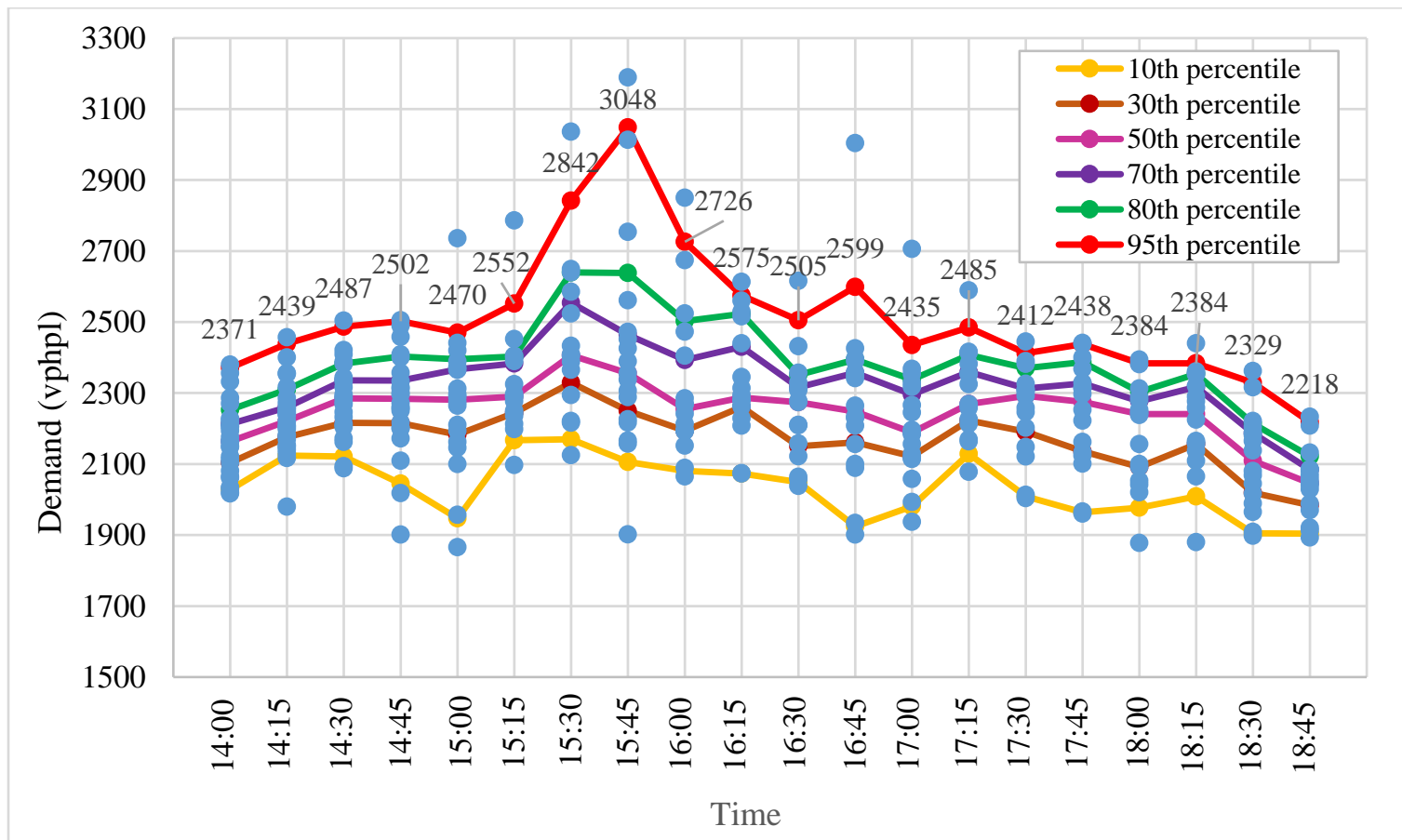

Figure 4-11: Historical Demand Distribution for the Afternoon Peak Period 
These distributions were used to derive the factors used as part of a simple prediction of the next 15-minute demands. As discussed in Section 3.4.4, the factors are derived based on the $80^{\text {th }}$ percentile demands and used as the basis for the next 15 -minute demand prediction in this research.

Using the historical demand distributions, three methods for the selection of the ramps for real-ime application are applied to randomly selected days with different conditions. For each condition (recurrent and non-recurrent), two random days were selected from the year 2015, and real-world data for these days were used to apply the aforementioned methods. The probability of breakdown method is only applicable to the recurrent conditions and event-free days. Using the capacity distribution illustrated in Figure 4-1, the probability of breakdown of $20 \%$ or more corresponds to the flow of 2,203 vphpl and more. Therefore, the breakdown method corresponds to the method developed in this dissertation when the activation is conducted based on predicting demands higher than this value. However, the breakdown method does not allow determining the number of ramps, which are required to be metered, in order to prevent the breakdown.

In order to extend the proposed methodology for real-time activation, the $20^{\text {th }}$ percentile capacity is used as the capacity value in order to be comparable to the probability of the breakdown method. Table 4-6 shows the look-up table derived from the analysis of the results of the off-line selection of ramps to meter for different $\mathrm{D} / \mathrm{C}$ ratios. This table provides a correspondance between each $\mathrm{D} / \mathrm{C}$ ratio for each condition (recurrent, incident with different lane blockages, and rainfalls with different rain intensities) to the $50^{\text {th }}$ and $80^{\text {th }}$ percentiles of the total number of ramps to meter. The $\mathrm{D} / \mathrm{C}$ values for the non-recurrent 
conditions are the values before the event occurrence. For instance, if the predicted D/C value for the next 15 -minute time interval is 0.93 according to recurrent conditions, none of the ramps would be required for the metering. However, once a shoulder incident is reported with the same predicted $\mathrm{D} / \mathrm{C}$ value (0.93), seven to ten ramps are required to be metered, depending on the peak period and, an agency's willingness to take risks (e.g., the $80 \%$ percentile eliminates breakdown for $80 \%$ of the cases for the specific scenario under consideration).

Table 4-6: Look-Up Table for Real-Time Activation of the Ramps

\begin{tabular}{|c|c|c|c|c|c|c|c|}
\hline \multirow{2}{*}{ Condition } & \multirow{2}{*}{ Time } & \multirow{2}{*}{ Percentile } & \multicolumn{5}{|c|}{ D/C Values } \\
\hline & & & $<0.8$ & $0.8-0.9$ & $0.9-1.0$ & $1.0-1.1$ & $>1.1$ \\
\hline \multirow{4}{*}{$\begin{array}{l}\text { Recurrent } \\
\text { Condition }\end{array}$} & \multirow{2}{*}{$\mathrm{AM}$} & 50 & 0 & 0 & 0 & 5 & 10 \\
\hline & & 80 & 0 & 0 & 0 & 7 & 10 \\
\hline & \multirow{2}{*}{ PM } & 50 & 0 & 0 & 0 & 5 & 10 \\
\hline & & 80 & 0 & 0 & 0 & 7 & 10 \\
\hline \multirow{4}{*}{$\begin{array}{l}\text { Medium } \\
\text { Rain }\end{array}$} & \multirow{2}{*}{$\mathrm{AM}$} & 50 & 0 & 2 & 7 & 10 & 10 \\
\hline & & 80 & 0 & 2 & 9 & 10 & 10 \\
\hline & \multirow{2}{*}{ PM } & 50 & 0 & 2 & 7 & 10 & 10 \\
\hline & & 80 & 0 & 2 & 10 & 10 & 10 \\
\hline \multirow{4}{*}{$\begin{array}{l}\text { Heavy } \\
\text { Rain }\end{array}$} & \multirow{2}{*}{$\mathrm{AM}$} & 50 & 6 & 8 & 10 & 10 & 10 \\
\hline & & 80 & 8 & 9 & 10 & 10 & 10 \\
\hline & \multirow{2}{*}{ PM } & 50 & 6 & 8 & 10 & 10 & 10 \\
\hline & & 80 & 8 & 9 & 10 & 10 & 10 \\
\hline \multirow{4}{*}{$\begin{array}{l}\text { Shoulder Blocked } \\
\text { Incident }\end{array}$} & \multirow{2}{*}{$\mathrm{AM}$} & 50 & 0 & 2 & 7 & 10 & 10 \\
\hline & & 80 & 0 & 3 & 9 & 10 & 10 \\
\hline & \multirow{2}{*}{ PM } & 50 & 0 & 2 & 8 & 10 & 10 \\
\hline & & 80 & 0 & 3 & 10 & 10 & 10 \\
\hline \multirow{4}{*}{$\begin{array}{l}\text { One Lane Blocked } \\
\text { Incident }\end{array}$} & \multirow{2}{*}{$\mathrm{AM}$} & 50 & 9 & 10 & 10 & 10 & 10 \\
\hline & & 80 & 10 & 10 & 10 & 10 & 10 \\
\hline & \multirow{2}{*}{ PM } & 50 & 6 & 10 & 10 & 10 & 10 \\
\hline & & 80 & 8 & 10 & 10 & 10 & 10 \\
\hline \multirow{3}{*}{$\begin{array}{c}\text { Two Lanes Blocked } \\
\text { Incident }\end{array}$} & \multirow{2}{*}{$\mathrm{AM}$} & 50 & 10 & 10 & 10 & 10 & 10 \\
\hline & & 80 & 10 & 10 & 10 & 10 & 10 \\
\hline & PM & 50 & 10 & 10 & 10 & 10 & 10 \\
\hline
\end{tabular}

Tables 4-7 and 4-8 present the results for the real-time selection of the ramps to meter for the morning and afternoon periods, respectively, for the days selected as case studies. The shaded cells represent the intervals with an event. For instance, in Table 4-7, 
the medium rain for Day 1 occurred from 7:30 AM to 8:15 AM. In Tables 4-7 and 4-8, the "P(B)" represents the Probability of Breakdown method, and the " 50 th Percentile" and " $80^{\text {th }}$

Percentile" refer to the look-up table method with these two percentiles, as shown in Table 4-6. "Programming" refers to the extension of methodology of the off-line selection of ramps to meter (proposed in this research) to real-time activation.

Table 4-7: Real-Time Activation Results for the Morning

\begin{tabular}{|c|c|c|c|c|c|c|c|c|c|c|c|c|c|c|c|c|}
\hline Condition & & $\begin{array}{c}\text { Ramp Selection } \\
\text { Method }\end{array}$ & ஜே & $\stackrel{10}{\ddot{\theta}}$ & $\stackrel{8}{\stackrel{\circ}{\sim}}$ & $\frac{n}{\ddot{n}}$ & $\stackrel{?}{\check{n}}$ & $\stackrel{n}{\stackrel{*}{*}}$ & 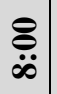 & $\frac{n}{\ddot{\infty}}$ & $\stackrel{?}{\ddot{\infty}}$ & $\begin{array}{c}10 \\
\ddot{+} \\
\ddot{\infty}\end{array}$ & ஜ̣̊. & $\frac{n}{\ddot{a}}$ & ஜே. & $\stackrel{\mathscr{n}}{\ddot{n}}$ \\
\hline \multirow{8}{*}{$\begin{array}{l}\text { Recurrent } \\
\text { Condition }\end{array}$} & \multirow{4}{*}{ Day 1} & $\mathrm{P}(\mathrm{B})$ & $\checkmark$ & $\checkmark$ & $\checkmark$ & $\checkmark$ & $\checkmark$ & $\checkmark$ & $\checkmark$ & $\checkmark$ & 0 & 0 & 0 & 0 & 0 & 0 \\
\hline & & $50^{\text {th }}$ Percentile & 5 & 5 & 5 & 5 & 5 & 5 & 5 & 5 & 0 & 0 & 0 & 0 & 0 & 0 \\
\hline & & $80^{\text {th }}$ Percentile & 7 & 7 & 7 & 7 & 7 & 7 & 7 & 7 & 0 & 0 & 0 & 0 & 0 & 0 \\
\hline & & Programming & 3 & 9 & 8 & 8 & 9 & 6 & 4 & 5 & 0 & 1 & 1 & 2 & 1 & 0 \\
\hline & \multirow{4}{*}{ Day2 } & $\mathrm{P}(\mathrm{B})$ & 0 & $\checkmark$ & $\checkmark$ & $\checkmark$ & $\checkmark$ & 0 & 0 & 0 & 0 & 0 & 0 & 0 & 0 & 0 \\
\hline & & $50^{\text {th }}$ Percentile & 0 & 5 & 5 & 5 & 5 & 0 & 0 & 0 & 0 & 0 & 0 & 0 & 0 & 0 \\
\hline & & $80^{\text {th }}$ Percentile & 0 & 7 & 7 & 7 & 7 & 0 & 0 & 0 & 0 & 0 & 0 & 0 & 0 & 0 \\
\hline & & Programming & 0 & 4 & 2 & 2 & 5 & 0 & 0 & 0 & 0 & 0 & 0 & 0 & 0 & 0 \\
\hline \multirow{6}{*}{$\begin{array}{l}\text { Medium } \\
\text { Rain }\end{array}$} & \multirow{3}{*}{ Day 1} & $50^{\text {th }}$ Percentile & 0 & 0 & 0 & 0 & 10 & 7 & 7 & 7 & 0 & \begin{tabular}{|l|l|}
0 \\
\end{tabular} & 0 & 0 & 0 & 0 \\
\hline & & $80^{\text {th }}$ Percentile & 0 & 0 & 0 & 0 & 10 & 9 & 9 & 9 & 0 & 0 & 0 & 0 & 0 & 0 \\
\hline & & Programming & 0 & 0 & 0 & 0 & 10 & 8 & 5 & 5 & 0 & 0 & 0 & 0 & 0 & 0 \\
\hline & \multirow{3}{*}{ Day2 } & $50^{\text {th }}$ Percentile & 0 & 5 & 7 & 7 & 10 & 7 & 7 & 0 & 0 & 0 & 0 & 0 & 0 & 0 \\
\hline & & $80^{\text {th }}$ Percentile & & 7 & 9 & 9 & 10 & 9 & 9 & 0 & 0 & 0 & 0 & 0 & 0 & 0 \\
\hline & & Programming & 0 & 2 & 9 & 9 & 10 & 8 & 5 & 0 & 0 & 0 & 0 & 0 & 0 & 0 \\
\hline \multirow{6}{*}{$\begin{array}{l}\text { Heavy } \\
\text { Rain }\end{array}$} & \multirow{3}{*}{ Day 1} & $50^{\text {th }}$ Percentile & 0 & 0 & 0 & 10 & 10 & 10 & 10 & 10 & 8 & 10 & 0 & 0 & 0 & 0 \\
\hline & & $80^{\text {th }}$ Percentile & 0 & 0 & 0 & 10 & 10 & 10 & 10 & 10 & 9 & 10 & 0 & 0 & 0 & 0 \\
\hline & & Programming & 0 & 0 & 0 & 10 & 10 & 10 & 10 & 10 & 7 & 9 & 0 & 0 & 0 & 0 \\
\hline & \multirow{3}{*}{ Day2 } & $50^{\text {th }}$ Percentile & 0 & 5 & 0 & 0 & 5 & 0 & 0 & 10 & 8 & 10 & 11 & 0 & 0 & 0 \\
\hline & & $80^{\text {th }}$ Percentile & 0 & 7 & 0 & 0 & 7 & 0 & 0 & 10 & 9 & 10 & 10 & 0 & 0 & 0 \\
\hline & & Programming & 0 & 1 & 0 & 0 & 2 & 0 & 0 & 10 & 8 & 9 & 9 & 0 & 0 & 0 \\
\hline \multirow{6}{*}{$\begin{array}{l}\text { Shoulder Blocked } \\
\text { Incident }\end{array}$} & \multirow{3}{*}{ Day 1} & $50^{\text {th }}$ Percentile & 0 & 0 & 0 & 7 & 7 & 2 & 2 & 0 & 0 & 0 & 0 & 0 & 0 & 0 \\
\hline & & $80^{\text {th }}$ Percentile & 0 & 0 & 0 & 9 & 9 & 3 & 3 & 0 & 0 & 0 & 0 & 0 & 0 & 0 \\
\hline & & Programming & 0 & 0 & 0 & 6 & 8 & 4 & 1 & 0 & 0 & 0 & 0 & 0 & 0 & 0 \\
\hline & \multirow{3}{*}{ Day2 } & $50^{\text {th }}$ Percentile & 0 & 0 & 0 & 7 & 10 & 7 & 0 & 0 & 0 & 0 & 0 & 0 & 0 & 0 \\
\hline & & $80^{\text {th }}$ Percentile & 0 & 0 & 0 & 9 & 10 & 9 & 0 & 0 & 0 & 0 & 0 & 0 & 0 & 0 \\
\hline & & Programming & 0 & 0 & 0 & 10 & 10 & 9 & 0 & 0 & 0 & 0 & 0 & 0 & 0 & 0 \\
\hline \multirow{6}{*}{$\begin{array}{l}\text { One Lane Blocked } \\
\text { Incident }\end{array}$} & \multirow{3}{*}{ Day 1} & $50^{\text {th }}$ Percentile & 0 & 0 & 0 & 10 & 10 & 10 & 10 & 10 & 10 & 5 & 5 & 0 & 0 & 0 \\
\hline & & $80^{\text {th }}$ Percentile & 0 & 0 & 0 & 10 & 10 & 10 & 10 & 10 & 10 & 7 & 7 & 0 & 0 & 0 \\
\hline & & Programming & 0 & 0 & 0 & 10 & 10 & 10 & 10 & 10 & 10 & 3 & 3 & 0 & 0 & 0 \\
\hline & \multirow{3}{*}{ Day2 } & $50^{\text {th }}$ Percentile & 0 & 0 & 0 & 0 & 0 & 0 & 0 & 0 & 10 & 10 & 10 & 10 & 10 & 10 \\
\hline & & $80^{\text {th }}$ Percentile & 0 & 0 & 0 & 0 & 0 & 0 & 0 & 0 & 10 & 10 & 10 & 10 & 10 & 10 \\
\hline & & Programming & 0 & 0 & 0 & 0 & 0 & 0 & 0 & 0 & 10 & 10 & 10 & 10 & 10 & 10 \\
\hline
\end{tabular}


Table 4-8: Real-Time Activation Results for the Afternoon

\begin{tabular}{|c|c|c|c|c|c|c|c|c|c|c|c|c|c|c|c|c|c|c|c|c|c|c|}
\hline Condi & & $\begin{array}{c}\text { Ramp Selection } \\
\text { Method }\end{array}$ & 華 & \begin{tabular}{|c|}
10 \\
$\ddot{\dot{\Xi}}$ \\
\end{tabular} & 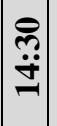 & $\begin{array}{c}10 \\
\stackrel{+}{ \pm} \\
-\end{array}$ & 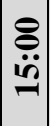 & $\begin{array}{l}n \\
\ddot{\ddot{n}} \\
=\end{array}$ & $\begin{array}{c}e \\
\grave{n} \\
\end{array}$ & \begin{tabular}{c}
$n$ \\
$\ddot{g}$ \\
\hdashline
\end{tabular} & فِ & $\frac{n}{\ddot{\ddot{\theta}}}$ & \begin{tabular}{|c|}
$\stackrel{\oplus}{\bullet}$ \\
$\ddot{=}$
\end{tabular} & : & ְِ & $\frac{n}{\ddot{x}}$ & ֻே. & 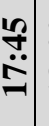 & : & & & 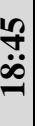 \\
\hline \multirow{8}{*}{$\begin{array}{l}\text { Recurrent } \\
\text { Condition }\end{array}$} & \multirow{4}{*}{ Day 1} & $\mathrm{P}(\mathrm{B})$ & 0 & $\checkmark$ & $\checkmark$ & $\checkmark$ & $\checkmark$ & $\checkmark$ & $\checkmark$ & $\checkmark$ & $\checkmark$ & $\checkmark$ & $\checkmark$ & $\checkmark$ & $\checkmark$ & 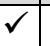 & $\checkmark$ & $\checkmark$ & $\checkmark$ & $\checkmark$ & 0 & 0 \\
\hline & & $50^{\text {th }}$ Percentile & 0 & 5 & \begin{tabular}{|l|}
5 \\
\end{tabular} & 5 & 5 & 5 & 10 & 10 & 10 & 5 & 5 & 5 & 5 & 5 & 5 & 5 & \begin{tabular}{l|l}
5 & 5 \\
\end{tabular} & 5 & \begin{tabular}{l|l}
0 & 0 \\
\end{tabular} & 0 \\
\hline & & $80^{\text {th }}$ Percentile & 0 & 7 & 7 & 7 & 7 & 7 & 10 & 10 & 10 & 7 & 7 & 7 & 7 & 7 & 7 & 7 & \begin{tabular}{l|l}
7 & 7 \\
\end{tabular} & 7 & \begin{tabular}{l|l}
0 & 0 \\
\end{tabular} & 0 \\
\hline & & Programming & 0 & 2 & 5 & 6 & 6 & 6 & 10 & 10 & 9 & 10 & 4 & 5 & 3 & 6 & 5 & 5 & \begin{tabular}{l|l}
2 & 2 \\
2
\end{tabular} & 4 & 0 & 0 \\
\hline & \multirow{4}{*}{ Day 2} & $\mathrm{P}(\mathrm{B})$ & 0 & 0 & $\checkmark$ & $\checkmark$ & $\checkmark$ & $\checkmark$ & $\checkmark$ & $\checkmark$ & $\checkmark$ & $\checkmark$ & 0 & $\checkmark$ & 0 & $\checkmark$ & 0 & 0 & \begin{tabular}{l|l}
0 & ( \\
\end{tabular} & 0 & \begin{tabular}{l|l}
0 & 0 \\
\end{tabular} & 0 \\
\hline & & $50^{\text {th }}$ Percentile & 0 & 0 & \begin{tabular}{|l|l|}
5 \\
\end{tabular} & 5 & 5 & 10 & 10 & 5 & 5 & 5 & 0 & 5 & 0 & 5 & 0 & 0 & \begin{tabular}{l|l}
0 & ( \\
\end{tabular} & \begin{tabular}{l|l}
0 & ( \\
\end{tabular} & \begin{tabular}{l|l}
0 & 0 \\
\end{tabular} & 0 \\
\hline & & $80^{\text {th }}$ Percentile & 0 & 0 & 7 & 7 & 7 & 10 & 10 & 7 & 7 & 7 & 0 & 7 & 0 & 7 & 0 & 0 & \begin{tabular}{l|l}
0 & 0 \\
\end{tabular} & 0 & \begin{tabular}{l|l}
0 & 0 \\
\end{tabular} & 0 \\
\hline & & Program & 0 & 0 & 2 & 2 & 2 & 2 & 10 & 10 & 6 & 7 & 0 & 2 & 0 & 2 & 0 & 0 & \begin{tabular}{l|l}
0 & ( \\
\end{tabular} & 0 & \begin{tabular}{l|l}
0 & 0 \\
\end{tabular} & 0 \\
\hline \multirow{6}{*}{$\begin{array}{l}\text { Medium } \\
\text { Rain }\end{array}$} & \multirow{3}{*}{ Day $1 \mid$} & $50^{\text {th }}$ Perce & 0 & 0 & \begin{tabular}{|l|l|}
0 \\
\end{tabular} & 5 & 5 & 5 & 10 & 10 & 10 & 10 & 7 & 7 & 0 & 0 & 0 & 0 & \begin{tabular}{l|l}
0 & ( \\
\end{tabular} & \begin{tabular}{l|l}
0 & ( \\
\end{tabular} & \begin{tabular}{l|l}
0 & 0 \\
\end{tabular} & 0 \\
\hline & & $80^{\text {th }}$ Percentile & 0 & 0 & 0 & 7 & 7 & 7 & 10 & 10 & 10 & 10 & 10 & 10 & 0 & 0 & 0 & 0 & \begin{tabular}{l|l}
0 & 0 \\
\end{tabular} & 0 & \begin{tabular}{l|l}
0 & 0 \\
\end{tabular} & 0 \\
\hline & & Programı & 0 & 0 & \begin{tabular}{|l|l|}
0 \\
\end{tabular} & 1 & 0 & 1 & 9 & \begin{tabular}{l|l}
9 \\
\end{tabular} & 10 & 10 & 8 & 9 & 0 & 0 & 0 & 0 & \begin{tabular}{l|l}
0 & ( \\
\end{tabular} & 0 & \begin{tabular}{l|l}
0 & 0 \\
\end{tabular} & 0 \\
\hline & \multirow{3}{*}{ Day 2} & $50^{\text {th }}$ Percentile & 0 & 0 & \begin{tabular}{|l|l|}
0 \\
\end{tabular} & 0 & 0 & 0 & 5 & 5 & 10 & 10 & 7 & 7 & 0 & 0 & 0 & 0 & \begin{tabular}{l|l}
0 & ( \\
\end{tabular} & \begin{tabular}{l|l}
0 & ( \\
\end{tabular} & \begin{tabular}{l|l}
0 & 0 \\
\end{tabular} & 0 \\
\hline & & $80^{\text {th }}$ Percentile & 0 & 0 & 0 & 0 & 0 & 0 & 7 & 7 & 10 & 10 & 10 & 10 & 0 & 0 & 0 & 0 & \begin{tabular}{l|l}
0 & 0 \\
\end{tabular} & 0 & \begin{tabular}{l|l}
0 & 0 \\
\end{tabular} & 0 \\
\hline & & Progran & 0 & 0 & 0 & 0 & 0 & 0 & 6 & \begin{tabular}{l|l}
6 & \\
\end{tabular} & 10 & 10 & 5 & 7 & 0 & 0 & 0 & 0 & \begin{tabular}{l|l}
0 & 0 \\
0
\end{tabular} & 0 & \begin{tabular}{l|l}
0 & 0 \\
\end{tabular} & 0 \\
\hline \multirow{6}{*}{$\begin{array}{l}\text { Heavy } \\
\text { Rain }\end{array}$} & \multirow{3}{*}{ Day 1} & $50^{\text {th }}$ Percentile & 0 & 0 & 10 & 10 & 10 & 10 & 10 & 10 & 5 & 0 & 0 & 0 & 0 & 0 & 0 & 0 & \begin{tabular}{l|l}
0 & ( \\
\end{tabular} & \begin{tabular}{l|l}
0 & ( \\
\end{tabular} & \begin{tabular}{l|l}
0 & 0 \\
\end{tabular} & 0 \\
\hline & & $80^{\text {th }}$ Percentile & 0 & 0 & 10 & 10 & 10 & 10 & 10 & 10 & 7 & 0 & 0 & 0 & 0 & 0 & 0 & 0 & \begin{tabular}{l|l}
0 & 0 \\
\end{tabular} & 0 & \begin{tabular}{l|l}
0 & 0 \\
\end{tabular} & 0 \\
\hline & & Programming & 0 & 0 & 10 & 10 & 10 & 10 & 10 & 10 & 3 & 0 & 0 & 0 & 0 & 0 & 0 & 0 & \begin{tabular}{l|l}
0 & ( \\
\end{tabular} & 0 & \begin{tabular}{l|l}
0 & 0 \\
\end{tabular} & 0 \\
\hline & \multirow{3}{*}{ Day 2} & $50^{\text {th }}$ Percentile & 0 & 0 & 0 & 0 & 0 & 0 & 5 & 5 & 5 & 5 & 0 & 0 & 0 & 0 & 0 & 101 & \begin{tabular}{l|l}
10 & 1 \\
\end{tabular} & 10 & 105 & 5 \\
\hline & & $80^{\text {th }}$ Percentile & 0 & 0 & 0 & 0 & 0 & 0 & 7 & 7 & 7 & 7 & 0 & 0 & 0 & 0 & 0 & 10 & \begin{tabular}{l|l}
10 & 1 \\
\end{tabular} & 10 & \begin{tabular}{l|l}
10 & 7 \\
\end{tabular} & 7 \\
\hline & & Programming & 0 & 0 & 0 & 0 & 0 & 0 & 5 & 5 & 1 & 1 & 0 & 0 & 0 & 0 & 0 & 10 & \begin{tabular}{l|l}
9 & 1 \\
\end{tabular} & 10 & \begin{tabular}{l|l}
92 \\
9
\end{tabular} & 2 \\
\hline \multirow{6}{*}{$\begin{array}{l}\text { Shoulder } \\
\text { Blocked } \\
\text { Incident }\end{array}$} & \multirow{3}{*}{ Day 1} & $50^{\text {th }}$ Percentile & 0 & 0 & 5 & 5 & 5 & 5 & 10 & 10 & 10 & 10 & 5 & 5 & 5 & 5 & 5 & 5 & \begin{tabular}{l|l}
0 & ( \\
\end{tabular} & 0 & \begin{tabular}{l|l}
0 & 0 \\
\end{tabular} & 0 \\
\hline & & $80^{\text {th }}$ Percentile & 0 & 0 & 7 & 7 & 7 & 7 & 10 & 10 & 10 & 10 & 5 & 7 & 7 & 7 & 7 & 7 & \begin{tabular}{l|l}
0 & 0 \\
\end{tabular} & 0 & \begin{tabular}{l|l}
0 & 0 \\
\end{tabular} & 0 \\
\hline & & Programming & 0 & 0 & 1 & 1 & 1 & 1 & 9 & 10 & 10 & 10 & 5 & 5 & 5 & 3 & 3 & 3 & \begin{tabular}{l|l}
0 & $(1$ \\
\end{tabular} & 0 & \begin{tabular}{l|l}
0 & 0 \\
\end{tabular} & 0 \\
\hline & \multirow{3}{*}{ Day 2} & $50^{\text {th }}$ Percentile & 0 & 5 & 5 & 5 & 5 & 5 & 10 & 10 & 10 & 10 & 5 & 5 & 5 & 5 & 5 & 5 & \begin{tabular}{l|l}
10 & 1 \\
\end{tabular} & \begin{tabular}{l|l}
0 & 1 \\
\end{tabular} & & 10 \\
\hline & & $80^{\text {th }}$ Percentile & 0 & 7 & 7 & 7 & 7 & 7 & 10 & 10 & 10 & 10 & 7 & 7 & 7 & 7 & 7 & 7 & \begin{tabular}{l|l}
10 & 1 \\
\end{tabular} & 10 & & 10 \\
\hline & & Progran & 0 & 1 & 4 & 5 & 4 & 5 & 10 & 10 & 8 & 8 & 2 & 4 & 1 & 4 & 3 & 3 & \begin{tabular}{l|l}
10 & 1 \\
\end{tabular} & \begin{tabular}{l|l}
10 & 1 \\
\end{tabular} & & 10 \\
\hline \multirow{6}{*}{$\begin{array}{l}\text { One Lane } \\
\text { Blocked } \\
\text { Incident }\end{array}$} & \multirow{3}{*}{ Day $1 \mid$} & $50^{\text {th }} \mathrm{Per}$ & 0 & 0 & 0 & 0 & 0 & 0 & 0 & 0 & 0 & 0 & 0 & 0 & 101 & 10 & $10 \mid 1$ & 101 & \begin{tabular}{l|l}
10 & 1 \\
\end{tabular} & 10 & 50 & 0 \\
\hline & & $80^{\text {th }}$ Perc & 0 & 0 & 0 & 0 & 0 & 0 & 0 & 0 & 0 & 0 & 0 & 0 & 10 & 10 & 10 & 101 & \begin{tabular}{l|l}
10 & 1 \\
\end{tabular} & 10 & 70 & 0 \\
\hline & & Progran & 0 & 0 & 0 & 0 & 0 & 0 & 0 & 0 & 0 & 0 & 0 & 0 & 101 & 10 & 10 & 101 & 105 & 9 & 50 & 0 \\
\hline & \multirow{3}{*}{ Day 2} & $50^{\text {th }}$ Percentile & 0 & 10 & 10 & 10 & 10 & 10 & 10 & 5 & 5 & 5 & 0 & 0 & 0 & 0 & 0 & 0 & \begin{tabular}{l|l}
0 & $(1$ \\
\end{tabular} & 0 & \begin{tabular}{l|l}
0 & 0 \\
\end{tabular} & 0 \\
\hline & & $80^{\text {th }}$ Percentile & 0 & 10 & 10 & 10 & 10 & 10 & 10 & 7 & 7 & 7 & 0 & 0 & 0 & 0 & 0 & 0 & \begin{tabular}{l|l}
0 & 0 \\
\end{tabular} & 0 & \begin{tabular}{l|l}
0 & 0 \\
\end{tabular} & 0 \\
\hline & & Programming & 0 & 10 & 10 & 10 & 10 & 10 & 9 & 5 & 5 & 3 & 0 & 0 & 0 & \begin{tabular}{l|l}
0 \\
\end{tabular} & 0 & \begin{tabular}{l|l}
0 \\
\end{tabular} & \begin{tabular}{l|l}
0 & $(1$ \\
\end{tabular} & & \begin{tabular}{l|l}
0 & 0 \\
\end{tabular} & 0 \\
\hline
\end{tabular}

According to the results shown in Tables 4-7 and 4-8, the three methodologies lead

to the same activation time. Therefore, the activation time results of the proposed methodology is compatible with the results of the probability of breakdown method. However, the probability of breakdown method does not deal with non-recurrent conditions and the number of ramps to activate. 
As seen in these two tables, the results of the programming formulation utilization in real-time (the extension of the off-line selection of the ramps) led to better adaption of the number of ramps to meter to the $\mathrm{D} / \mathrm{C}$ value of each case, compared to the look-up table. This is because, in the case of the look-up table method, the D/C values are categorized in groups, with each group covering a range of $\mathrm{D} / \mathrm{C}$ values, while the programming formulation utilizes the exact value of the $\mathrm{D} / \mathrm{C}$ value for the selection of ramps. Therefore, it is logical that the programming formulation is more adaptive in its selection of the ramps to meter. It is interesting to see that the results of the programming formulation are closer to the results of using the $50^{\text {th }}$ percentile in the look-up table compared to using the $80^{\text {th }}$ percentile in the look-up table. The $80^{\text {th }}$ percentile results of the look-up table are more conservative compared to the $50^{\text {th }}$ percentile and programming formulation, which is reasonable. Thus, if an agency decides to use the look-up table method because of its simplicity, the $50^{\text {th }}$ percentile values should be used.

\subsection{Summary}

The recurrent bottleneck was determined to be located upstream of the I-95 onramp from Commercial Boulevard in Fort Lauderdale, Florida. The capacity distribution of the bottleneck was assessed by utilizing the PLM method. The VISSIM microscopic simulation was used to evaluate the performances of ramp metering when considering local and system-wide conditions in selecting ramps for metering in terms of breakdown occurrence time and travel time on the on-ramps as well as the mainline. Four percentile capacity values were used for this comparison. In the case of the $95^{\text {th }}$ percentile capacity,

application of locally-justified approach led to preventing the breakdown with slight speed 
drop at the bottleneck location. However, system-justified approach resulted in the prevention of the speed drop at the bottleneck. In the case of the $80^{\text {th }}$ percentile capacity, locally-justified approach postponed the breakdown for 15 minutes. While, systemjustified approach postponed the breakdown by 30 minutes and resulted in a decrease in the spatial extent of the queue. In the case of the $50^{\text {th }}$ and $30^{\text {th }}$ percentile capacities at the bottleneck, earlier and more severe breakdowns occurred. In both cases, the systemjustified approach could further postpone the breakdown and its physical extent. In terms of ravel time on the mainline, system-justified approach resulted in $14 \%$ reduction compared to locally justifed approach. Moreover, application of the system-justified approach resulted in $29.3 \%$ reduction in average travel time on the on-ramps compared to the locally justifed approach. The results showed that the benefit-cost ratio of the systemjustified approach compared to the locally-justified approach was about 2.06.

The Monte Carlo simulation was used to consider the stochasticity of the demand and capacity. The results show that about $13 \%$ and $30 \%$ of the conducted Monte Carlo experiments, required the metering of all the on-ramps of the case study corridor for the morning and afternoon peak periods, respectively. Similarly, the results show that with lane blockage incidents and heavy rain during the peak hours, all 10 ramps will have to be activated in most cases. The benefit-cost analysis of the case study showed a benefit-cost ratio of 9.4 for application of the proposed methodology.

For real-time activation of metering, three approaches were compared in terms of the activation time and number of the ramps to meter. The results show that all the approaches led to starting times of activation. However, in terms of the number of ramps 
to be metered, programming formulation utilization in real-time led to better adaption of the number of the ramps to meter to the $\mathrm{D} / \mathrm{C}$ value of each case compared to the look-up table. However, the results for the $50^{\text {th }}$ percentile values of the look-up table are similar to the linear programmimg formulation results. 


\section{CHAPTER 5 \\ CONCLUSIONS}

\subsection{Summary and Conclusions}

Ramp metering is an important traffic management strategy for preventing or at least delaying traffic breakdown and congestion on freeways by regulating the entering flows and using traffic signals installed at on-ramps. Ramp Metering helps maintain the full capacity of the freeway and improves traffic performance in terms of mobility, safety, and environmental impacts. However, ramp metering may cause spillback due to the long queues on the on-ramps to the upstream arterial segments. Therefore, it is crucial to properly select the ramps to meter and to apply appropriate metering strategies to realize the maximum benefits of ramp metering and to avoid any adverse impacts of on-ramp queues. State agencies have developed guidelines and warrants to support the decisions to select ramps for metering. These warrants solely consider the local conditions of each onramp as an isolated element, focusing on geometry and traffic conditions at the on-ramp and its merge area. On the other hand, most current applications of ramp metering implement advanced ramp metering algorithms, which consider system bottleneck conditions in calculating the metering rates. Such implementations lead to much better results compared to the implementation of local algorithms. This has created a disconnection between existing metering warrants and the subsequent management and operations of the ramp meters since most ramp meters operate utilizing system-based metering algorithms. Moreover, the warrants do not employ detailed analysis of traffic conditions that are possible with the increasing availability of data from multiple sources. In addition, the existing local warrants only consider recurrent conditions to justify ramp 
metering installation with no consideration of the benefit of metering during non-recurrent events such as incidents and adverse weather.

This dissertation is intended to bridge the existing gap between ramp metering identification for metering and the operational practices. The first step of the methodology was assessing the need to develop a system-based methodology, in addition to the existing local warrants. For this purpose, a linear programming formulation, combined with the consideration of the stochasticity of bottleneck capacity, was used in this study to select the ramps to be metered based on the system bottleneck. The stochasticity of capacity at the bottleneck location was accounted for by identifying the historical real-world capacity distribution. The study demonstrated that more ramps can be justified when using the linear programming formulation compared to the ramps identified based on existing local warrants.

The application results of the local and system-based ramp selection approaches were compared based on microscopic simulation. The dissertation research found that the selection of additional ramps for metering based on system bottlenecks, in addition to those justified by local warrants, can delay the breakdown at the system bottleneck location and improve the performance of the freeway mainline. Another important benefit of system justified metering is that it distributes the on-ramp delays and queues due to metering among additional metered ramps, reducing the delays experienced on the ramps compared to metering only ramps selected utilizing the existing warrants based on local conditions.

Based on the above observations, this study concludes that considering system bottleneck and traffic conditions for selecting ramps for metering, in addition to the 
existing local warrants, can improve traffic conditions for both the freeway mainline and on-ramps. Therefore, it is highly recommended to select ramps for metering based on system-wide traffic conditions, as well as traffic conditions in the immediate vicinity of the subject ramp for use by states that are considering the installation of ramp metering.

The next step of the methodology is to develop a method for selecting ramps for metering based on system recurrent and non-recurrent conditions. In most cases, metering the immediate ramps upstream of the bottleneck is not sufficient for preventing or significantly delaying breakdown on the freeway mainline. A ramp may not be a candidate for ramp signal installation according to its local traffic conditions; however, it can play a significant role in addressing the traffic congestion at a system bottleneck located miles downstream of the ramp. The methodology developed in this study can be used in conjunction with existing local warrants for installing metering to bridge the gap between the installation decisions and operation and management policies and strategies. The proposed ramp selection methodology considers both recurrent and non-recurrent conditions (e.g., incident and rainfall). The Monte Carlo simulation was used to consider the stochastic nature of the capacity and demands. The outputs from the Monte Carlo simulation was used as input to the developed formulation to select the ramps to meter. To address the influence of non-recurrent conditions on ramp selection results, the impacts of each type of non-recurrent events on demand and capacity were included in the developed methodology.

The application of the methodology to select the ramps for metering attempts to prevent the breakdown at bottleneck locations by keeping the bottleneck flow below the 
capacity and limiting the entering flow from the ramps upstream of the bottleneck locations, while considering the queuing storage capacity of the on-ramps. The results of the analysis conducted in this disseration show that in all cases when the demand exceeds the capacity, metering on-ramps adjacent to the bottleneck location is not sufficient for preventing congestion considering the constraints on the selection of the metering rates. The analysis shows that about $13 \%$ and $30 \%$ of the conducted Monte Carlo experiments for the case study, representing days with different demand and capacity values during recurrent conditions, requires the selection for metering of all 10 ramps of the case study corridor for the morning and afternoon peak periods, respectively. Moreover, the results show that with lane blockage incidents and heavy rain during the peak hours, all 10 ramps will have to be activated in most cases. The benefits of system-wide metering is calculated in terms of delay savings, and this calculation can be used to support the decision to select a subset of the on-ramps for metering. The results are used to conduct benefit-cost analysis of the ramp metering deployment and to support associated decisions such as which ramp to meter and when to activate. Assuming the project life to be seven years and the interest rate to be $6 \%$, the benefit-cost analysis of the case study shows a benefit-cost ratio of 9.4.

For real-time activation of the ramps, three approaches are compared. For the probability of breakdown based on previous studies, which only is applicable to recurrent conditions, the look-up table resulted from the Monte Carlo simulation as input of the proposed methodology and eventually used the real-world data traffic data as the inputs to the proposed methodology. In terms of activation, the three approaches resulted in similar starting times for application. In regard to the number of ramps to be metered, the results of the programming formulation utilization in real-time led to better adaption of the number 
of the ramps to meter to the $\mathrm{D} / \mathrm{C}$ value of each case compared to the look-up table. However, if an agency decides to use the look-up table method because of the simplicity of utilizing the look-up table, the $50^{\text {th }}$ percentile values are recommended to be used.

\subsection{Research Contributions}

This dissertation research contributes to the existing body of knowledge by adding the system-wide traffic conditions to the existing local traffic conditions in the off-line selection of on-ramps for metering in the planning stage. Moreover, the stochastic nature of the demand and capacity is addressed in the proposed methodology of this research.

Non-recurrent traffic conditions such as incident and rainfall highly impact the performance of freeway facilities; however, they are not incorporated into the existing decision-making procedures for installation of the ramp metering. This dissertation contributes to the literature by taking incident and rainfall events into consideration for offline selection, as well as real-time activation of the on-ramps for metering.

\subsection{Study Limitations and Recommendations for Future Research}

The analysis of this dissertation is focused on the peak period traffic conditions and does not consider non-recurrent events which occurred during off-peak periods. The ramp detectors for collecting detailed traffic data are not installed on the ramps in the case study of this dissertation. Therefore, the volume data are the average of the collected data for three days in a year. More detailed data on the ramps will provide better insight about the predicted queue length on the on-ramps. 
The proposed methodology of this dissertation can benefit from further research on the appropriate ramp storage and acceleration lengths for each on-ramp. Future research efforts can cover the non-recurrent events which occur in off-peak periods to provide more comprehensive suggestions for installation of ramp signals. 


\section{REFERENCES}

AASHTO, A Policy on Geometric Design of Highways and Streets, American Association of State Highway and Transportation Officials, Washington, D.C., 2011.

Aghdashi, S. B., Traffic Flow Optimization in a Freeway with Stochastic Segments Capacity, North Carolina State University, 2013.

Arnold, E. D., Ramp Metering: A Review of the Literature, Virginia Transportation Research Council, pp.8-10, December 1998.

Atkins, Ramp Metering Feasibility Study for Durham and Wake Counties, North Carolina Department of Transportation, 2013.

Balke, K., P. Chaudhary, P. Songchitruksa, and G. Pesti, Development of Criteria and Guidelines for Installing, Operating, and Removing TxDOT Ramp Control Signals, Texas Department of Transportation, 2009.

Bellemans, T., B. De Schutter, and B. De Moor, Model Predictive Control for Ramp Metering of Motorway Traffic: A Case Study, Delft University of Technology, 2006.

Bertini, S., and S. Ahn, Using Archived ITS Data to Measure the Operational Benefits of A System-Wide Adaptive Ramp Metering System, Oregon Department of Transportation, 2006.

Bogenberger, K., H. Keller, and S. G. Ritchie, Adaptive Fuzzy Systems for Traffic Responsive and Coordinated Ramp Metering, Institute of Transportation Studies, University of California, Irvine, 2001.

Bogenberger, K., and A.D. May, Advanced Coordinated Traffic Responsive Ramp Metering Strategies, Institute of Transportation Studies, University of California, Berkeley, 1999.

Brilon, W., J. Geistefeldt, and M. Regler, Reliability of Freeway Traffic Flow: A stochastic Concept of Capacity, Proceedings of the $16^{\text {th }}$ International Symposium on Transportation and Traffic Theory, pp. 125 - 144, College Park, Maryland, 2005.

Caltrans, California Ramp Meter Design Manual, California Department of Transportation, 2000.

Camacho, E., and C. Bordons, Model Predictive Control in the Process Industry, Springer, Berlin, 1995. 
Cambridge Systematics, Inc., Twin Cities Ramp Meter Evaluation, Minnesota Department of Transportation, 2001.

Elefteriadou, L., A. Kondyli, W. Brilon, L. Jacobson, F. Hall, And B. Persaud, Proactive Ramp Management under the Threat of Freeway-Flow Breakdown, National Cooperative Highway Research Program, 2009.

Elefteriadou, L., and P. Lertworawanich, Defining, Measuring and Estimating Freeway Capacity, Proceedings of the $82^{\text {nd }}$ Annual Meeting of Transportation Research Board, Washington D.C., 2003.

Elefteriadou, L., R.P. Roess, and W.R. McShane, Probabilistic Nature of Breakdown at Freeway Merge Junctions, Transportation Research Record No. 1484, Washington D.C., 1995.

Fartash, H., M. Hadi, Y. Xiao, T. Wang, and R. Ponnaluri, Assessing the Need for SystemWide Ramp Metering Installation Warrants, Transportation Research Record: Journal of the Transportation Research Board, 2017.

Fartash, H., M. Hadi, and R. Ponnaluri, Methodology to Identify On-Ramps for Metering with Consideration of System-Wide Recurrent and Non-Recurrent Congestion, Transportation Research Record: Journal of the Transportation Research Board, 2018.

FDOT, Manual of Uniform Minimum Standards for Design, Construction and Maintenance for Streets and Highways, Florida Department of Transportation, Florida, 2016.

FHWA, Empirical Studies on Traffic Flow in Inclement Weather, US Department of Transportation, Federal Highway Administration, 2006.

FHWA, Ramp Management and Control Handbook, US Department of Transportation, Federal Highway Administration, 2006.

FHWA, How Do Weather Events Impact Roads?, http://ops.fhwa.dot.gov/Weather/q1_roadimpact.htm, Assessed 2015.

FHWA, Traffic Congestion and Bottlenecks; Identification, Diagnosis, Solutions, US Department of Transportation, Federal Highway Administration, 2015.

Gaisser, T., and K. DePinto, I-70 East Ramp Metering Assessment, Colorado Department of Transportation, 2015. 
Gan, A., K. Liu, P. Alluri, and X. Zhu, Integrated Database and Analysis System for the Evaluation of Freeway Corridors for Potential Ramp Signaling, Florida Department of Transportation, 2011.

Goolsby, M. E., Influence of Incidents on Freeway Quality of Service, Transportation Research Record No. 349, Washington D.C., 1971.

Hadi, M., P. Sinha, and A. Wang, Modeling Reduction in Freeway Capacity due to Incidents in Microscopic Simulation Models, Proceedings of the $85^{\text {th }}$ Annual Meeting of Transportation Research Board, Washington D.C., 2007.

Hadi, M., Y. Xiao, C. Zhan, and A. Gan, Use of the HCM Freeway Facility Procedures Combined with ITS Data Archives to Assess the Benefits of Incident Management Systems, Transportation Research Record No. 2173, 2010.

Hadi, M., C. Zhan, and P. Alvarez, Traffic Management Simulation Development, Florida Department of Transportation, 2011.

Hadi, M., Y. Xiao, and M. L. Rojas, Estimation of Diversion Rate during Incidents on Basis of Mainline Detector Data, Transportation Research Record 2396, 2013.

Haj-Salem, H. and M. Papageorgiou, Ramp Metering Impact on Urban Corridor Traffic: Field Results, Transportation Research Part A. Vol. 29A, 1995.

Hasan, M., Evaluation of Ramp Control Algorithms Using a Microscopic Traffic Simualtion Laboratory, Massachusetts Institute of Technology, 1999.

Highway Capacity Manual, Transportation Research Board, Washington D.C., 2000.

Highway Capacity Manual, Transportation Research Board, Washington D.C., 2010.

Highway Capacity Manual $6^{\text {th }}$ Edition, Transportation Research Board, Washington D.C., 2016.

Hourdakis, J., and P.G. Michalopoulos, Evaluation of Ramp Control Effectiveness in Two Twin Cities Freeways, Proceedings of the $81^{\text {st }}$ Annual Meeting of Transportation Research Board, Washington D.C., 2002.

Ibrahim, A. T., and F. L. Hall, Effect of Adverse Weather Conditions on Speed- Flow Occupancy Relationships, Transportation Research Record No. 1457, Washington D.C., 1994. 
WisDOT, Intelligent Transportation Systems (ITS) Design Manual, Wisconsin Department of Transportation, 2000.

Jacobs, Managed Lanes and Ramp Metering Manual, Part 2: Implementation Plan, Nevada Department of Transportation, 2013.

Jacobson, L., K. Henry, and O. Mahyar, Real-time Metering Algorithm for Centralized Control, Transportation Research Record No. 1232, 1989.

Kang, S., and D. Gillen, Assessing the Benefits and Costs of Intelligent Transportation Systems: Ramp Meters, California Partners For Advanced Transit And Highways Research Report, 1999.

Kaplan, E. L., and P. Meier, Nonparametric Estimation from Incomplete Observations, Journal of the American Statistical Association, 53, pp. 457-481, 1958.

Knoop, V. L., S.P. Hoogendoorn, and K. Adams, Capacity Reductions at Incidents Sites on Motorways, European Journal of Transport and Infrastructure Research 9(4), 2009.

Kristeleit, T. P., Analysis and Evaluation of Ramp Metering Algorithms, University of the Federal Armed Forces, Munich, 2014.

Leiman, L., M. Bouaunia, and A.D. May, Integrated System of Freeway Corridor Simulation Models, Transportation Research Record No. 1320, Washington, D.C., 1991.

Lipp, L., L. Corcoran, and G. Hickman, Benefits of Central Computer Control for the Denver Ramp Metering System, Proceedings of the $70^{\text {th }}$ Annual Meeting of Transportation Research Board, Washington D.C., 1991.

Li, Z., L. Elefteriadou, and A. Kondyli, Modeling Weather Impacts on Traffic Operations: Implementation into Florida's Travel Time Reliability Model, Proceedings of the $93^{\text {rd }}$ Annual Meeting of Transportation Research Board, Washington D.C., 2014.

Lorenz, M., and L. Elefteriadou, A Probabilistic Approach to Defining Freeway Capacity and Breakdown, $4^{\text {th }}$ International Symposium on Highway Capacity, pp. 84-95. TRBCircular E-C018, Washington D.C., Transportation Research Board, 2000.

Maciejowski, J., Predictive Control with Constraints, Pearson Education, Harlow, 2002.

Mahadevan, S., Monte Carlo Simulation. Reliability-Based Mechanical, Marcel Dekker, New York, 1996. 
May, A. D., Traffic Flow Fundamentals, Englewood Cliffs, N.J., 1990.

May, A. D., Application of Simulation Models in Traffic Management Operations, University of California, Berkely, 1976.

Manual on Uniform Traffic Control Devices, US Department of Transportation, Federal Highway Administration, 2003.

Manual on Uniform Traffic Control Devices, US Department of Transportation, Federal Highway Administration, 2009.

Oh, H. U., and V.P. Sisiopiku, A Modified ALINEA Ramp Metering Model, Proceedings of the $80^{\text {th }}$ Annual Meeting of Transportation Research Board, Washington D.C., 2001.

Okamura, H., S. Watanabe, and T. Watanabe, An Empirical Study on the Capacity of Bottlenecks on the Basic Suburban Expressway Sections in Japan, Transportation Research Board, 2000. the $4^{\text {th }}$ International Symposium on Highway Capacity, pp. 120-129.TRB Circular E-C018.

Papageorgiou, M., J.M. Blosseville, and H. Hadj-Salem, Modeling and Real-Time Control of Traffic Flow on the Southern Part of Boulevard Peripherique in Parris, Part II: Coordinated On-Ramp Metering, Transportation Research Part A, Vol. 24A, 1990.

Piotrowicz, G., and J. Robinson, Ramp Metering Status in North America-1995 Update, US Department of Transportation, Federal Highway Administration, 1995.

Ponzlet, M., Dynamik der Leistungsfähigkeiten von Autobahnen (Dynamics of Freeway Capacity), Schriftenreihe des Lehrstuhls fuer Verkehrswesen der Ruhr Universitaet Bochum, No. 16. Bochum, 1996.

Qi, L., and B. Smith, Characterization of Accident Capacity Reduction, Center for Transportation Studies, University of Virginia, 2001.

Rodriguez, J., K. Kawamura, and A. Samimi, FREQ Simulation and Ramp Meter/HOV Bypass Optimization, University of California, Berkeley, 2008.

Smargdis, E. , M. Papageorgiou, and E. Kosmatopouls, A Flow-Maximizing Adaptive Local Ramp Metering Strategy, Journal of Transportation. Research., Vol. 38, 2004.

Shea, M. S., T. Le, and R. Porter, A Combined Crash Frequency-Crash Severity Evaluation of Geometric Design Decisions: Entrance-Exit Ramp Spacing and Auxiliary Lane 
Presence, Proceedings of the $94^{\text {th }}$ Annual Meeting of Transportation Research Board, Washington D.C., 2015.

Sheu, J., and H. Yang, An Integrated Toll and Ramp Control Methodology for Dynamic, Physica A-Statistical Mechanics and ITS Applications, Vol. 387, pp.16-17, 2008.

Simpson, S., and F. Yasmin, Ramp Metering Design Guide, Arizona Department of Transportation, 2013.

Stralen, V., S.C. Calvert, and E.J. Molin, The Influence of Adverse Weather Conditions on the Probability of Congestion on Dutch Motorways, Proceedings of the $93^{\text {rd }}$ Annual Meeting of Transportation Research Board, Washington D.C., 2014.

Tian, Z., H. Xu, G. Yang, A. Khan, and Y. Zhao, Queue Storage and Acceleration Lane Length Design at Metered On-Ramps in California. Final Report for California Department of Transportation, Research Project \# 65A0486, 2016.

TransCore, Advance Traffic Management System Design Manual, Utah Department of Transportation, January 2001.

Varaiya, P., Congestion, Ramp Metering and Tolls, Philosophical Transactions of the Royal Society, 2008.

Wilbur Smith Associates, Wisconsin Statewide Ramp Control Plan, Wisconsin Department of Transportation, 2006.

Wu, J., Traffic Diversion Resulting from Ramp Metering, The University of Wisconsin, Milwaukee, 2001.

Wu, J., X. Jin, and A. Horowitz, Methodologies for Estimating Metered On-Ramp Vehicle Queue Length, Proceedings of the $87^{\text {th }}$ Annual Meeting of Transportation Research Board, Washington D.C., 2008.

Wu, J., X. Jin, A. Horowitz, and D. Gong, Experiment to Improve Estimation of Vehicle Queue Length at Metered On-Ramps, Proceedings of the $88^{\text {th }}$ Annual Meeting of Transportation Research Board, Washington D.C., 2009.

Yang, G., H. Xu, Z. Tian, and Z. Wang, Investigating Truck Acceleration Capability at Metered On-Ramps, Proceedings of the $95^{\text {th }}$ Annual Meeting of Transportation Research Board, Washington D.C., 2016. 
Zhang, M., T. Kim, X. Nie, W. Jin, L. Chu, and W. Recker, Evaluation of On-Ramp Control Algorithms, California PATH Research Report UCB-ITS-PRR-2001-36, 2001. 
VITA

HOMA FARTASH

EDUCATION

$2006-2010$

B.Sc., Civil Engineering

Iran University of Science and Technology, Tehran, Iran

$2010-2012$

M.Sc., Civil Engineering (Transportation) Iran University of Science and Technology, Tehran, Iran

2013 - Present

Ph.D., Civil Engineering (Transportation)

Department of Civil and Environmental Engineering

Florida International University

Miami, Florida

$2016-2017$

President, ITE Student Chapter at FIU

$2016-2018$

Chair of the Membership Committee, South Florida WTS

Fall 2016

$2015-2016$

Graduate Representative, SWE Student Chapter at FIU

Vice President, ITE Student Chapter at FIU

- Outstanding Doctoral Degree Graduate Student, Department of Civil and Environmental Engineering, Florida International University, Spring 2018.

- Outstanding Doctoral Degree Graduate Student Nominee, College of Engineering and Computing, Florida International University, Spring 2018.

- 2017 Best Freeway Operations Paper Award (International Award), Transportation Research Board, 2017.

- Second Place of Student Presentation Competition, University Transportation Center (UTC) Conference for the Southeastern Region, University of Florida, 2017.

- Second Place of Student Poster Competition, ITE District 10 and ITS Florida Annual Meeting, Orlando, 2017.

- Fang Zhao Women in Engineering Leadership Award, FIU, 2017.

- Graduate Scholar Award Finalist for Student Life Award, FIU, 2017.

- Dissertation Year Fellowship Award, Florida International University, 2017.

- SFWTS Helen M. Overly Memorial Scholarship Award (State-wide Award), 2017.

- Florida Section of ITE Bill McGrath Scholarship Award (State-wide Award), 2016.

- Florida Section of ITE Henry P. Boggs Best Paper Award (State-wide Award), 2016.

- GCCITE BOOK Scholarship, Essay Competition, 2016.

- First Place for Anne Brewer Scholarship, ITS Florida (State-wide Award), 2016.

- Second place of Poster Competition, ITE District 10 Annual Meeting, Tampa, 2015. 
- Sanchez Grand Prix Scholarship, FIU, 2015.

- Outstanding Student of the Year, Iran University of Science and Technology, 2011.

- Outstanding Student of the Year, Iran University of Science and Technology, 2010.

\section{PUBLICATIONS AND PRESENTATIONS}

- Fartash, H., M. Hadi, and R. Ponnaluri, Methodology to Identify On-Ramps for Metering with Consideration of System-Wide Recurrent and Non-Recurrent Congestion, Transportation Research Record: Journal of the Transportation Research Board, 2018.

- Fartash, H., M. Hadi, and R. Ponnaluri, Methodology to Identify On-Ramps for Metering with Consideration of System-Wide Recurrent and Non-Recurrent Congestion, Proceedings of the $97^{\text {th }}$ Transportation Research Board Annual Meeting, January 2018.

- Fartash, H., M. Hadi, Y. Xiao, T. Wang, and R. Ponnaluri, Assessing the Need for System-Wide Ramp Metering Installation Warrants, Transportation Research Record: Journal of the Transportation Research Board, 2017.

- Fartash, H., M. Hadi, Y. Xiao, and R. Ponnaluri, Assessment of the Need for System Warrants in Addition to Local Warrants for Ramp Metering Installation, Proceedings of the $96^{\text {th }}$ Transportation Research Board Annual Meeting, January 2017.

- Fartash, H., P. Alluri, A. Gan, M. Lavasani, and K. Haleem, Performance of Rectangular Rapid Flashing Beacons (RRFBs) at Midblock Pedestrian Crossings, Proceedings of the $95^{\text {th }}$ Transportation Research Board Annual Meeting, January 2016.

- Fartash, H., M. Hadi, and Y. Xiao, Utilization of the HCM Urban Facility Procedures for the Estimation and Real-Time Prediction of Travel Time with Consideration of Rain Impacts, Proceedings of the $95^{\text {th }}$ Transportation Research Board Annual Meeting, January 2016.

- Sadeghvaziri, E., P. Alluri, A. Gan, K. Haleem, and H. Fartash, Effects of Different Guide Signs on Driver Behavior at Express Lane Entrance: A Driving Simulation Study, Proceedings of the $95^{\text {th }}$ Transportation Research Board Annual Meeting, January 2016.

- Lavasani, M., M. Latifi Namin, and H. Fartash, Experimental Investigation on Mineral and Organic Fibers Effect on Resilient Modulus and Dynamic Creep of Stone Matrix Asphalt and Continuous Graded Mixtures in Three Temperature Levels, Journal of Construction and Building Materials, Elsevier, July 2015.

- Gan, A., H. Fartash, and P. Alluri, Evaluation of Rectangular Rapid Flashing Beacon (RRFB), Pedestrian Traffic Signal, and Pedestrian Hybrid Beacon (PHB) Locations on West Flagler Street in Miami, Final Report Prepared for District Six of Florida Department of Transportation, August 2014. 